


\section{DOCUMENT AVAILABILITY}

Reports produced after January 1, 1996, are generally available free via US Department of Energy (DOE) SciTech Connect.

Website http://www.osti.gov/scitech/

Reports produced before January 1, 1996, may be purchased by members of the public from the following source:

National Technical Information Service

5285 Port Royal Road

Springfield, VA 22161

Telephone 703-605-6000 (1-800-553-6847)

TDD 703-487-4639

Fax 703-605-6900

E-mail info@ntis.gov

Website http://www.ntis.gov/support/ordernowabout.htm

Reports are available to DOE employees, DOE contractors, Energy Technology Data Exchange representatives, and International Nuclear Information System representatives from the following source:

Office of Scientific and Technical Information

PO Box 62

Oak Ridge, TN 37831

Telephone 865-576-8401

Fax 865-576-5728

E-mail reports@osti.gov

Website http://www.osti.gov/contact.html

This report was prepared as an account of work sponsored by an agency of the United States Government. Neither the United States Government nor any agency thereof, nor any of their employees, makes any warranty, express or implied, or assumes any legal liability or responsibility for the accuracy, completeness, or usefulness of any information, apparatus, product, or process disclosed, or represents that its use would not infringe privately owned rights. Reference herein to any specific commercial product, process, or service by trade name, trademark, manufacturer, or otherwise, does not necessarily constitute or imply its endorsement, recommendation, or favoring by the United States Government or any agency thereof. The views and opinions of authors expressed herein do not necessarily state or reflect those of the United States Government or any agency thereof. 
ORNL/TM-2013/478

\title{
Sustainable Transportation Program 2012 Annual Report
}

\author{
Compiled by \\ Kathi H. Vaughan \\ for \\ Ronald L. Graves, Director \\ ORNL Sustainable Transportation Program
}

Date Published: September 2013

Prepared by

OAK RIDGE NATIONAL LABORATORY

Oak Ridge, Tennessee 37831-6283

managed by

UT-BATTELLE, LLC

for the

U.S. DEPARTMENT OF ENERGY

under contract DE-AC05-00OR22725 



\section{Table of Contents}

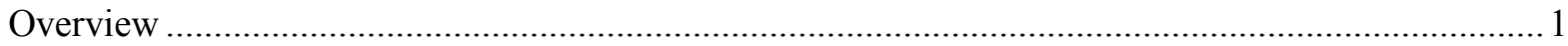

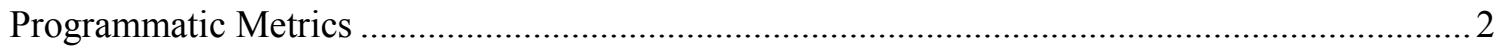

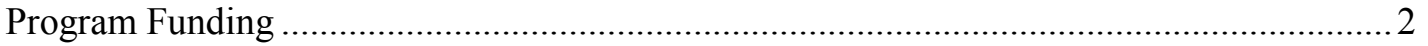

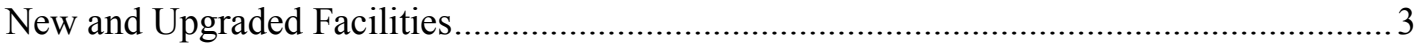

Publications, Presentations, Patents, and Invention Disclosures .......................................... 4

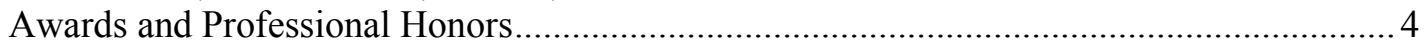

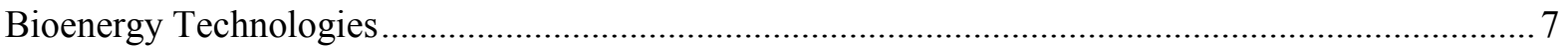

Catalytic Conversion of Ethanol to Hydrocarbon via Pool Mechanism........................................ 7

Materials Compatibility Studies for Thermochemical Processing of Biomass ............................. 8

Selecting and Deploying Bioenergy Sustainability Indicators …............................................... 9

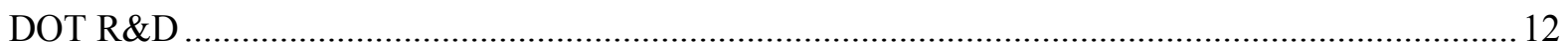

Greenhouse Gas Cost-Effectiveness Calculator ................................................................... 12

ORNL Studies Potential for Valves to Improve Pipeline Safety ................................................ 13

Regenerative Braking Potential for Tractor-Trailer Efficiency .............................................. 14

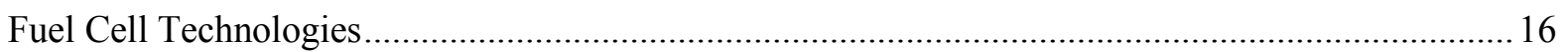

Advanced Fuel Cell Plates Promise Cost, Performance Benefits.............................................. 16

Friction Stir Welding Enables SCCVs to Exceed DOE Targets ................................................ 17

How DOE Technical Targets Impact Penetration of Hydrogen Vehicles .................................... 18

Sensitivity of Hydrogen Vehicle Sales to Consumer Preferences .............................................. 19

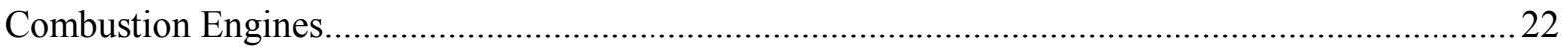

Accelerating Predictive Engine Simulation with High-Performance Computing .......................22

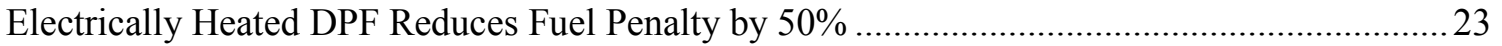

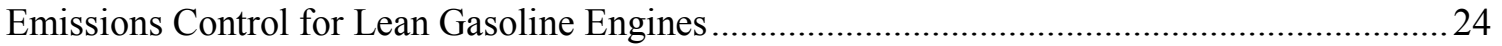

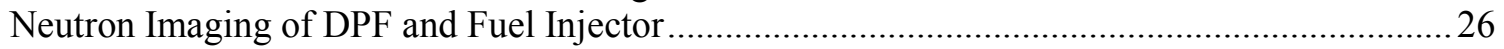

Potential for E85 Engine Optimization under Revised Specification........................................22

RCCI Potential Explored Using Vehicle Simulation and Engine Map ......................................28

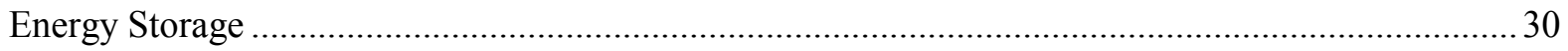

Composite Electrolyte to Stabilize Metallic Lithium Anodes ................................................... 30

Computer Aided Engineering to Improve Battery Performance, Safety .................................... 31

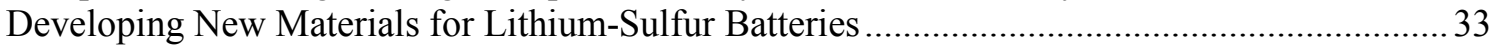

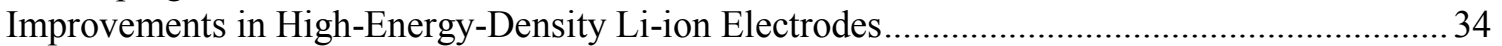

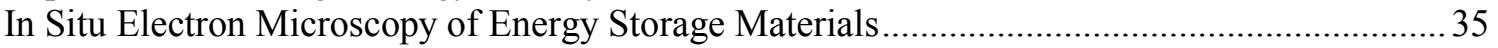

Nondestructive Evaluation to Cut Waste in Lithium Battery Production...................................... 37

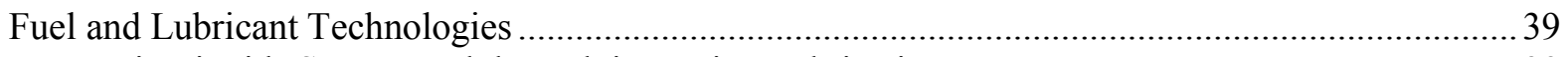

Ionic Liquids Score Breakthrough in Engine Lubrication......................................................... 39

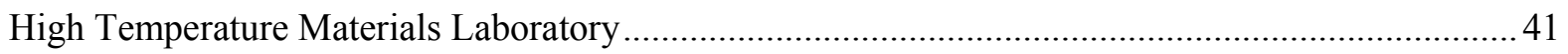

Determining Residual Stresses in Deep-Roll-Peened Titanium .............................................. 41

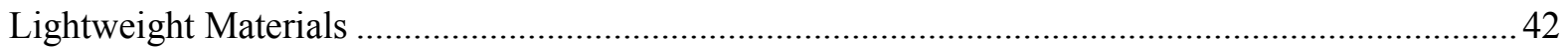

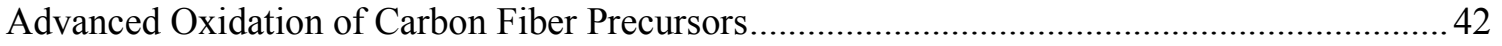

Equipment Installed and Tested at Carbon Fiber Technology Facility ....................................... 43

Cost Modeling of Alternative CF Manufacturing Technologies and Materials ........................... 44

Textile-grade PAN Promising Low-cost, High-strength CF Precursor .......................................... 46

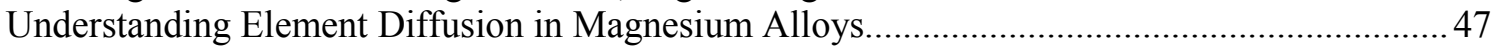

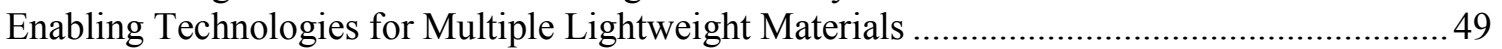

Infrared Thermography Enables Nondestructive Online Weld Inspection..................................51

Manufacturing and Processing of AHSS and Magnesium Alloys................................................5 


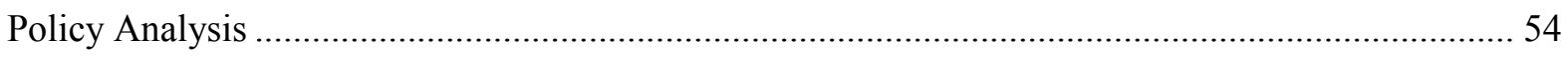

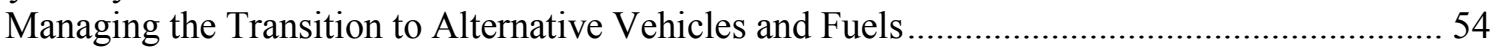

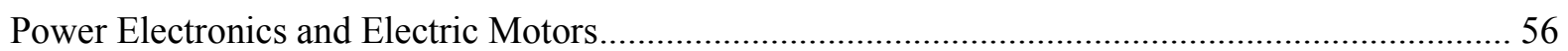

Benchmarking Commercial Advances in Electric Vehicle Technologies ................................ 56

Increasing Electric Vehicle Efficiency by Improving Motor Materials .................................... 57

Segmented Drive Inverter Can Improve Drive Systems in Electric Vehicles............................ 58

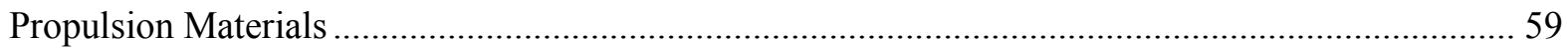

Combining Simulation and Experiment to Develop Improved Catalysts .................................... 59

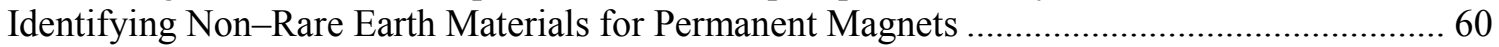

Thermoelectric Materials: Predicting, Attaining, and Verifying Performance ............................ 61

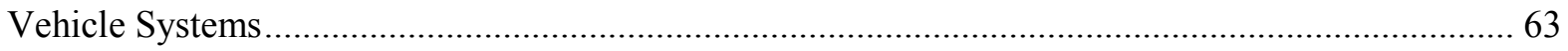

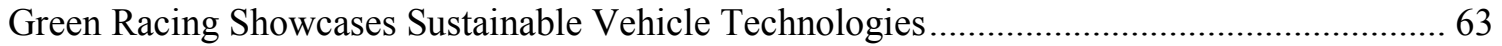




\section{Introduction}

\section{Overview}

Oak Ridge National Laboratory's (ORNL)

Sustainable Transportation Program

performs research and development

(R\&D) leading to new vehicle and transportation system technologies. Its R\&D portfolio includes alternative fuels, advanced combustion engines, efficient vehicle components, advanced materials, transportation electrification, vehicle systems integration, and intelligent transportation systems and operations. ORNL also provides data and analysis supporting policy- and decision-making by the Department of Energy (DOE) Office of Energy Efficiency and Renewable Energy (EERE) and the Department of Transportation (DOT).

The focus of the program is clean, efficient, intelligent paths to reducing transportation petroleum consumption and emissions and to improving US energy security by increasing the supplies of domestically available fuels and reducing petroleum imports.

The Program's primary support comes from DOE EERE, through three technology development offices: Vehicle Technologies, Fuel Cell Technologies, and Bioenergy Technologies. Support also comes from DOT, other federal agencies, and the private sector.

The Sustainable Transportation research program pursues an "all of the above" strategy that incorporates accelerating the market penetration of electric vehicles, both battery and fuel cell; increasing the efficiency of all types of vehicles though lighter-weight materials and advanced combustion and power train technologies; enabling the use of alternative fuels such as biofuels and natural gas; and collecting, analyzing, and disseminating data to advance efficient fleet operation, in-vehicle intelligent systems, and congestion management technologies.

These efforts are directed toward attaining

- Safe, secure, affordable vehicles for passengers and freight

- Domestic production of transportation fuel

- Reduction of the environmental impacts of transportation

- Predictability and reliability in transport scheduling

Transportation is a huge factor in the energy and environmental future of the United States. Highway transportation - light-, medium-, and heavy-duty vehicles accounted for more than $25 \%$ of US greenhouse gas emissions ${ }^{1}$ and about $60 \%$ of US petroleum consumption in 2011. ${ }^{2}$ While energy use by passenger vehicles is projected to decline by about $20 \%$ by 2040 largely as a result of more stringent greenhouse gas and corporate average fuel economy regulations, energy use by commercial light-duty trucks is projected to rise by about $5 \%$ during the same period. And energy use by freight trucks is projected to rise by about $47 \%{ }^{3}$ Developing a sustainable transportation system is indispensable to a sustainable future.

Notable achievements in research supporting the Vehicle Technologies Office included the design and development of an all-solid lithium-sulfur battery

\footnotetext{
${ }^{1}$ S. C. Davis, S. W. Diegel, and R. G. Boundy, Transportation Energy Data Book: Edition 32, ORNL6989, Table 1.17, 2013.

2 Ibid, Table 11.4.

3 US Energy Information Administration, Annual Energy Outlook 2013 with Projections to 2040, US Department of Energy, Washington, D.C., Table A7, 2013.
} 
configuration that eliminates the polysulfide shuttling that reduces battery efficiency and cycle life; a breakthrough in ionic liquid lubricant additives to reduce engine friction and wear; advances in lowcost carbon fiber development, including equipment installation and testing in the new Carbon Fiber Technology Facility; and the development and demonstration of an electrically regenerated diesel particulate filter that dramatically reduces the fuel and time required for regeneration. Researchers in this program are using supercomputers to accelerate predictive engine simulations and continue to use neutron imagining to examine components and processes such as fuel injection and particulate filters.

Continuing an effort of several years under the Fuel Cell Technologies Office, ORNL and its industrial partner conducted more than 1,000 hours of fuel cell and manufacturing evaluations of bipolar plates made from an iron-chromium-vanadium alloy that forms a protective nitride coating. The evaluations indicate the nitrided plates perform as well as or better than more costly conventional plates and can be manufactured using current stamping practices. In another project, cost modeling showed that a lowcost steel-concrete composite vessel fabricated using ORNL's friction stir welding process can exceed DOE technical targets for hydrogen storage. Modeling studies evaluated how consumer

\section{Programmatic Metrics}

\section{Program Funding}

The Sustainable Transportation Program received $\$ 71.1 \mathrm{M}$ in new funding in FY 2012. Of that total, $\$ 9.4 \mathrm{M}$, or $13 \%$, was received for projects selected competitively preferences and progress toward DOE technical targets are likely to affect the market penetration of hydrogen vehicles.

Researchers supporting Bioenergy Technologies demonstrated that high-yield conversion of ethanol to hydrocarbons occurs via a pool mechanism at the relatively mild conditions of $350^{\circ} \mathrm{C}$ at atmospheric pressure. ORNL used electron microscopy and $\mathrm{x}$-ray scattering to characterize materials exposed to the chemical compounds generated in thermochemical biomass processing systems. The goal of the project is to determine the least expensive alloy that meets durability targets for use in these systems.

In support of DOT, ORNL completed a study that developed a representative drive cycle for Class 8 tractor-trailers and used it to quantify how advanced technologies affect fuel savings and emissions. The results suggest that an efficient regenerative braking system for tractor-trailers may save more fuel than any other technology evaluated. Sustainable Transportation Program researchers also completed a study of the potential of measures such as automatic shutoff valves and remote control valves to improve the safety of natural gas and hazardous liquid pipelines.

Highlights of these and other Sustainable Transportation Program R\&D efforts begin on page 7 .

by DOE EERE via Funding Opportunity Announcements, a relatively new way of doing business between DOE EERE and its national laboratories. 


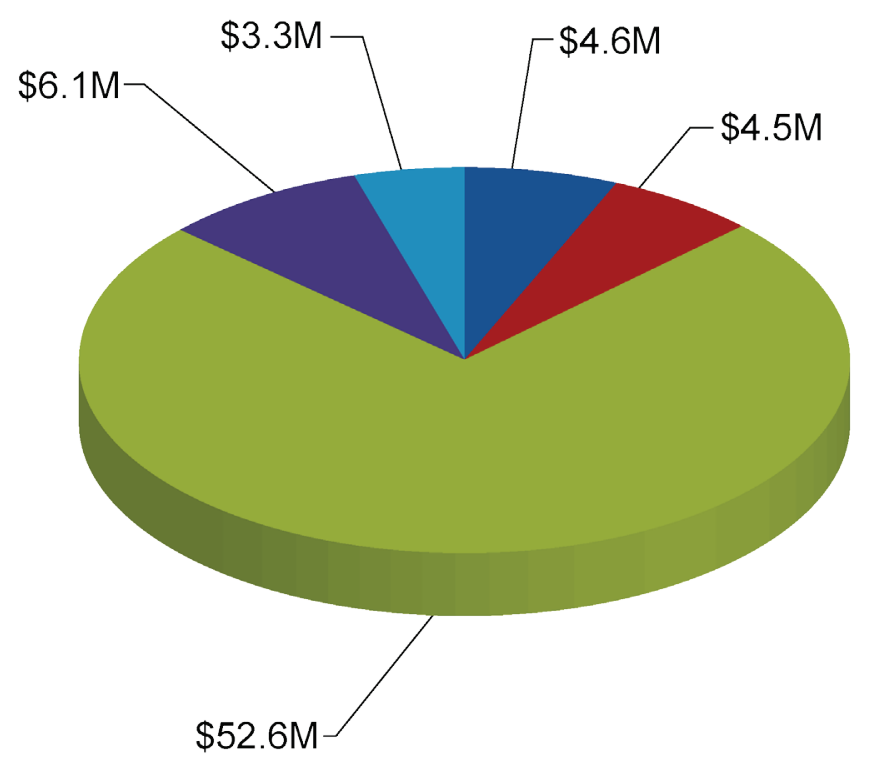

- DOE Bioenergy Technologies

- DOE Fuel Cell Technologies

DOE Vehicle Technologies

Department of Transportation

- Industry and Others

\section{New and Upgraded Facilities}

Energy storage. The new $\$ 3$ million Battery Manufacturing Facility was completed and commissioned and is now available to industry to demonstrate new materials and manufacturing processes. The facility houses state-of-the-art equipment for producing batteries with up to 7 ampere-hours capacity, a size that provides good demonstration capability but requires only small amounts of advanced or new materials, which typically are scarce in their development stages.

A transfer stage was developed for taking samples from glovebox to scanning electron microscope without exposure to air and moisture. This is important for imaging air-sensitive materials used in lithium-sulfur batteries and other lithiumion batteries. A paper describing the achievement was published in J. Mater. Sci. (J. Y. Howe et al., February 2012, 47(3), 1572-1577).

Combustion, fuels and lubricants. A General Motors 2.0-liter LNF gasoline direct-injection (GDI) engine modified for flex-fuel capabilities, along with an advanced open control system, was installed and commissioned. The engine, loaned by Robert Bosch, LLC, will be used in research related to high-dilution stoichiometric GDI combustion stability and particulate studies.

The multi-cylinder high-efficiency clean combustion engine test cell was upgraded from an eddy-current dynamometer to a motoring AC dynamometer.

The air handling system for the singlecylinder research engine was upgraded to allow the engine to be operated with simulated boost, backpressure, cooled external exhaust gas recirculation, and improved thermal management. This upgrade enables research on expanding the high load limits of advanced combustion, and research into pre-ignition phenomena in boosted spark-ignition conditions.

Fuel cells. A large-scale evaluation system was added, designed to evaluate a full-size single cell, a $250 \mathrm{~cm}^{2}$ cell, or a small stack of up to $3 \mathrm{~kW}$. 
Carbon Fiber Technology Facility. ORNL accepted "beneficial occupancy" of the facility. Equipment for the carbon fiber semi-production line, the melt-spinning semi-production line, and surface treatment was received and installed well ahead of schedule.

\section{Publications, Presentations, Patents, and Invention Disclosures}

During FY 2012, Sustainable

Transportation Program research resulted in more than 180 publications and more than 170 presentations.

Sustainable Transportation Program researchers submitted 51 invention disclosures in FY 2012 supported by Vehicle Technologies Office, Fuel Cell Technologies Office, and related efforts from other federal agencies, as well as ORNL strategic investments such as Laboratory Directed Research and Development. As of the end of FY 2012, 10 had been selected for patent filing, with filing decisions pending on another 32 disclosures.

During FY 2012, 10 patents were awarded based on previous filings.

“Permanent-magnet-less synchronous reluctance system." US Patent 8,264,120. Inventor: John S. Hsu.

“Apparatus for pre-stress-straining rodtype specimens in tension for in-situ passive fracture testing." US Patent 8,230,748. Inventors: Jy-an Wang, Ken C. Liu, and Zhili Feng.

"Microbial fuel cell treatment of ethanol fermentation process water." US Patent 8,192,854. Inventor: Abhijeet P. Borole.
“Apparatuses for prestressing rod-type specimens in torsion for in-situ passive fracture toughness testing in an extremely high-pressure environment of hydrogen." US Patent 8,176,795. Inventors: Jy-an Wang, Ken C. Liu, and Zhili Feng.

"Electronically commutated serial-parallel switching for motor windings." US Patent 8,143,834. Inventor: John S. Hsu.

"Permanent-magnet-less machine having an enclosed air gap." US Patent 8,110,961. Inventor: John S. Hsu.

"Power conversion apparatus and method." US Patent 8,110,948. Inventor: Gui-Jia Su.

"Friction stir method for forming structures and materials." US Patent 8,061,579. Inventors: Zhili Feng, Stan A. David, and David Alan Frederick.

"Apparatus and method for carbon fiber surface treatment." US Patent 8,227,051. Inventors: Felix L. Paulauskas and Daniel M. Sherman.

"Oxygen concentration sensors and methods of rapidly measuring the concentration of oxygen in fluids." US Patent 8,248,612. Inventors: James E. Parks II and William P. Partridge Jr.

\section{Awards and Professional Honors}

Research staff members received numerous awards and professional accolades, reflecting significant contributions to research and technology development as well as peer recognition. A selection of the most notable of these is shown in Table 1. 
Table 1. Awards and professional honors received by ORNL Sustainable Transportation Program researchers in FY 2012

\begin{tabular}{|c|c|}
\hline Michael P. Brady & $\begin{array}{l}\text { Federal Laboratory Consortium Award for Excellence in Technology } \\
\text { Transfer for a clean-burning cookstove designed for the developing } \\
\text { world (with Envirofit International and Colorado State University) }\end{array}$ \\
\hline Michael P. Brady & $\begin{array}{l}\text { Invited keynote speaker at Technoport Renewable Energy Research } \\
\text { Conference in Trondheim, Norway }\end{array}$ \\
\hline Madhu Chinthavali & $\begin{array}{l}\text { Best presentation in the technical session for poster titled "Feasibility } \\
\text { study of a 55-kW air-cooled automotive inverter," The Applied Power } \\
\text { Electronics Conference and Exposition }\end{array}$ \\
\hline David Cullen & $\begin{array}{l}\text { Third place at the Fuel Cell Seminar and Exposition in Orlando, Florida, } \\
\text { for technical poster titled "Comparison of quantitative electron } \\
\text { microscopy methods for determining Pt-loss in PEM fuel cells" }\end{array}$ \\
\hline Virginia Dale & $\begin{array}{l}\text { "Eye on Biodiesel" Innovation Award from the National Biodiesel } \\
\text { Conference }\end{array}$ \\
\hline Virginia Dale & $\begin{array}{l}\text { Invited plenary speaker at National Science Foundation Emerging } \\
\text { Frontiers in Research Innovation, Resilient and Sustainable } \\
\text { Infrastructures Program Workshop }\end{array}$ \\
\hline Sujit Das & $\begin{array}{l}\text { Invited to serve on Natural Sciences and Engineering Research Council of } \\
\text { Canada site visit committee }\end{array}$ \\
\hline Diane Davidson & $\begin{array}{l}\text { Chair, Transportation Research Board's National Cooperative Freight } \\
\text { Research Program Technical Panel }\end{array}$ \\
\hline Nancy Dudney & $\begin{array}{l}\text { Invited discussion leader for opening session at Gordon Research } \\
\text { Conference on Batteries }\end{array}$ \\
\hline Zhili Feng & Elected Fellow of the American Welding Society \\
\hline David Greene & $\begin{array}{l}\text { Edward L. Ullman Award in Transportation Geography from the } \\
\text { American Association of Geographers }\end{array}$ \\
\hline David Greene & $\begin{array}{l}\text { Appointed to the Transportation Research Board Special Task Force on } \\
\text { Climate Change and Energy }\end{array}$ \\
\hline David Greene & $\begin{array}{l}\text { Invited keynote speaker at the National Research Council, Transportation } \\
\text { Research Board, Workshop on Data Needs in Transportation }\end{array}$ \\
\hline David Greene & $\begin{array}{l}\text { Invited to present the Fleming Lecture in Transportation Geography at } \\
\text { the Association of American Geographers Annual Meeting }\end{array}$ \\
\hline David Greene & $\begin{array}{l}\text { Appointed to the National Research Council Committee on Light-Duty } \\
\text { Vehicle Fuel Economy }\end{array}$ \\
\hline David Greene & $\begin{array}{l}\text { Invited presentation at the Advanced Research Projects Agency-Energy } \\
\text { Transportation Behavior and New Technology Workshop }\end{array}$ \\
\hline John S. Hsu & $\begin{array}{l}\text { Cyril Veinott Electromechanical Energy Conversion Award from the } \\
\text { IEEE Power and Energy Society }\end{array}$ \\
\hline Keith Kline & $\begin{array}{l}\text { "Eye on Biodiesel” Innovation Award from the National Biodiesel } \\
\text { Conference }\end{array}$ \\
\hline Andreas Malikopoulos & $\begin{array}{l}\text { Board of Associates, Internal Combustion Engine Division of the } \\
\text { American Society of Mechanical Engineers }\end{array}$ \\
\hline
\end{tabular}




\begin{tabular}{|l|l|}
\hline Andreas Malikopoulos & $\begin{array}{l}\text { Invited participant in the National Academies Keck Futures Initiative } \\
\text { Conference }\end{array}$ \\
\hline Jonathan Mielenz & $\begin{array}{l}\text { Elected to the Board of Directors, Society of Industrial Microbiology and } \\
\text { Biotechnology }\end{array}$ \\
\hline John Miller & $\begin{array}{l}\text { Elected Fellow of SAE International } \\
\text { for a technical poster titled “Comparison of quantitative electron } \\
\text { microscopy methods for determining Pt-loss in PEM fuel cells" }\end{array}$ \\
\hline Karren More & $\begin{array}{l}\text { Invited keynote lecture at International Workshop on the } \\
\text { Characterization and Quantification of MEA Degradation Processes, } \\
\text { Grenoble, France }\end{array}$ \\
\hline Karren More & $\begin{array}{l}\text { Stanley I. Auerbach Award for sustained excellence using computable } \\
\text { general equilibrium modeling to understand how economic activity } \\
\text { responds to environmental and market shocks and shifts }\end{array}$ \\
\hline Gbadebo Oladosu & $\begin{array}{l}\text { Invited keynote speaker for Environmental Catalysis Session of the } \\
\text { EuropaCatX Conference, University of Glasgow, Scotland }\end{array}$ \\
\hline William Partridge & 2012 DOE Vehicle Technologies Program R\&D Award \\
\hline Felix Paulauskas & $\begin{array}{l}\text { SAE International Excellence in Oral Presentation Award for "NMOG } \\
\text { emissions characterizations and estimation for vehicles using ethanol- } \\
\text { blended fuels," presented at the SAE International Congress }\end{array}$ \\
\hline Scott Sluder & Chairman, SAE International Land and Sea Operating Group \\
\hline Scott Sluder & Member, SAE International Engineering Meetings Board \\
\hline Scott Sluder & $\begin{array}{l}\text { Named Forest Biotechnologist of the Year by the Forest Biotechnology } \\
\text { Partnership }\end{array}$ \\
\hline Gerry Tuskan & $\begin{array}{l}\text { Birks Award from the Microanalysis Society for the Best Contributed } \\
\text { Paper at the 2011 Microscopy and Microanalysis Meeting }\end{array}$ \\
\hline Ray Unocic & Associate Editor, SAE International's International Journal of Engines \\
\hline ORnL Early Career Award for Engineering Accomplishment \\
\hline David L. Wood III & ORngert \\
\hline
\end{tabular}




\section{Bioenergy Technologies}

\section{Catalytic Conversion of Ethanol to Hydrocarbon via Pool Mechanism}

The emphasis on renewable energy sources has focused attention on biomass-derived fuels, which will represent an estimated $11 \%$ of all liquid fuels in the United States by 2035. The successful deployment of biomassderived ethanol, primarily in transportation, is an important step. However, use of renewable fuels is dictated by available technology; at this time, there is a limit of 10$15 \%$ ethanol in the fuel mix for most gasoline-powered vehicles. A higher-ethanol mixture, E85, has been available for several years but can be used only in flex-fuel vehicles, which represent a small percentage of vehicles on the road.

Expansion of the biomass-derived ethanol industry and distribution channels during the last 20 years has created interest in the conversion of ethanol to industrial chemicals, resulting in the commercialization of ethylene derived from bio-ethanol. ORNL researchers have found that conversion of ethanol to hydrocarbons -dependent on both temperature and space velocity-occurs through a pool mechanism, not by ethylene upgrading.

Most ethanol converts to ethylene at $250^{\circ} \mathrm{C}$ with approximately $10 \%$ C3+

hydrocarbons. An increase in temperature results in a decrease in $\mathrm{C} 2$ hydrocarbon formation, reaching a minimum of $10 \%$ at $350^{\circ} \mathrm{C}$. However, $\mathrm{CO}$ formation also begins at $350^{\circ} \mathrm{C}$, resulting in decomposition of the product stream into coke, which can deposit on the catalyst. The input stream can be a fermentation stream or ethanol at any stage of purification. The output stream contains $\mathrm{C} 2+$ hydrocarbons and water, which are easily separated.

ORNL researchers conducted tests on a modified Sturman variable-valve actuation
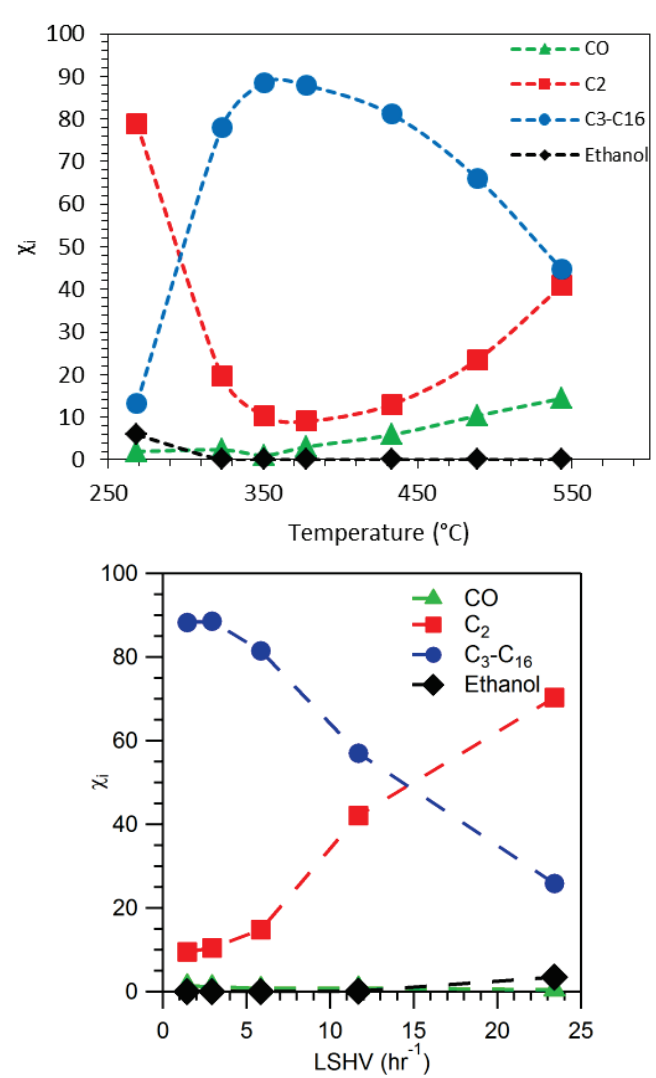

Ethanol conversion to hydrocarbons as a function of temperature (top) and liquid hourly space velocity at $350^{\circ} \mathrm{C}$ (bottom).

engine with ported fuel injection warmed up using a gasoline direct injection fueling system without consuming test fuel. Gasoline blend-stock or certification gasoline was then introduced, and performance data such as cylinder pressure and heat release rate were recorded. These parameters for engine operation on blend-stock were found to be identical to the parameters for engine operation on certification gasoline.

The results of the ORNL study show it is possible to convert ethanol under relatively mild conditions of $350^{\circ} \mathrm{C}$ at atmospheric pressure in high yields. The catalyst is durable, but periodic decoking is required as 
coke builds up. The catalyst recovers after a regeneration cycle. The fractional collection allows for amassing blend-stock for gasoline, diesel, or various jet fuels.

\section{Patents and Presentations}

[1] C. K. Narula, B. H. Davison, and M. Keller, "Zeolitic Catalytic Conversion of Alcohols to Hydrocarbons," Patent WO2012174205, December 20, 2012.

[2] R. A. Geiger, et al., "Direct catalytic conversion of ethanol to fuel," presented at 243rd American Chemical Society National Meeting and Exposition, March 25-29, San Diego, 2012.

\section{Materials Compatibility Studies for Thermochemical Processing of Biomass}

Thermochemical processing of biomass produces raw materials that can be converted into hydrocarbon fuels. One processing method, biomass pyrolysis (chemical change brought on by heat), produces liquids with certain advantages for further conversion. However, these biomass-derived oils - or bio-oils - have other features that could be barriers to commercial fuel production. Specifically, the liquids produced via pyrolysis typically are highly acidic, contain a significant amount of water and oxygenbearing organic compounds, and may have contaminants such as sulfur or chlorine. Therefore, the potential for corrosion of containment materials during production, storage, or transport of bio-oils is a serious concern.

Research with untreated pyrolysis oil consistently shows that corrosion rates for carbon steel and $21 / 4 \mathrm{Cr}$ - 1 Mo steel are unacceptable and remain high with "stabilized" bio-oil. Type 409 stainless steel alloy, containing about $11 \%$ chromium, shows mixed results with fairly high corrosion rates in some bio-oils. Tests conducted in hydrotreated bio-oils with reduced oxygen content at various temperatures show corrosion rates of less than $0.01 \mathrm{~mm} /$ year.

Studies also examined materials exposed in operating biomass processing systems.
Scanning electron microscopy and energy dispersive $x$-ray analysis (EDS) were completed for an alloy tube inserted in the transfer line after the thermal cracker $\left(\sim 550^{\circ} \mathrm{C}\right)$ in the National Renewable Energy Laboratory's pyrolysis system. Evidence of crack-like, localized attack, in some cases related to grain boundaries, was observed in all of the alloys. EDS indicated the presence of chlorine, calcium, potassium, oxygen, and/or carbon in the attack regions in several samples. Based on these findings, researchers are pursuing additional trials under controlled conditions to assess the extent and nature of susceptibility to attack. The goal is to determine the lowest-cost alloy that can meet durability targets for biomass processing production equipment.

Researchers are also using existing analytical tools to characterize the bio-oils. The complex chemical compounds and physical phases produced in upgrading biomass hinder the direct reduction of corrosivity for further upgrading. In 2012, the ORNL pyrolysis oil corrosion team began developing a suite of analytical approaches targeting improved speciation of bio-oils and by-products by focusing on the specific phase (aqueous versus organic) each family of corrosive compounds occupies. A pattern of acid masking by inclusion in hydrophobic, loosely 
aggregated oil particles has emerged in comparisons of aqueous phase with extracted organic phase samples. This could
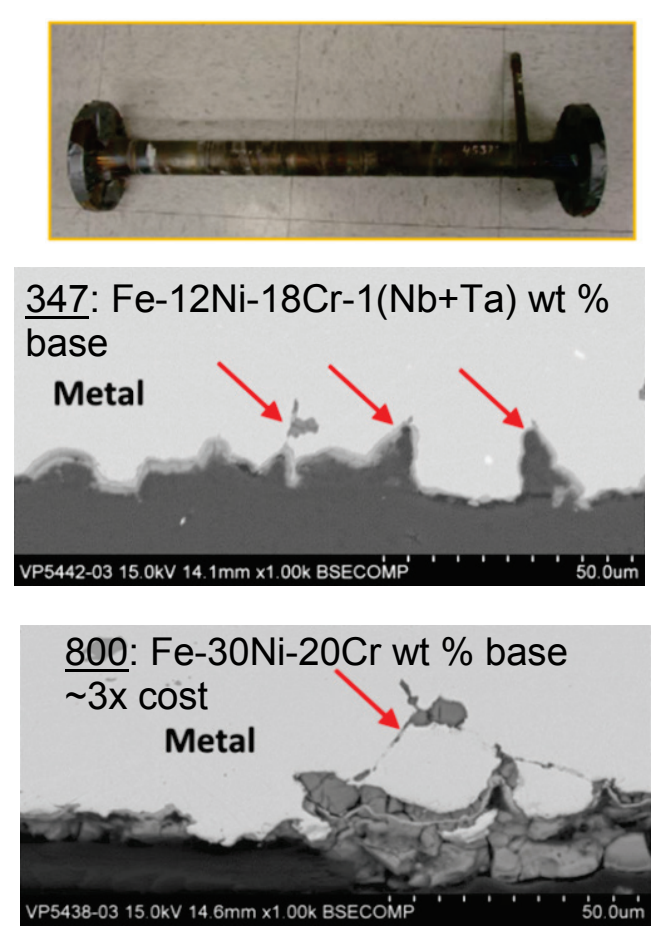

have implications for material corrosion at higher temperatures, at which bio-oil viscosity and metal wetting are increased.
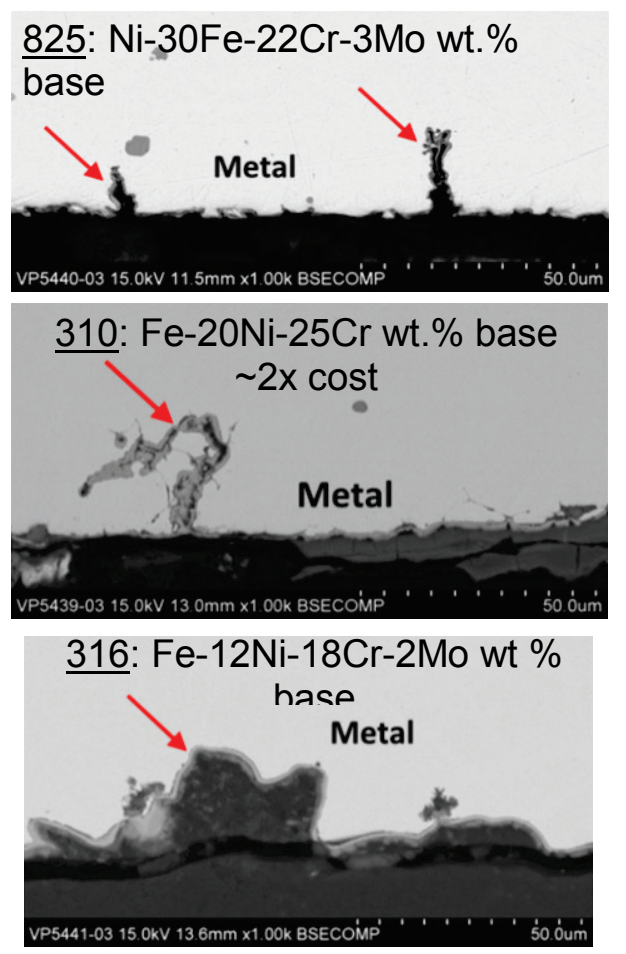

Transfer tube after exposure in National Renewable Energy Laboratory pyrolysis system. Scanning electron micrographs (backscatter mode) of cross sections show the surface regions of the tested alloys. Red arrows mark the areas of attack.

\section{Selecting and Deploying Bioenergy Sustainability Indicators}

Effective indicators can help identify and quantify socioeconomic and environmental sustainability attributes of bioenergy systems. ORNL researchers have selected key indicators of bioenergy sustainability and proposed how they can best be used in particular contexts. The analysis addressed three goals:

1. Choosing the indicators most useful to decision makers

2. Selecting measures of sustainability applicable across the entire bioenergy supply chain
3. Identifying a minimum set of practical, doable indicators that incorporate key areas of interest to science

The proposed indicators represent a suite designed to reflect major bioenergy sustainability considerations. Nineteen indicators fit into the major environmental sustainability categories of soil quality, water quality and quantity, greenhouse gases, biodiversity, air quality, and productivity. Sixteen socioeconomic indicators fall into the categories of social well-being, energy security, trade, profitability, resource conservation, and social acceptability. 
Together, this suite of indicators is hypothesized to reflect major environmental and socioeconomic effects of the full supply chain for bioenergy, including feedstock production and logistics, conversion to biofuels, biofuel logistics, and biofuel end uses. They provide a basis for quantifying and evaluating the sustainability of bioenergy systems across many regions.

It is important to interpret these indicators of bioenergy sustainability in particular contexts, because the context of any particular application strongly affects the choice, measurement, and interpretation of sustainability indicators. Considerations include the purpose of the analysis, the specific fuel production and distribution system, policy influences, stakeholders and their values, baseline attributes, available information, and spatial and temporal scales of interest. Knowing the context is essential for setting priorities for assessment, defining the purpose, setting the temporal and spatial boundaries for consideration, and determining the practicality and utility of measures.

ORNL's Center for BioEnergy Sustainability has also worked with agronomists to analyze how evaluations of agricultural sustainability should consider the effects of farm activities on social, economic, and environmental conditions both locally and regionally. Adoption of more sustainable agricultural practices entails defining sustainability, developing easily measured indicators of sustainability, moving toward integrated agricultural systems, and offering incentives or imposing regulations to affect farmers' behavior. Landscape ecology is useful in considering sustainability because it provides theory and methods for dealing with spatial heterogeneity, scaling, integration, and complexity. To move toward more sustainable agriculture, the team proposes adopting a systems perspective, recognizing spatial heterogeneity, integrating landscapedesign principles, and addressing the influences of context.

\section{Publications and Presentations}

[1] V. H. Dale et al., “ Indicators for assessing socioeconomic sustainability of bioenergy systems: A short list of practical measures," Ecol. Indic. 26, 87102 (2013).

[2] V. H. Dale et al., “A landscape perspective on sustainability of agricultural systems," Landscape Ecol. 28(6) (2012).

[3] R. A. Efroymson et al., "Environmental indicators of biofuel sustainability: what about context?" Environ. Manage. 37(1) (2012).

[4] McBride et al., "Indicators to support environmental sustainability of bioenergy systems," Ecol. Indic. 11(5), 1277-1289 (2011). 


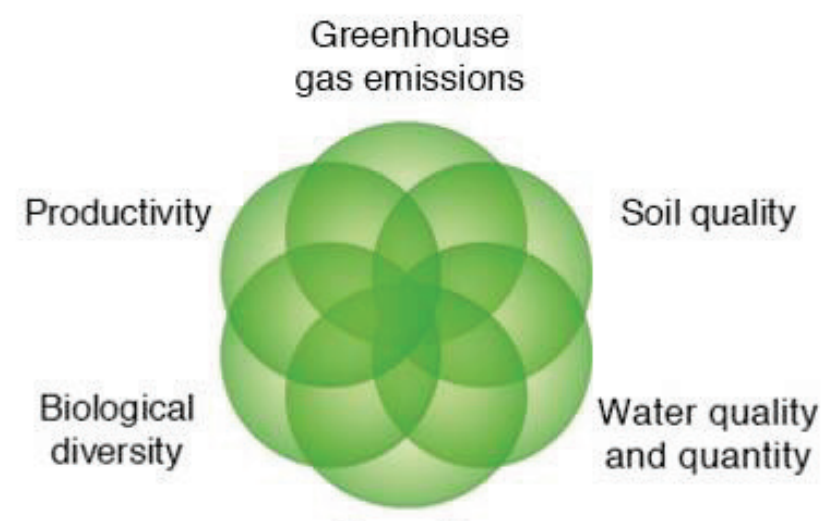

Air quality

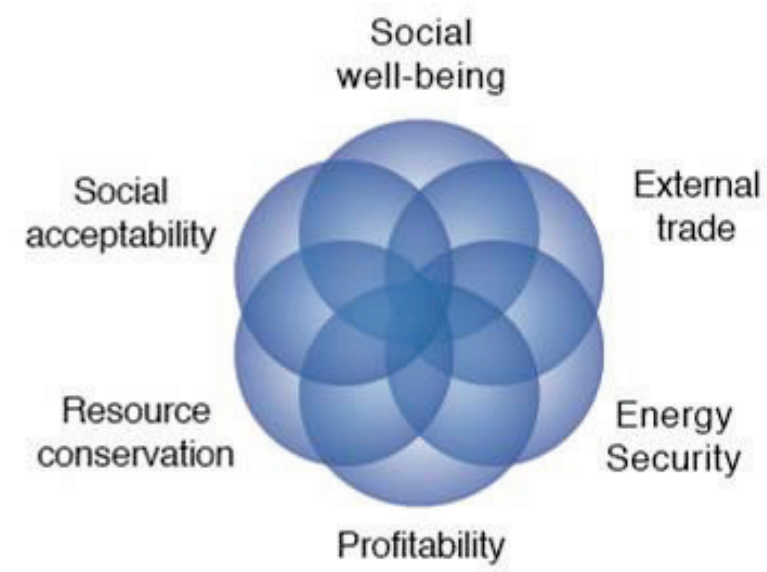

Major sustainability categories (top) and indicators of environmental and socioeconomic sustainability (bottom). 


\section{DOT RED Highlights}

\section{DOT R\&D}

\section{Greenhouse Gas Cost-Effectiveness Calculator}

The Federal Transit Administration project

“Developing a Greenhouse Gas Emissions

Calculator Incorporating Electric Vehicle

Options" is devising a calculator to help public transit agencies evaluate alternative transit vehicle technologies, including existing and anticipated electric vehicle options, based on their cost-effectiveness in reducing greenhouse gas (GHG) emissions.

The calculator will help transit agencies compare the performance of alternative vehicle technologies on the basis of purchase price, operating and maintenance costs, energy consumption and fuel efficiency, and GHG emissions. To provide a more complete analysis of alternativefuel fleet vehicles, the calculator will also provide output related to criteria pollutant emissions. Attention will be given to electric drive vehicles, enabling transit agencies to assess the benefits of these vehicles as candidates for their fleets.

The calculator includes three new embedded modules:

- $\quad$ a scaled tractive power operating mode bin calculator

- a MOVES-matrix emissions rates lookup table

- $\quad$ a hybrid bus energy-balance model designed to shift energy demand across scaled tractive power operating mode bins

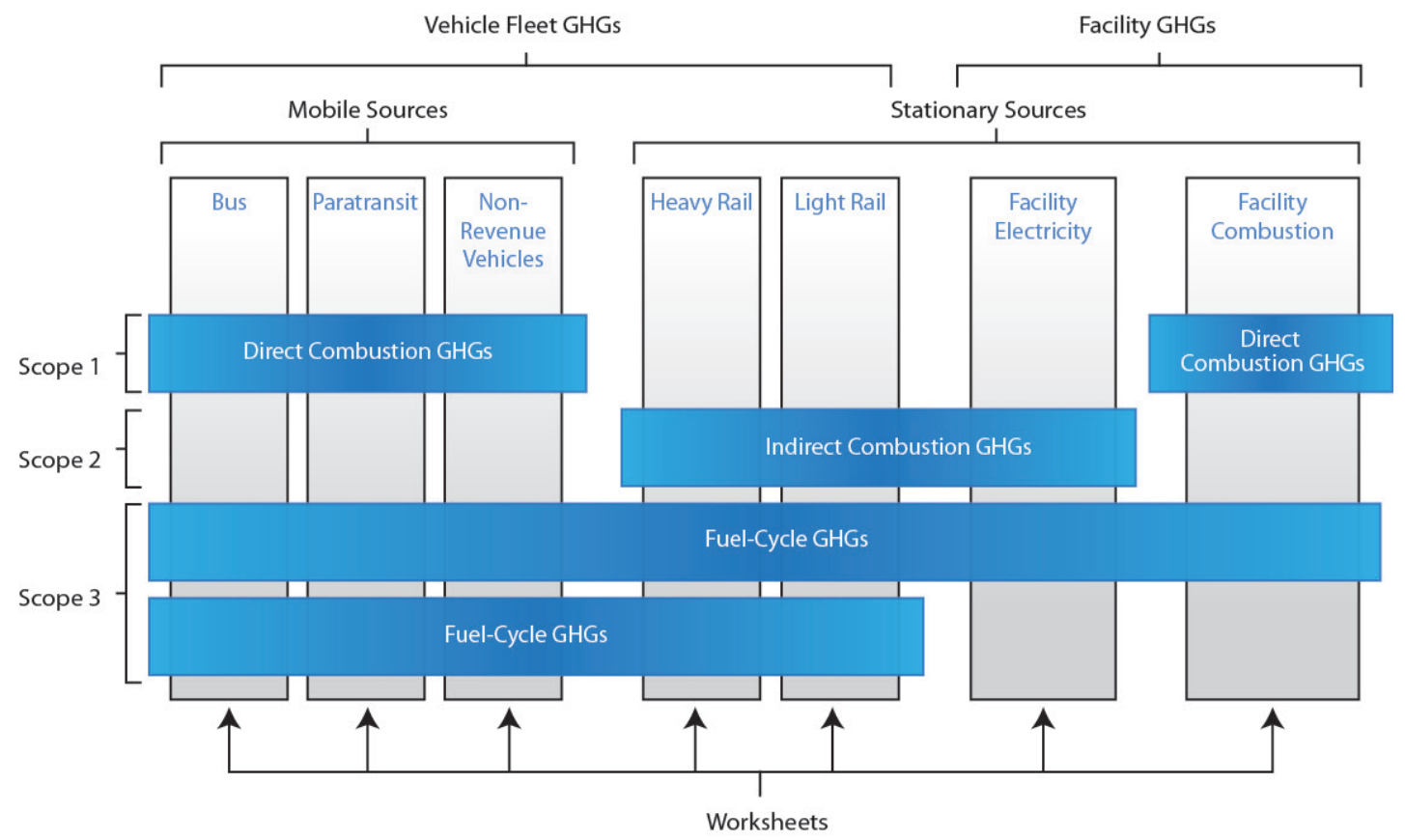

Overview of the transit GHG calculator.

It allows emissions comparisons across vehicle operating modes, enabling users to compare fuel consumption and vehicle emissions across energy technologies based on route characteristics such as road grade, number of stops, and average speed. The interface features summary input and output by operating mode in the 
same worksheet. Scenario options for the input interface allow users to enter combinations of fuel and vehicle technologies as well as route characteristics. The team has documented the calculator development process and completed documentation for the MOVESmatrix emissions lookup table development and the hybrid bus energy balancing model development.

\section{ORNL Studies Potential for Valves to Improve Pipeline Safety}

An unintended release anywhere on the 2.3 million miles of natural gas and hazardous liquid pipelines in the United States could have devastating consequences. An ORNL team has completed a study aimed at enhancing pipeline safety by identifying measures to mitigate release impacts.

Congress requires the US Department of Transportation's Pipeline and Hazardous Materials Safety Administration (PHMSA) to evaluate the use of automatic shutoff valves (ASVs) and remote control valves (RCVs) when feasible on new and replaced pipelines. The ORNL study, conducted at PHMSA's request, found that ASVs and RCVs can mitigate the consequences of unintended pipeline release, but their technical and economic feasibility must be evaluated case-by-case.

PHMSA is also evaluating concerns raised by the National Transportation Safety Board (NTSB) regarding a September 2010 natural gas pipeline rupture in San Bruno, California, that caused eight deaths. NTSB concluded that ASVs and RCVs could have significantly reduced the damage caused by the rupture.

Natural gas pipelines must incorporate sectionalizing block valves at intervals that vary depending on population density. The valves are not required to be remotely operable or to operate automatically in case of an unexpected pressure reduction such as a pipeline rupture. However, pipeline operators are required to assess risks for their pipelines and take additional measures, including installing ASVs or RCVs, to mitigate the consequences of a failure in a high-consequence area. Hazardous liquid pipeline operators must install block valves at prescribed locations to facilitate isolation of pump stations, breakout storage tanks, and points near designated bodies of water and populated areas, and must consider installing emergency flow-restricting devices on pipeline segments.

The study used risk analyses of hypothetical pipeline failure scenarios as the basis for assessing, within a potential impact radius,

- $\quad$ fire damage caused by natural gas pipeline releases and subsequent gas ignition

- fire damage caused by liquid pipeline releases and subsequent ignition of released propane

- $\quad$ socioeconomic and environmental damage in high-consequence areas caused by releases of crude oil from liquid pipelines

Feasibility evaluations for the hypothetical scenarios show installing ASVs and RCVs in new and replaced pipelines is feasible and has a positive cost benefit. However, the results may not apply to all pipelines because parameters that influence risk and feasibility may vary significantly among pipeline segments and differ from those considered in the study. In addition, RCVs and ASVs improve safety only in conjunction with rapid, well-coordinated emergency response. 


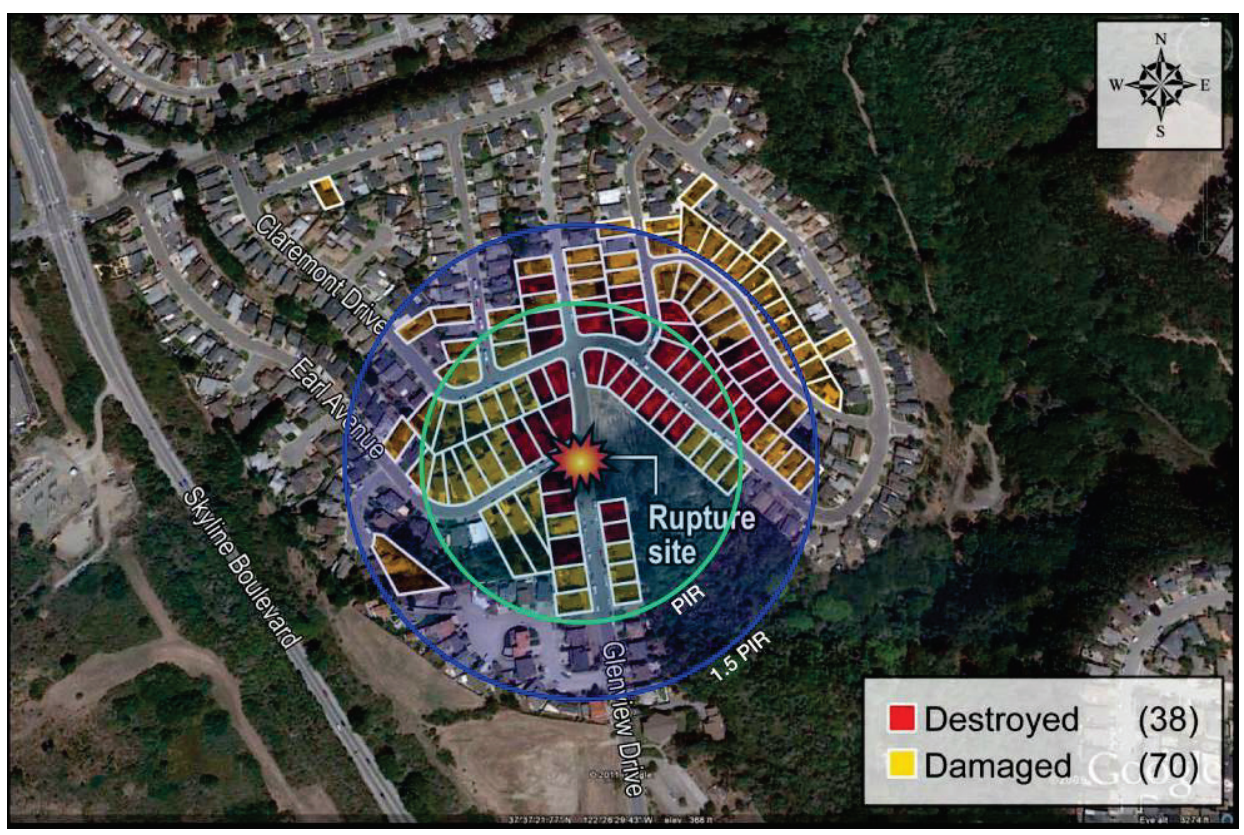

Aerial view of natural gas pipeline release in San Bruno, California, showing residential properties damaged and destroyed. Eight people died as a result of the release.

\section{Publication}

[1] C. B. Oland et al., Studies for the Requirements of Automatic and Remotely Controlled Shutoff Valves on Hazardous Liquids and Natural Gas Pipelines with
Respect to Public and Environmental Safety, ORNL/TM-2012/411, Oak Ridge National Laboratory, 2012.

\section{Regenerative Braking Potential for Tractor-Trailer Efficiency}

ORNL has completed a study funded by the National Highway Traffic Safety

Administration to evaluate fuel efficiency and emissions benefits achievable on Class 8 tractor-trailers using advanced efficiency technologies. Software was developed to perform a detailed statistical evaluation of measured drive cycle data. Measurements were taken during a full year of normal operation in a freight shipping fleet and analyzed to develop a drive cycle highly representative of the overall usage of the tested vehicles. The characteristic drive cycle was then used to quantify the fuel savings and emissions reduction potential of various advanced efficiency technologies used individually or together.
Medium- and heavy-duty trucks and buses are responsible for more than $28 \%$ of the energy used and emissions generated in highway transportation, and class 8 tractor-trailers operating in long-haul and regional cargo transport are responsible for about $75 \%$ of all fuel consumed by commercial trucks. Drive cycle data representative of a vehicle's or fleet's usage are crucial for an accurate evaluation of fuel economy or to identify the best technologies to cost-effectively reduce fuel consumption and emissions.

Using a high-fidelity, statistically meaningful set of drive cycle data collected in a prior ORNL study, researchers characterized the freeway-dominant 
operation of the class 8 tractor-trailer application evaluated for the study, using software tools developed as part of the project. A drive cycle was developed with a distribution of speeds and accelerations that closely matched the complete set of measured data.

The study provided some unexpected results. An analysis using the characteristic drive cycle indicated that about $10 \%$ of all tractive energy losses, which are largely responsible for vehicle fuel consumption, were generated by braking and engine braking. This represents a moderately

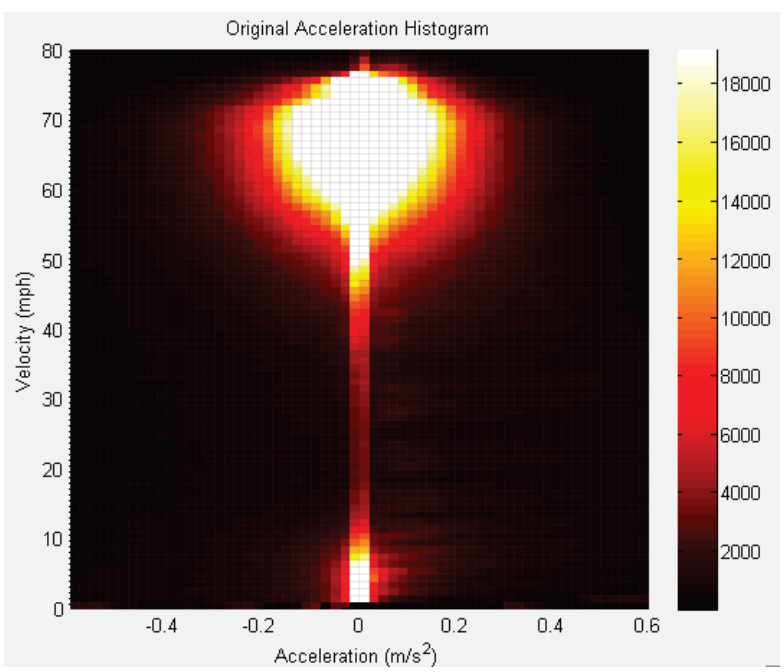

Histogram of speeds and accelerations provides a concise characterization of fleet usage. significant quantity of energy that could be recovered using a regenerative braking system, which previously was considered to hold limited potential for reducing fuel consumption and emissions. The results suggest that an efficient regenerative braking system for class 8 tractor-trailers may produce greater fuel savings than any of the other technology options evaluated. Furthermore, regenerative braking can increase the reductions achieved with more conventional technologies, such as low-rolling-resistance tires and aerodynamic drag reduction devices.

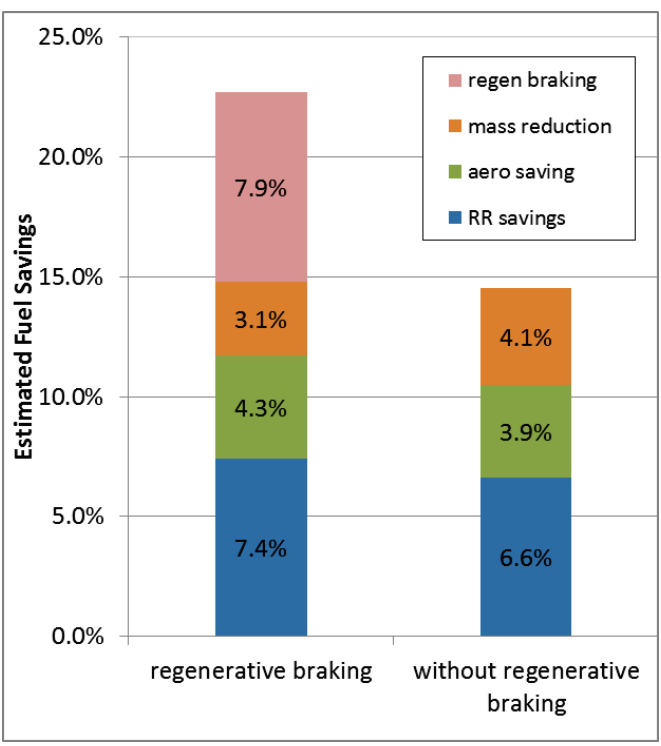

Fuel savings estimates associated with implementing various advanced efficiency technologies, compared with a conventional tractor-trailer configuration.

[2] T. J. LaClair, Z. Gao, A. Siekmann, J. S. $\mathrm{Fu}$, J. Calcagno, and J. Yun, Truck Technology Efficiency Assessment Final Report, ORNL/TM-2012/586, Oak Ridge National Laboratory, 2012. 


\section{Fuel Cell Technologies RED Highlights}

\section{Fuel Cell Technologies}

\section{Advanced Fuel Cell Plates Promise Cost, Performance Benefits}

A successful multi-year collaboration with industry, universities, and other national laboratories enabled the development and demonstration of a technology developed at ORNL for next-generation fuel cells. A novel nitriding approach used in conjunction with a ferritic stainless steel alloy enables the production of thin stamped bipolar plates for fuel cell stacks that are less expensive and thinner and perform at least as well as current technologies.

The design basis of the iron-chromiumvanadium stainless steel alloy evolved from studies of protective nitride surface layer formation on more expensive titanium-base and nickel-base alloys. Unlike many conventional stainless steels, this ferritic alloy contains vanadium, which, during thermal treatment, aids the formation of a protective nitride coating with properties that support excellent corrosion resistance and electrical conductivity.

Extensive studies of corrosion resistance and electrical properties and more than
1,000 hours of single-cell fuel cell evaluation under cyclic conditions have shown that the thin-stamped, nitrided, metallic bipolar plate provides a surface resistant to interfacial contact and corrosion, with no observed performance decline attributable to the plates. The results indicate performance comparable to or better than that of conventional plates.

The alloy is less expensive to manufacture than graphite, which is commonly used to form bipolar plates. Because the bipolar plates are thinner than graphite plates (less than $0.1 \mathrm{~mm}$ ), more of them can be added to fuel cell stacks for high power density in automotive or other applications.

(Typically, 100 or more bipolar plates are employed inside a proton exchange membrane fuel cell stack, the device that chemically converts the energy in hydrogen into electricity. Each plate electrically connects the anode of one cell to the cathode of another to produce a voltage.)

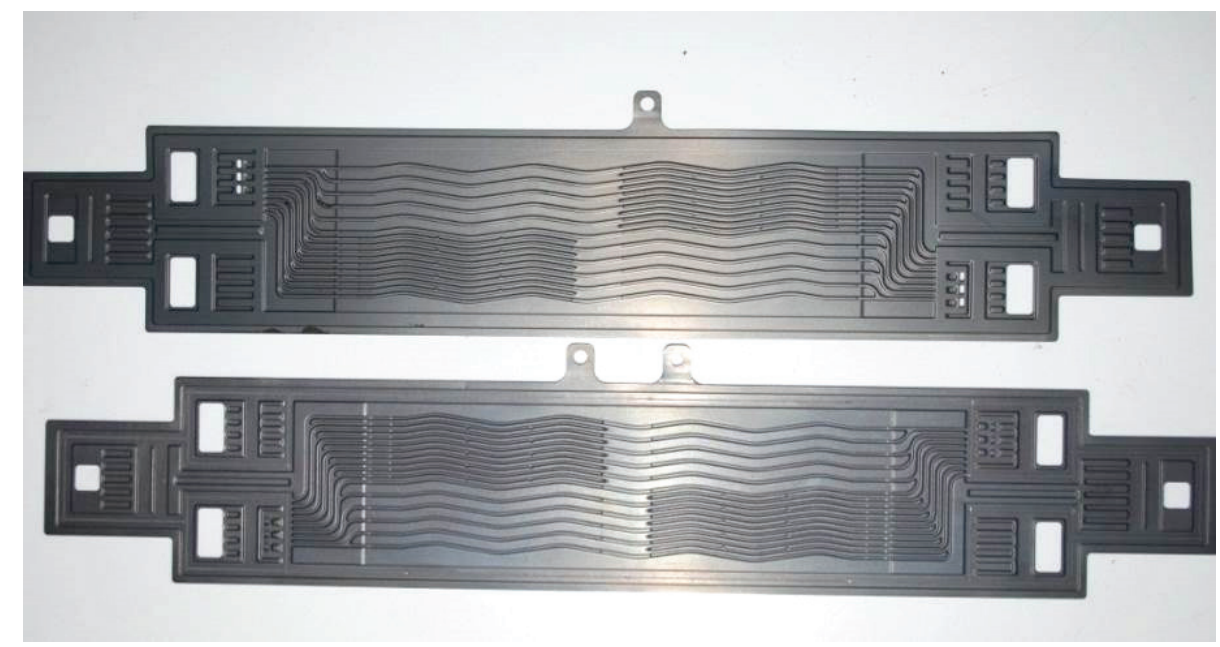

Bipolar plate assemblies. 
In 2011, General Motors Research Laboratories conducted manufacturing and fuel cell assessments to explore the promising properties of the ORNL nitrided alloy. Using current General Motors stamping practices and plate design, the nitrided material was manufactured into an automotive bipolar plate and was found to be amenable to laser welding assembly. Under relative humidity cycling for singlecell fuel cell performance evaluation (5001,000 hours of operation), the nitrided bipolar plates maintained low contact resistance and the proton exchange membrane exhibited only trace levels of metal ion contamination. These results are consistent with good corrosion resistance under fuel cell operating conditions. They were published in the April 15, 2013 edition of the International Journal of Hydrogen Energy.

\section{Publication}

[1] M. P. Brady, M. Abd Elhamid, G. Dadheech, J. Bradley, T. J. Toops, H. M. Meyer III, and P. F. Tortorelli, "Manufacturing and performance assessment of stamped, laser welded, and nitrided $\mathrm{FeCrV}$ stainless steel bipolar plates for proton exchange membrane fuel cells," Int. J. Hydrogen Energy 38(11), 4734-4739 (2013).

\section{Friction Stir Welding Enables SCCVs to Exceed DOE Targets}

Cost modeling shows that low-cost steel/concrete composite vessels (SCCVs) for high-pressure hydrogen storage, fabricated using friction stir welding (FSW) techniques developed at ORNL, can exceed DOE 2020 technical targets for hydrogen storage.

SCCV technology uses commodity materials, including structural steels and concretes, to meet cost, performance, and safety requirements. It mitigates the hydrogen embrittlement of high-strength low-alloy steels, a major safety and durability issue for current pressure vessel technology, through the use of a unique layered steel shell structure.

To obtain a real-world representative cost estimate for manufacturing SCCVs, ORNL collaborated with two engineering design firms to develop a high-fidelity cost analysis tool in FY 2012. A thorough study was performed to optimize the design and fabrication cost of SCCVs for hydrogen storage. The cost study considered only those SCCVs that can be readily manufactured in existing US fabrication facilities without major capital equipment purchases and upgrades.

The detailed cost analysis shows that a major pathway for further reducing the total composite SCCV cost is the development of an advanced welding process to replace labor-intensive conventional arc welding of steel shells.

In FY 2012, ORNL successfully developed a novel multi-layer, multi-pass FSW process (US Patent 7,762,447 B2) to weld 15 mm thick (0.6 in.) pressure vessel steel plates, nearly tripling the thickness of steel weldable by single-pass FSW. Mechanical testing of thick steel plates joined by FSW shows that failures occur at the base metal rather than at the weld, indicating the high performance of FSW joints. The highly automated FSW process is expected to significantly reduce labor costs while improving weld quality. 


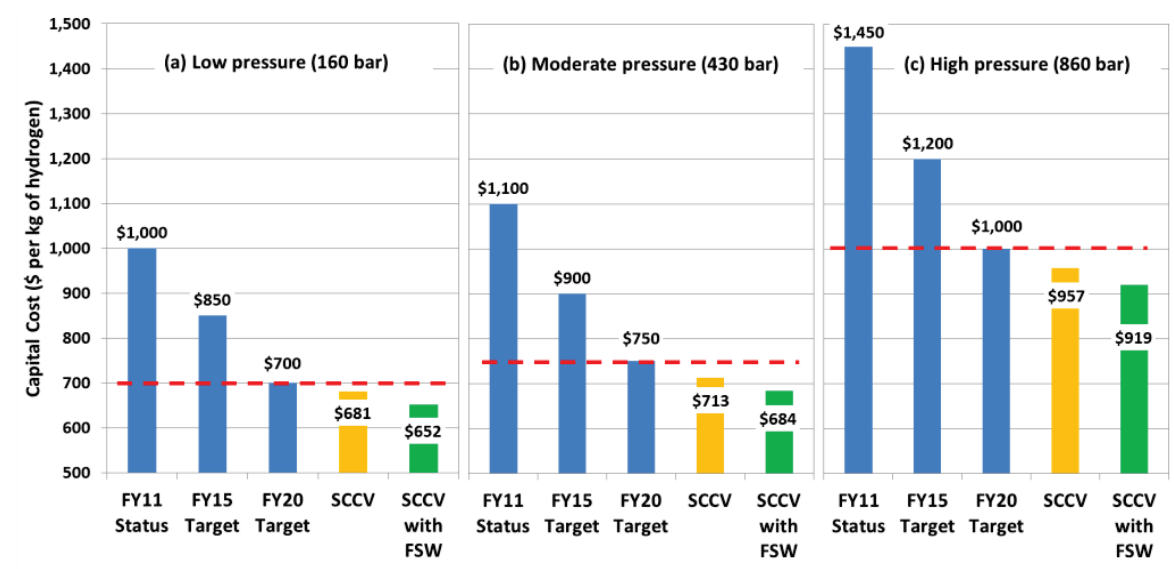

Comparison between SCCV unit costs and DOE technical targets for hydrogen pressures of (a) 160 bar, (b) 430 bar and (c) 860 bar. SCCV technology can exceed DOE FY 2020 technical targets by about $4 \%$ at all three pressures levels and by $8 \%$ with FSW.

\section{Publications and Presentations}

[1] W. Zhang, F. Ren, Z. Feng, J. Wang, M. Jawad, M. Kelly, and F. Vossoughi, "Design analysis of steel concrete composite vessel for stationary storage of high-pressure hydrogen," accepted for publication in Proc. 2012 Int. Hydrogen Conf., Sept. 9-12, 2012, Moran, WY.

[2] W. Zhang, F. Ren, Z. Feng, and J. Wang, Manufacturing Cost Analysis of Novel Steel/Concrete Composite Vessel for Stationary Storage of High-Pressure Hydrogen, ORNL/TM-2013/113,
Oak Ridge National Laboratory, September 2012.

[3] Z. Feng, J. Wang, and W. Zhang, "Vessel design and fabrication technology for stationary highpressure hydrogen storage," presented at the 2012 DOE Hydrogen and Fuel Cells Program Annual Merit Review and Peer Evaluation Meeting, May 14-18, 2012, Washington, D.C.

Available at www.hydrogen.energy.gov/pdfs/rev iew12/pd088_zhang_2012_o.pdf.

\section{How DOE Technical Targets Impact Penetration of Hydrogen Vehicles}

Hydrogen vehicles (H2Vs) offer great potential to reduce petroleum consumption in vehicles. DOE has adopted technical targets for vehicle component technologies to address key technical barriers to widespread commercialization of H2Vs. This study is using the ORNL MA3T model to simulate market acceptance of $\mathrm{H} 2 \mathrm{Vs}$ and the resulting social benefits for 41 scenarios that reflect a wide range of progress in meeting these technical targets.
The overall modeling approach involves constructing 41 scenarios to reflect different combinations of hydrogen prices, costs, and vehicle component progress relative to the DOE technical targets. Each scenario is described by a distinct input file, which includes exogenous settings of vehicle attributes, consumer segmentation, energy prices, infrastructure deployment, and policies. The input file is fed into the MA3T model. MA3T estimates annual sales, from 2010 to 2050, of each of 
40 vehicle choices to each of its 1458 consumer segments that collectively represent the US household light-duty vehicle market.

MA3T then outputs, by year and by technology, vehicle stock, energy use (gasoline, diesel, natural gas, hydrogen and electricity), well-to-wheel greenhouse gas emissions, and vehicle subsidy. The Hydrogen Infrastructure Cash Flows model uses the hydrogen availability, hydrogen price, and full-utilization hydrogen cost from the exogenous inputs and the projected hydrogen use output from MA3T to calculate the infrastructure subsidy required to balance the difference between hydrogen price and underutilization (or actual) hydrogen cost.

Some of the most important findings are these:

- With infrastructure, H2Vs could capture a $20-70 \%$ market share by 2050.

- $\quad$ A 5\% hydrogen availability will probably need to precede the onset of an $\mathrm{H} 2 \mathrm{~V}$ market.

- Diversification of vehicle technology research and development increases benefits and provides benefit insurance.

- $\quad$ Fuel cell plug-in hybrid electric vehicles allow both fuel cells and plug-in batteries to dominate the market.

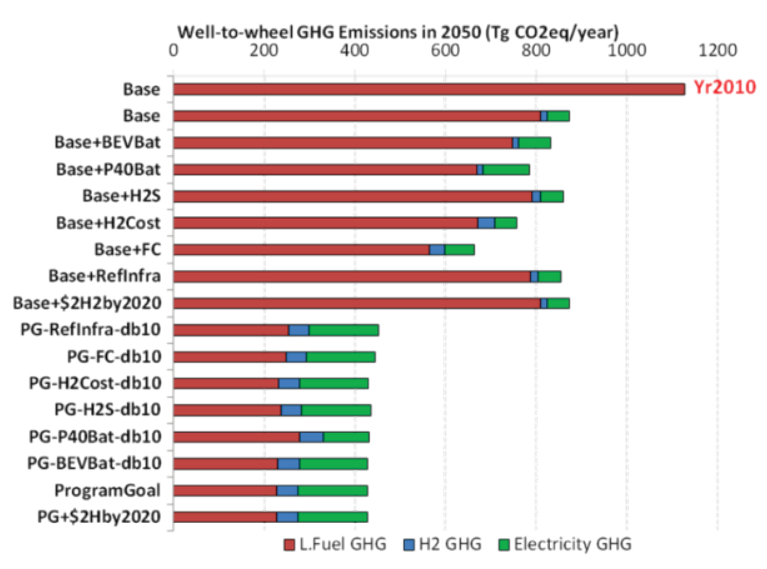

Long-term impact of targets on greenhouse gas emissions.

\section{Publication}

[1] Zhenhong Lin, Jing Dong, David L. Greene, "Hydrogen vehicles: Impacts of DOE technical targets on market acceptance and societal benefits," Int. J. Hydrogen Energy, available online May 20, 2013. (http://www.sciencedirect. com/science/article/pii/S03603199130 $\underline{10446)}$

\section{Sensitivity of Hydrogen Vehicle Sales to Consumer Preferences}

The future market success of hydrogen vehicles will depend on consumer behavior as well as technology, energy prices, and public policy. An ORNL study examining how consumer preferences will affect future market shares for hydrogen vehicles predicts that improvements in hydrogen drive trains will drive marketability more than fuel cost and driving range.

The effects of varying four key parameters describing car buyers' preferences were tested in two technology scenarios. The base case assumes little progress beyond current technology, and the "technology success" case simulates the effects of achieving DOE program goals for hydrogen vehicles. The technology success case is tested at two long-run hydrogen prices that bracket DOE's goals: $\$ 2.50$ and $\$ 4.00$ per kilogram.

Sensitivity analysis of the scenarios was carried out using DOE's Market 
Acceptance of Advanced Automotive Technologies (MA3T) model, which estimates future market shares of 20 power train technologies and makes projections to the year 2050. The technology sets include plug-in versions of both internal combustion engine and fuel cell-powered vehicles, as well as battery electric vehicles.

MA3T includes a detailed segmentation of the motor vehicle market to represent heterogeneity in consumer demand. Each market segment is a different "representative consumer" with distinct attributes and preferences. The 1,458 segments account for differences among regions, degree of urbanization, housing types, risk preferences, daily vehicle use, and availability of recharging at work for plug-in vehicles. Within nine census regions, lightduty vehicle sales are divided among urban, suburban, and rural areas and further subdivided according to consumer attitudes toward novel technologies: early adopters $(16 \%)$, early majority (34\%), and late majority (50\%).
The model analyzed the sensitivity of the market for hydrogen vehicles and other technologies to consumer preferences for the following ranges of four factors:

- $\quad$ Sensitivity to purchase price $( \pm 20 \%)$

- Value of future fuel costs $(3,5,10$ year payback periods)

- Importance of fuel availability ( $\pm 50 \%)$

- Importance of limited range and long recharging time (\$10/day, $\$ 30 /$ day, $\$ 50 /$ day)

The market potential of hydrogen vehicles is most sensitive to the improvement of hydrogen drive train technology, especially cost reduction. Meeting DOE program goals doubles the estimated 2050 market share of hydrogen vehicles (60 to $70 \%$ ) relative to the share with more modest improvements over current technology (25 to $35 \%$ share). The market success of hydrogen vehicles is much less sensitive to the price elasticity of vehicle choice, how consumers value future fuel costs, and fuel availability and limited driving range.

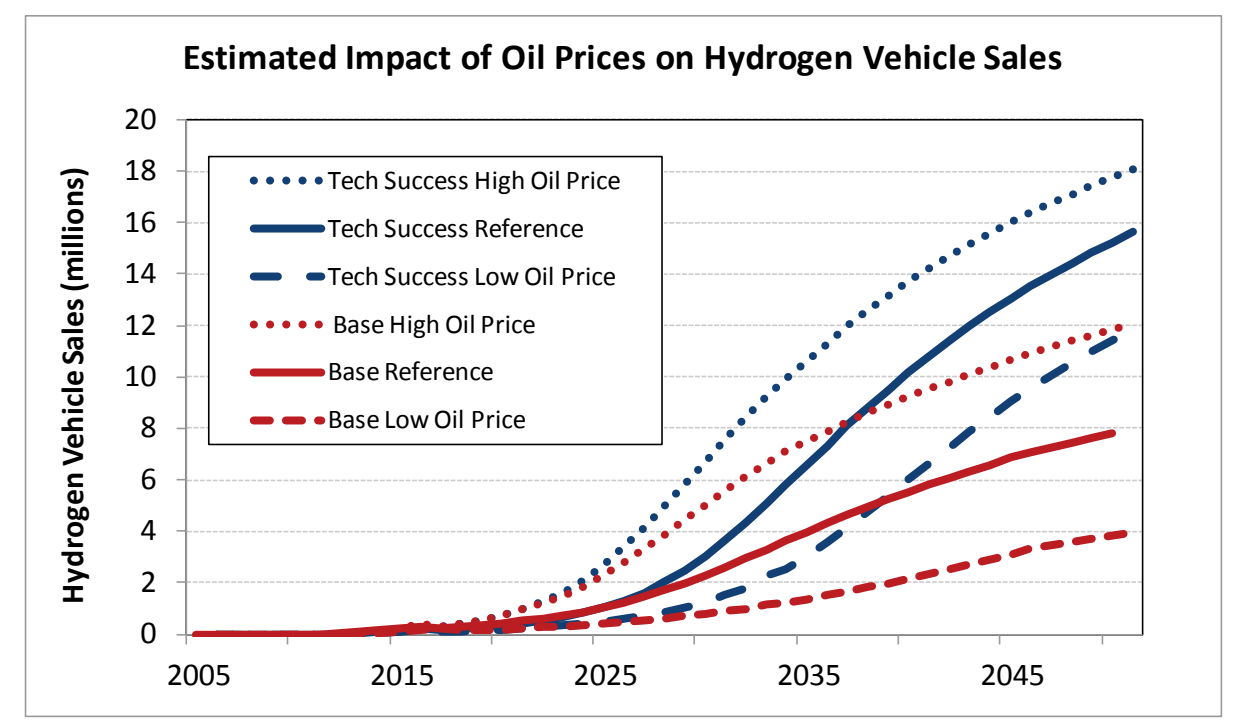

Estimated impact of oil prices on hydrogen vehicle sales. 


\section{Publications}

[1] Lin, Z., MA3T Model: Modeling the Market Acceptance of Advanced Automotive Technologies, Center for Transportation Analysis, Oak Ridge National Laboratory, 2012.

http://cta.ornl.gov/ma3t/.
[2] D. L. Greene, Z. Lin, and J. Dong, "Sensitivity analysis of H2-vehicles' market prospects, costs and benefits," AN023, Fuel Cell Technologies Program FY 2012 Annual Progress Report, Washington, D.C., US Department of Energy, 2012. 


\section{Vehicle Technologies RED Highlights}

\section{Combustion Engines}

\section{Accelerating Predictive Engine Simulation with High-Performance Computing}

This project supports rapid advancement in engine design, optimization, and control to meet new Corporate Average Fuel Economy standards and emissions regulations through the use of highperformance computing (HPC). It couples ORNL's leadership in HPC with experimental and modeling expertise in engine and emissions-control technologies. The project currently focuses on two tasks:

1 Highly parallelized engine modeling to understand the stochastic and deterministic processes that drive cycle-to-cycle variability in dilute combustion systems (in collaboration with Ford Motor Company and Convergent Science).

2 Detailed computational fluid dynamics (CFD) simulation to understand and optimize the design of direct-injection gasoline fuel injectors (in collaboration with GM).

Initial efforts in 2012 focused on assembling tools and resources, such as software for use on ORNL's HPCs, including the Titan supercomputer. Convergent Science's Converge CFD software, OpenFOAM, and various submodels were licensed and ported to ORNL HPCs. A total 3.1 million hours of computing time on ORNL's supercomputers was awarded for both tasks.

Dilute combustion is a potential pathway to efficiency and emissions improvements in light-duty engines. However, high dilution levels result in complex cycle-tocycle combustion variability that undermines the benefits of charge dilution. Computational simulation could elucidate the physics and chemistry behind these phenomena, but the amount of computer time required for serial simulation of combustion cycles is prohibitive.

Task 1 substitutes single-cycle engine simulations for long, multi-cycle runs. Each single-cycle simulation starts with different model parameter values and/or initial conditions. The resulting responses are then analyzed to find the parameters with the most significant impact on combustion stability. These parameters are further explored to refine knowledge of their impacts. By intelligently sampling the parameter space through an adaptive sparse grid approach, researchers can construct a meta-model of engine behavior that is computationally trivial compared with the CFD simulations but provides the same statistical response to key input and feedback parameters.

This approach was demonstrated using a simplified engine combustion model that is computationally inexpensive but retains the correct global dynamics. Once the adaptive, concurrent simulation strategy is fully demonstrated with the simple combustion model, researchers will repeat the meta-model-building procedure with highly detailed CFD combustion models running on massively parallel computers. The objective is to create and use refined meta-models to more intensively explore the combustion instability hyperspace. Early results suggest the meta-models can accurately capture much of the complex dynamics of the simple combustion model.

\section{Publications and Presentations}

[1] C. E. A. Finney et al., "Application of high-performance computing for 


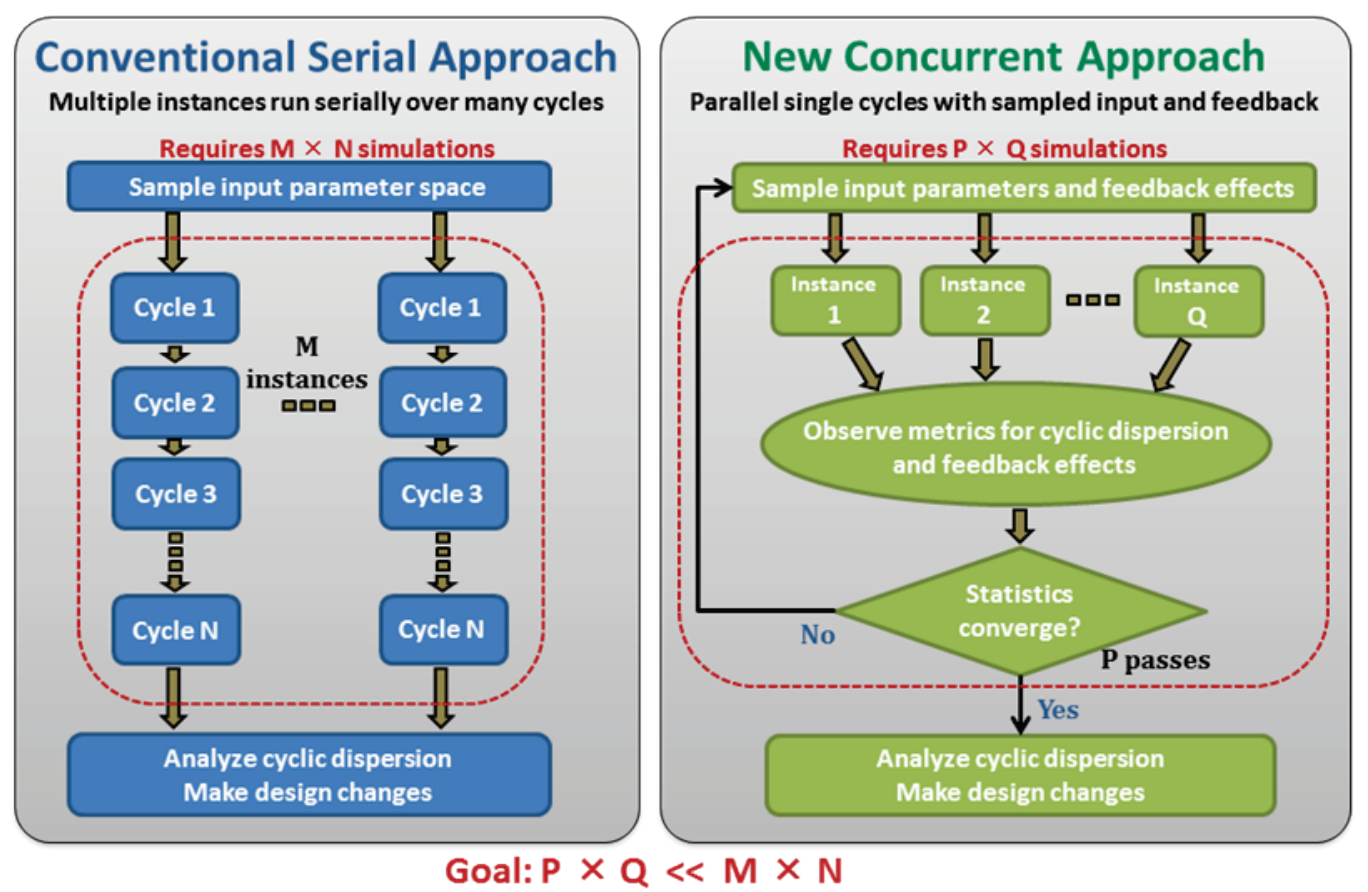

The concurrent modeling strategy replaces serial combustion simulations over many engine cycles with multiple single-cycle simulations.

simulating the unstable dynamics of dilute, spark-ignited combustion," Proc. 2012 Int. Conf. on Theory and Applications of Nonlinear Dynamics (ICAND), Seattle, August 2012.
[2] R. M. Wagner and S. Pannala, “Highperformance computing: Accelerating the development of high-efficiency engines," presented at 2012 Global Powertrain Congress, Troy, MI, October 2012.

\section{Electrically Heated DPF Reduces Fuel Penalty by $50 \%$}

A technology developed by General Motors - the electrically assisted diesel particulate filter (EADPF) - uses a combination of electrical heating and fuel addition by in-cylinder injection to provide heat and control the temperature for soot oxidation during regeneration of a DPF. Studies at ORNL using a $1.9 \mathrm{~L}$ diesel engine demonstrated a 50\% reduction in the fuel penalty and a $60 \%$ reduction in regeneration time compared with DPF regeneration via fuel only. Both changes are significant for light-duty applications with low exhaust temperatures and shorter trip times.
In addition to the fuel penalty measurement, ORNL measured substrate temperatures during the regeneration process and studied the mechanical properties of the EADPF cordierite substrate (a silicate of aluminum, iron, and magnesium). These data improve understanding of the regeneration process and potential for material failure.

To measure substrate temperatures, ORNL developed a fiber-optic technique based on blackbody radiation (see illustration). Optical fibers with angled tips were inserted into DPF channels at several locations to collect light emitted from the 
hot substrate during regeneration. The light spectra collected were analyzed to determine the substrate temperature. Results confirmed that oxidation occurred as a self-sustaining thermal wave along the flow axis and showed that peak substrate temperatures were highly dependent on soot loading before regeneration. Electrical heating initiated the thermal wave and allowed greater control of the process, reducing both the fuel and the time required to sustain DPF temperatures suitable for soot oxidation.

The ORNL team used a combination of modeling and experimental techniques to measure the material properties of the DPF cordierite substrate. The substrate's elastic modulus was a factor of 5 to 10 lower than values previously reported in the literature. Model predictions based on these more accurate measurements showed greater durability and resistance to DPF failure during regeneration.
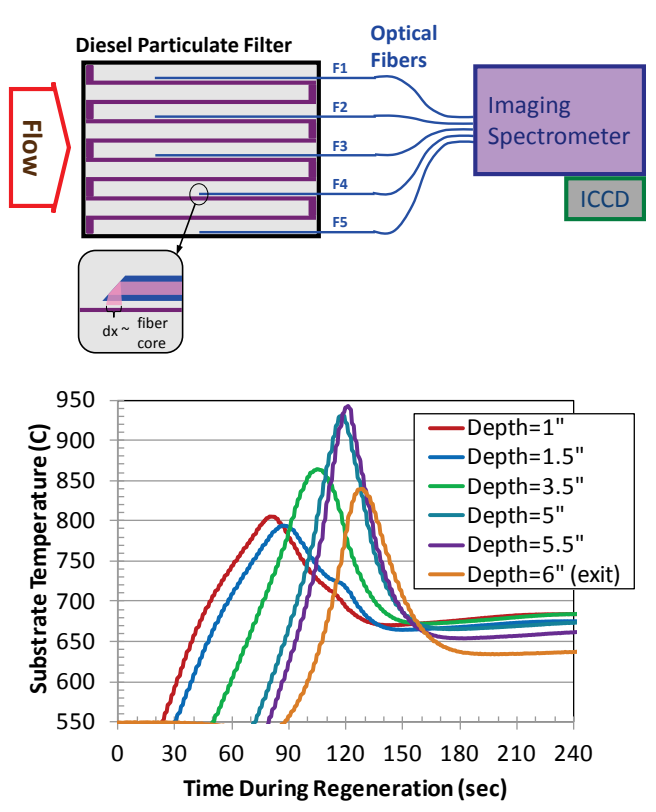

A schematic of the fiber optic-based substrate temperature measurement technique (top) and resulting data (bottom) shows a thermal wave due to heat released by exothermic soot oxidation.

\section{Emissions Control for Lean Gasoline Engines}

The US passenger car market is dominated by gasoline powertrains operating at stoichiometric air-to-fuel ratios - mixing sufficient fuel in air to combust all oxygen. Stoichiometric combustion leads to exhaust conditions suitable for three-way catalysts (TWC) to reduce oxides of nitrogen (NOx), carbon monoxide (CO), and hydrocarbon emissions to extremely low levels. "Lean" engine operation, with less fuel and more air, is more fuelefficient; however, the oxygen in the exhaust prevents the TWC from reducing NOx. Lean operation over much of a vehicle's operating range is relatively straightforward; therefore, the toughest challenge to lean combustion in gasoline engines is emissions control.
ORNL researchers are working to reduce emissions from lean gasoline engines in a cost-effective and fuel-efficient manner. Through this project, researchers determined the effect of lean-rich timing on a commercial lean NOx trap catalyst (LNT) as it impacts NOx reduction as well as ammonia $\left(\mathrm{NH}_{3}\right)$ and nitrous oxide $\left(\mathrm{N}_{2} \mathrm{O}\right)$ production. They characterized the control of a representative lean gasoline engine vehicle (European BMW 120i) and installed that engine with a custom controller in an engine dynamometer laboratory as a research platform for onengine studies.

The vehicle uses an LNT that absorbs NOx during lean operation and then releases and reduces the $\mathrm{NOx}$ to $\mathrm{N}_{2}$ during rich 
operation. LNTs have been deployed successfully in the United States on diesel vehicles; but two characteristics make their use challenging in gasoline engines: higher temperatures that reduce NOx storage capacity and higher NOx concentrations. The combination requires more frequent LNT regeneration and higher fuel penalties. This research focuses on reducing temperatures and NOx concentrations.

Most diesel vehicles employ an ammoniabased selective catalytic reduction (SCR) approach with urea as the ammonia source; however, using a urea solution is not considered viable for lean gasoline vehicles. This study investigated onboard ammonia generation approaches

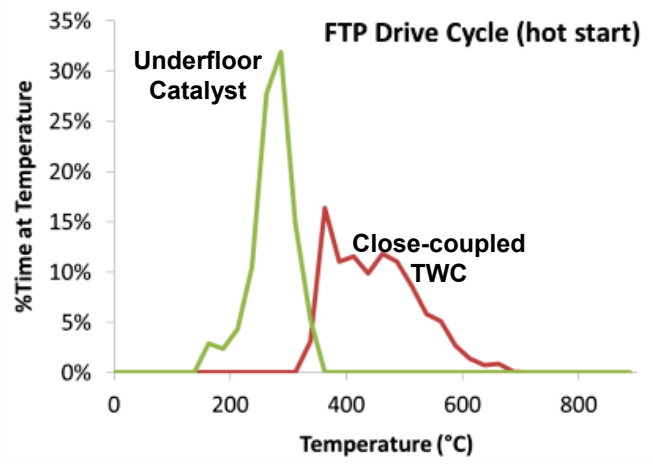

employing LNTs and TWCs along with SCR. The key is to generate ammonia under rich engine operation and then store it on a downstream SCR. When the engine returns to lean combustion, the stored ammonia reduces NOx that is not converted by the TWC and LNT.

Researchers studied which conditions allowed ammonia generation and how it could be used while cycling between lean and rich conditions, with a particular emphasis on ammonia storage capacity and NOx reduction performance. Finally, the potential of the approach was demonstrated using a flow reactor system that could simulate a close-coupled TWC with an underfloor SCR.

Temperature histogram of a close-coupled catalyst and an underfloor catalyst during the federal test procedure drive cycle of a lean gasoline vehicle (left). $\mathrm{NH}_{3}$ storage capacity under lean and rich conditions, illustrating the potential synergy between the high temperature $\mathrm{NH}_{3}$ production in the close-coupled catalyst and the low temperature storage in the underfloor catalyst (right).

\section{Publications and Presentations}

[1] J. A. Pihl et al., “Lean NOx trap chemistry under lean-gasoline exhaust conditions: Impact of high temperature and high $\mathrm{NOx}$ operation," Top. Catal. 56, 89-93 (2013).

[2] T. J. Toops et al., “ $\mathrm{NH}_{3}$ generation over commercial three-way catalysts

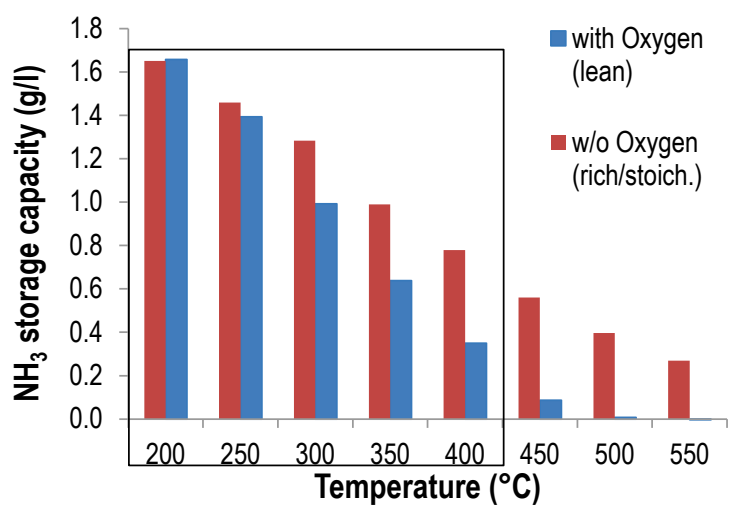


American Institute of Chemical Engineers 2012 Annual Meeting, Pittsburgh, PA, Oct. 29, 2012.

[4] T. J. Toops et al., "Emissions control for lean gasoline engines," 2012 DOE Annual Merit Review, Crystal City, VA, May 14-18, 2012.

\section{Neutron Imaging of DPF and Fuel Injector}

Neutron imaging is an advanced nondestructive characterization tool that is uniquely suited to studying engine system components. The approach is based on measuring a neutron beam attenuated by a sample (i.e., it compares an open beam with one affected by a given sample). Where neutrons vary from other nondestructive techniques is that they are highly sensitive to light atoms like hydrogen and can penetrate metal.

Neutrons can be used to generate threedimensional images of working fluids inside real devices. Samples can be analyzed at one cross-section, or a complete reconstruction can provide a 3-D image of the entire sample. This approach can provide data difficult to obtain using destructive techniques without altering the materials or fluids being used.

This effort used neutron imaging to study a diesel particulate filter (DPF) and a diesel injector. The DPF is a key component of the emissions control system for modern diesel engines. The results of the DPF measurements provide critical data to the aftertreatment modeling community on the evolution of soot profiles, which are important factors in modeling fuelintensive DPF regeneration.
[5] J. A. Pihl, J. E. Parks, and T. J. Toops, "Lean NOx trap chemistry under leangasoline exhaust conditions: Impact of high temperature and high NOx operation," 9th International Congress on Catalysis and Automotive Pollution Control (CAPoC9), Aug. 2931, 2012, Brussels, Belgium.
Three silicon carbide (SiC) DPFs were loaded to 3, 5, and $7 \mathrm{~g}$ particulate per liter of DPF. Researchers determined the soot cake densities of all three initial samples were statistically identical. During controlled regeneration, the soot cake layer decreased in thickness sharply during the initial $20 \%$ for all three samples, and the overall density increased. Continuing to the $50 \%$ regeneration level, the thickness decreased very little as the overall porosity started to increase. This increasing porosity continued at the $70 \%$ regeneration level and we observed that the DPF was fully regenerated at the rear of the inlet channels first.

The fuel injector study is aimed at investigated intra-nozzle flow and cavitation during dynamic spraying to improve understanding of how external conditions influence internal dynamics related to advanced combustion regimes and injector durability. Initial efforts were conducted to define the spatial and temporal resolution possible with the current setup and identify needed improvements. Computed tomography scans can be employed to investigate crosssections of the fuel injector and highlight areas where voids can occur. Cavitation is a major contributor to injector failure and 


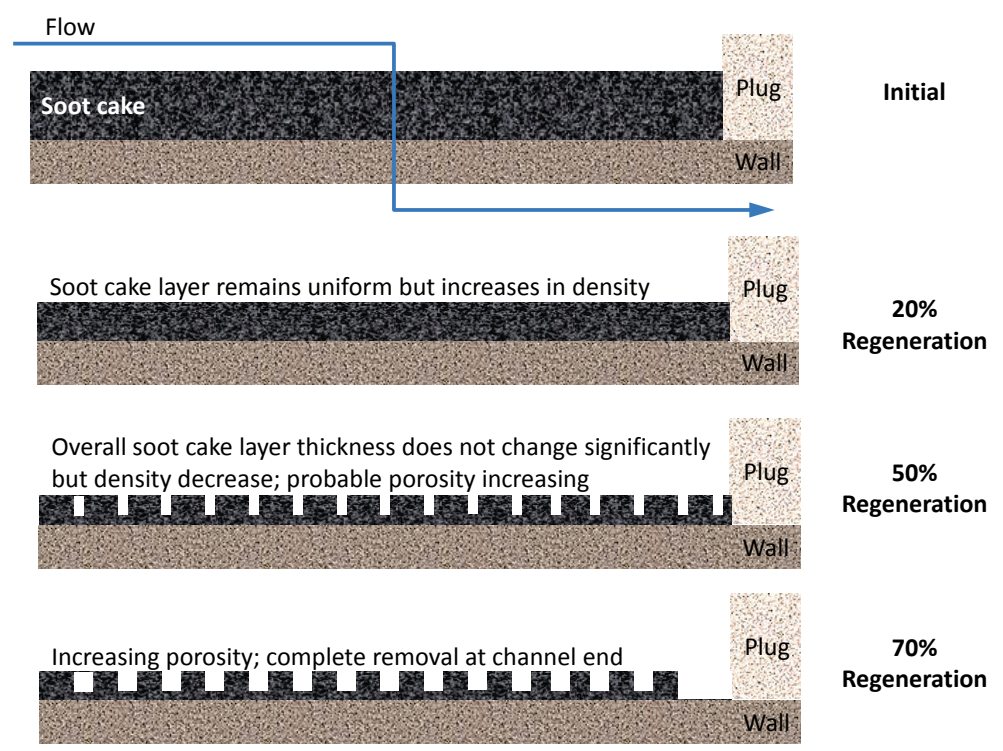

Conceptual model of the progression of the soot cake layer during regeneration.

impacts the combustion flame front;

understanding conditions and injector geometries that lead to cavitation is important for new, highly efficient combustion strategies.

\section{Publications and Presentations}

[1] Todd J. Toops et al., "Non-destructive neutron imaging to analyze particulate filters," 2012 Directions in Engine-Efficiency and Emissions Research Conference, Dearborn, MI, Oct. 18, 2012.

[2] Todd J. Toops et al., "Neutron imaging of advanced transportation technologies," 2012 DOE Annual Merit Review, Crystal City, VA, May 14-18, 2012.

[3] Todd J. Toops et al., "Non-destructive, non-invasive neutron imaging of soot, ash and washcoat deposition in particulate filters," 2012 Cross-cut Lean Exhaust Emissions Reduction Simulations Workshop, Dearborn, MI, Apr. 30-May 2, 2012.

[4] Todd J. Toops et al., "Non-destructive, non-invasive neutron imaging of soot, ash and washcoat deposition in particulate filters," 2012 SAE World Congress, Detroit, Apr. 24-26, 2012.

\section{Potential for E85 Engine Optimization under Revised Specification}

Ethanol has a high chemical octane number and a high latent heat of vaporization, making it an attractive fuel option. When an engine is optimized to take advantage of these fuel properties, both efficiency and power can be increased through higher compression ratio, direct fuel injection, higher levels of boost, and a reduced need for enrichment to mitigate knock or protect the engine and aftertreatment system from overheating.

The ASTM D5798 specification for highlevel ethanol blends, commonly called "E85," underwent a major revision in 2011. The minimum ethanol content was revised downward from 68 to $51 \mathrm{vol} \%$, which, combined with the use of low-octane 
blending streams such as natural gas liquids and straight run gasoline, introduces the possibility of a lower-octane E85. The low-octane fuel is suitable for current ethanol tolerant flex-fuel vehicles, but an ORNL study examines whether engines can be optimized further for the fuel resulting from the revised specification.

The performance of six ethanol fuel blends, ranging from 51 to $85 \%$ ethanol, was compared with a premium-grade gasoline in a single-cylinder engine at knock-prone engine conditions. Premium-grade gasoline $($ research octane number $[\mathrm{RON}]=$ 96.1), light, straight run gasoline $(\mathrm{RON}=$ 63.6), and n-heptane ( $\mathrm{RON}=0)$ were used as hydrocarbon blending streams for the ethanol blends to establish knock resistance for high-ethanol fuels.

The results showed that nearly all ethanolcontaining fuels are more resistant to engine knock than unleaded test gasoline96 (the only exception was the ethanol blend with $49 \%$ n-heptane). This knock resistance allows ethanol blends made with 33 and $49 \%$ light, straight run gasoline and 33\% n-heptane to be operated at higher engine loads and at significantly more advanced combustion phasing for higher efficiency.
The experimental results show the octane number of the hydrocarbon blend stock does impact engine performance, but significant opportunity remains to optimize engine operation for even the lowest-octane fuels (in compliance with the current ASTM D5798) compared with premium-grade gasoline.

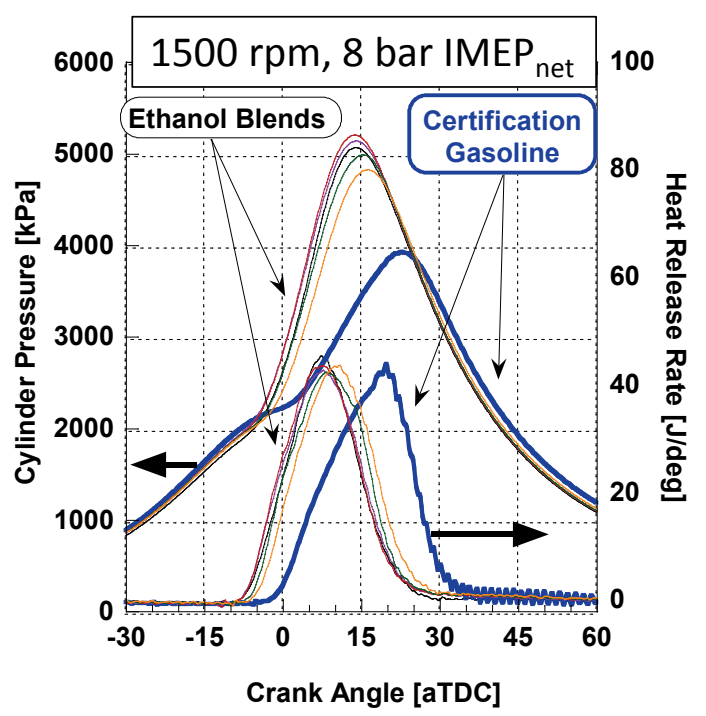

Cylinder pressure and heat release rate for ethanol blends and premium grade certification gasoline. Note that the ethanol blends provide superior anti-knock performance compared with certification gasoline despite some being blended with low octane hydrocarbon streams.

\section{RCCI Potential Explored Using Vehicle Simulation and Engine Map}

Leading DOE efforts on the development of reactivity controlled compression ignition (RCCI) combustion on a multi-cylinder engine, ORNL researchers made significant progress in understanding the potential fuel economy improvements. RCCI combustion uses in-cylinder blending of two fuels of differing reactivity to tailor the reactivity of the fuel charge for improved control of the combustion process. This allows stable low- temperature combustion to be extended over more of the light-duty drive cycle load range.

Research has shown opportunities to improve engine efficiency as well as nitrogen oxides (NOx) and particulate matter emissions using RCCI, but it has been limited to simulation and idealized single-cylinder research engines. Since many advanced combustion strategies are 
inherently unstable, previous multicylinder research helped in understanding the transition to multi-cylinder engines with production-viable hardware, a research area critical to understanding real-world fuel economy potential. RCCI's potential was investigated by simulating the fuel economy and emissions for a multi-mode RCCI-enabled vehicle operating over a variety of US drive cycles in a first of its kind study. The approach used a vehicle simulation with experimental engine maps compared with a 2009 port-fuel injected (PFI) gasoline engine in the same vehicle-a midsize sedan with an automatic transmission.

An experimental RCCI engine map was developed on a four-cylinder 1.9 L diesel engine modified for port fuel injection with pistons designed for RCCI. A multimode RCCI strategy was employed when the engine switched from RCCI to conventional diesel combustion (CDC) as the demanded speed and load fell outside the RCCI range of the map.

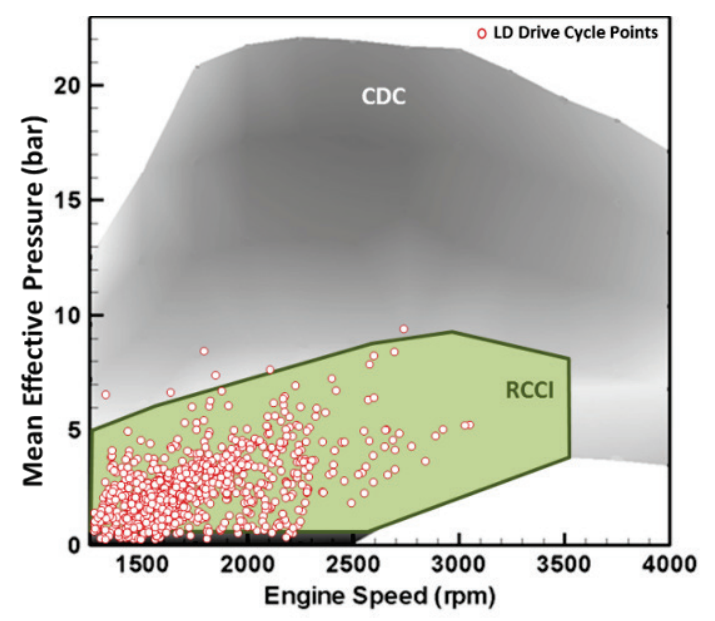

$\mathrm{RCCl}$ (green) coverage of engine speed and load compared with CDC (gray), with light-duty (LD) city drive cycle operating points overlaid. A multi-mode strategy switching from $\mathrm{RCCl}$ to $C D C$ is needed if $\mathrm{RCCl}$ cannot cover the entire drive cycle range.
Multi-mode RCCI operation was found to increase drive cycle fuel economy by at least $15 \%$ compared with the modeled PFI baseline over all hot drive cycles examined. Increased efficiency with RCCI over much of the map allowed for increased fuel economy. Fuel usage over the drive cycles showed nearly equal amounts of gasoline and diesel fuel would need to be carried on board for RCCI multi-mode operation. During RCCI-only operation, fuel usage was between 57 and $69 \%$ gasoline. Engine-out drive cycle emissions were compared with those from CDC operation over the full load-speed range, and NOx emissions were found to decrease by at least $20 \%$ on both city and highway driving cycles. However, hydrocarbon and carbon monoxide emissions doubled or tripled with RCCI. The increased hydrocarbon and carbon monoxide emissions and reduced exhaust temperatures will be a challenge for exhaust aftertreatments.

\section{Publications and Presentations}

[1] S. J. Curran, R. M. Hanson, and R. M. Wagner, "Reactivity controlled compression ignition (RCCI) combustion on a multi-cylinder lightduty diesel engine," Int. J. Engine Res. 13(3), 216-225 (2012).

[2] S. J. Curran, J. P. Szybist, and R. M. Wagner, "Reactivity controlled compression ignition performance with renewable fuels," ICEF201292192, Proc. ASME 2012 Internal Combustion Engine Division Fall Technical Conference, Vancouver, B.C., Canada, Sept. 23-26, 2012. 


\section{Energy Storage}

\section{Composite Electrolyte to Stabilize Metallic Lithium Anodes}

Advanced lithium ( $\mathrm{Li}$ ) batteries require strong protection of the metallic $\mathrm{Li}$ anode to remain mechanically and chemically stable. Any reaction or roughening of the $\mathrm{Li}$ will reduce capacity and degrade performance and may compromise safety. The solution is a robust solid electrolyte to protect the Li while ensuring rapid cycling. However, identifying and fabricating a solid electrolyte with the required ionic transport, electrochemical stability, and mechanical strength is a technical challenge. In addition, the electrolyte must be thin, lightweight, and cost effective for large-scale manufacturing. Furthermore, to provide a $\mathrm{Li}$ anode with significantly higher energy density than current Li ion anodes, all components of the anodeincluding the packaging, current collector, protective electrolyte, and the Li itselfmust be minimized.

No single solid electrolyte-polymer, ceramic, or glass - currently meets all of those requirements. So a program at ORNL is addressing the fabrication and testing of a composite polymer-ceramic structure, both experimentally and through computer simulation. In such a composite, it will be critical that the properties of the interface formed between the two different electrolytes offer mechanical integrity while still enabling the transport of Li ions.

Investigations are probing how the materials forming the interface can be functionalized or activated to promote good adhesion and high conductivity. Using electrochemical impedance spectroscopy (EIS), the measured impedance of the bilayer (a two-layered film or membrane) is compared with the sum of the impedance of the individual components. Results from these investigations provide parameters for the interface phase in composite simulations. The evaluated composites generally are layered or have dispersed hard ceramic particles. Based on study results, selected materials and mixtures are prepared as composites. As work progresses, alternative fabrication methods and materials will be investigated to improve performance.

Results from bilayer studies show that sometimes the interfacial resistance between a polymer and a ceramic $\mathrm{Li}$ electrolyte can be very large; this may be minimized by appropriate fabrication techniques, choice of materials, and preparation of the surfaces. Simulations of dispersed composites are being developed to predict the relative conductivity and mechanical stability for a highly conductive ceramic, such as garnet electrolytes, in a polymer electrolyte matrix. Fabrication of experimental composites loaded heavily with the conductive ceramic phase will continue, and researchers will investigate the formation of grain boundaries from larger particle contacts and evaluate the composites for their mechanical properties and stability with Li metal electrodes.

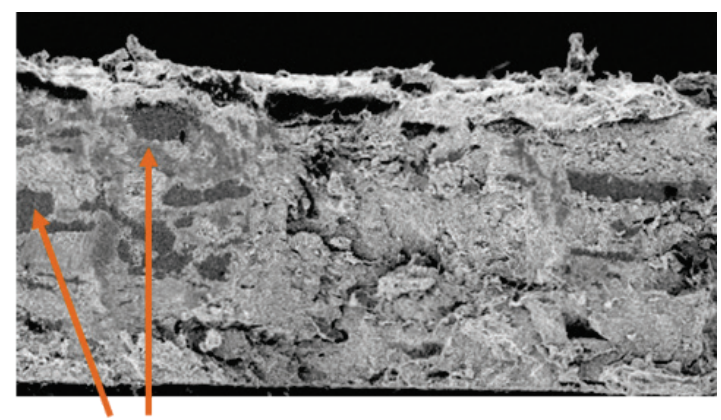

Fracture edge of composite with $60 \mathrm{vol} \%$ ceramic particles. Arrows indicate polymer-rich regions. 


\section{Publications and Presentations}

[1] N. J. Dudney et al., “Transport and mechanical properties of pure and composite solid lithium electrolytes," invited presentation at the 5th meeting for Beyond Li-ion Batteries, Berkeley, Calif., June 2012.

[2] N. J. Dudney et al., "Solid electrolytes for Li battery applications - Are lithium metal containing batteries a good idea?" Invited presentation at Electronic Materials and Applications, American Ceramic Society, Orlando, Fla., January 2012.
[3] W. E. Tenhaeff et al., "Tough solid composite electrolytes to enable lithium metal anodes," Prime Pacific Rim Meeting on Electrochemical and Solid-State Science, Honolulu, Hawaii, October 2012.

[4] W. E. Tenhaeff, K. A. Perry, and N. J. Dudney. "Impedance characterization of $\mathrm{Li}$ ion transport at the interface between laminated ceramic and polymeric electrolytes," J. Electrochem. Soc., 159(12), A2118-A2123 (2012). doi: $\underline{10.1149 / 2.063212 \text { jes }}$

\section{Computer Aided Engineering to Improve Battery Performance, Safety}

Adequately meeting future transportation needs in the United States will require the development of better electrical energy storage devices. Given the complexities of this technology, a predictive simulation capability must guide rapid design by considering performance, material components and geometry, safety, and durability.

Computational tools for battery system performance and safety analysis rely heavily on established parameters. Existing computational models are limited in their ability to capture temperature variations or potential in the electrical circuits of battery cells and packs. No current design tool for batteries can leverage the significant investments across DOE and academia. DOE has established a public private partnership with several software companies and national laboratories to develop an open, flexible computational framework incorporating existing and new capabilities for comprehensive Computer Aided Engineering of Batteries (CAEBAT) that provides a foundation for a predictive tool for rapid battery design and prototyping.

ORNL is a partner on CAEBAT. ORNL researchers are developing the robust, computationally scalable open-architecture framework that integrates multiphysics and multiscale battery models to study charge and thermal transport, electrochemical reactions, and mechanical stresses. The framework operates across the porous 3-dimensional structure of a battery's electrodes, solid or liquid electrolyte system, and other components to enable seamless integration of the physical phenomena necessary for developing realistic, predictive battery performance and safety models.

The short-term CAEBAT goal is to create a modular software infrastructure that supports multiple modeling formulations and computer codes for simulation of battery performance and safety. The framework design will offer extensibility and computational scalability from desktop to high-performance computing platforms. 


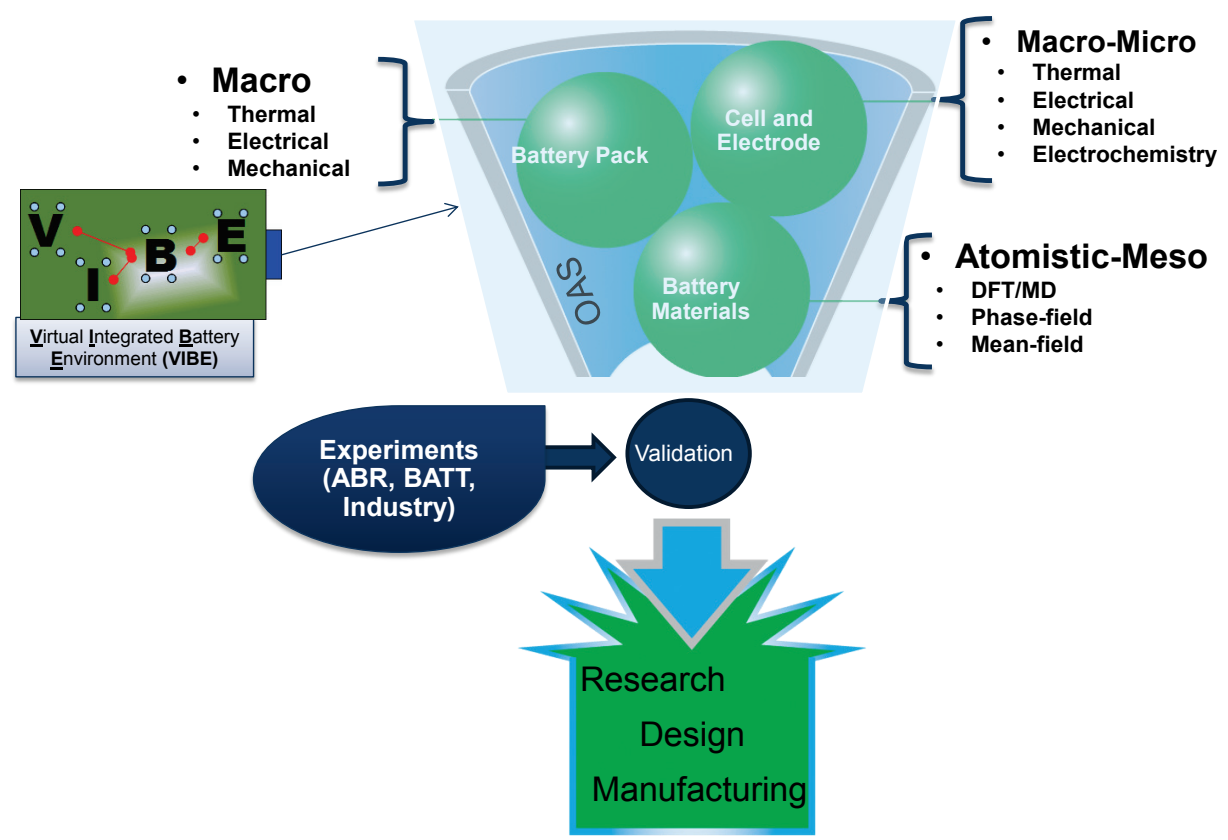

Schematic of the OAS modeling framework and interactions with other tasks within the CAEBAT program and external activities.

The long-term CAEBAT project goal is to develop a mathematical and computational infrastructure and modeling framework that will enable seamless multiscale and multiphysics simulations of battery performance and safety. The modeling framework will transfer the information between models to evaluate both spatial and temporal variations. The result will be a verified, computationally scalable, portable, extensible framework that is easily modified and can integrate models from other CAEBAT tasks and industrial partners. Researchers will use the framework to validate modeling approaches against experiments and to support rapid prototyping of advanced battery concepts.

ORNL successfully developed the CAEBAT Open Access Software (OAS) framework and included several components for modeling cell electrochemical and thermal/electrical transport processes. CAEBAT project partners are evaluating the beta version of the software.

\section{Publications and Presentations}

[1] S. Pannala et al., "CAEBAT OAS: Beta Release V1," 2012.

[2] S. Allu et al., "Computational framework for modeling multiphysics phenomenon of Li-ion batteries across various hierarchies." Abstract, ECS Meeting Abstracts MA2012-02(10), 1067 (2012).

[3] W. R. Elwasif et al., "Parameter sweep and optimization of loosely coupled simulations using the DAKOTA toolkit," presented at International Conferences on Computational Science and Engineering, Paphos, Cyprus, 2012.

[4] S. Pannala et al., "Hierarchical models for batteries: Overview with some case studies," presented at the Advanced Automotive Battery Conference, Orlando, Fla., 2012. 


\section{Developing New Materials for Lithium-Sulfur Batteries}

ORNL researchers exploring lithiumsulfur (LiS) battery chemistry have found phosphorous pentasulfide $\left(\mathrm{P}_{2} \mathrm{~S}_{5}\right)$ to be suitable as an electrolyte additive for LiS batteries with liquid electrolytes. They have designed and developed an all-solid LiS battery configuration that eliminates the polysulfide shuttling that reduces cycle life and efficiency.

Achieving the price and energy density necessary for large-scale deployment of electric vehicles requires the development of new battery materials. LiS batteries are less expensive than Li-ion batteries, the current industry standard, and have high energy density. But they also have short cycle-life and poor efficiency. Elemental sulfur is abundant and inexpensive, and LiS battery chemistry provides a theoretical energy density two to five times higher than known Li-ion battery chemistries based on transition metal compounds. This project seeks to innovate LiS battery technology by discovering advanced materials to address its deficiencies while taking advantage of the benefits.

A conventional LiS battery uses metallic Li as the anode, sulfur-carbon composites as the cathode, and an organic liquid electrolyte, which must have a good solubility for Li polysulfides (products of the cathode discharge process). The liquid electrolyte delivers $\mathrm{Li}$ ions and enables the electrochemical cycling of elemental sulfur, an insulator of both electrons and ions. The dissolution of polysulfides enables the electrochemical cycling of the batteries but also causes short cycle-life and low energy efficiency. The dissolved active cathode materials lead to the diffusion-driven migration of sulfur inside the electrochemical cell, which results in permanent loss of capacity. Apart from the challenges of the sulfur cathode, the electrochemical cycling of the metallic $\mathrm{Li}$ anode is a long-standing problem for $\mathrm{Li}$ batteries with liquid electrolytes.

The ORNL team sought to design a cell that would enable the safe cycling of metallic Li and sulfur without the dissolution of Li polysulfide. Metallic Li can be cycled safely over 10,000 cycles in a thin film battery using a solid electrolyte, which also benefits the sulfur cathode because there is no dissolution and shuttling of polysulfide in solid electrolytes. Thus the polysulfide shuttle is eliminated in all-solid LiS batteries.

The researchers identified the technical hurdles for all-solid LiS batteries and then developed new solid electrolytes and sulfur compounds to address those hurdles. $\mathrm{P}_{2} \mathrm{~S}_{5}$ was found to prolong the cycle-life of high-energy LiS batteries. The additive promotes the dissolution of lithium sulfide $\left(\mathrm{Li}_{2} \mathrm{~S}\right)$, alleviates the loss of capacity caused by the $\mathrm{Li}_{2} \mathrm{~S}$ precipitation, inactivates the surface of Li metal, and eliminates the polysulfide shuttle phenomenon.

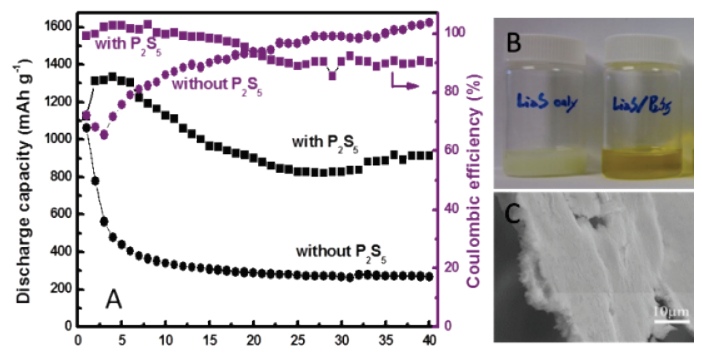

Cycling performance of LiS batteries with and without $\mathrm{P}_{2} \mathrm{~S}_{5}(\mathrm{~A})$. Photos showing the promoted solubility of $\mathrm{Li}_{2} \mathrm{~S}$ in liquid electrolyte by $\mathrm{P}_{2} \mathrm{~S}_{5}(\mathrm{~B})$ and a micrograph of the passivation layer on lithium anode surface (C). 


\section{Publications, Presentations, and Patent Applications}

[1] Z. Lin et al., "Phosphorous pentasulfide as a novel additive for high-performance lithium-sulfur Batteries," Adv. Funct. Mater. 23(8), 1064 (2013).

[2] C. Liang, "Carbon/sulfur nanocomposites and additives for high-energy lithium sulfur batteries," presentation at 2012 DOE Annual Peer Review Meeting, May 2012.

[3] C. Liang, N. Dudney, Z. Lin, and Z. Liu, "All-solid Li-S batteries," presentation at sixth US-China Electric Vehicle and Battery Technology Workshop, University of Massachusetts-Boston, June 24, 2012.
[4] C. Liang, Z. Lin, Z. Liu, N. Dudney, A. J. Rodinone, and E. A. Payzant, "Nanostructured $\beta-\mathrm{Li}_{3} \mathrm{PS}_{4}$ for all-solid lithium-sulfur batteries," presentation at The Electrochemical Society Meeting, Honolulu, October 2012.

[5] Z. Liu, W. Fu, Z. Lin, N. J. Dudney, E. A. Payzant, and C. Liang, "Nanocrystalline solid electrolyte: $\beta-\mathrm{Li}_{3} \mathrm{PS}_{4}$," presentation at The Electrochemical Society Meeting, Honolulu, October 2012.

[6] C. Liang et al., "Lithium sulfide compositions for battery electrolyte and electrode coatings," US Patent Application 13/463451, filed May 3, 2012.

\section{Improvements in High-Energy-Density Li-ion Electrodes}

ORNL researchers have extensively studied lithium ( $\mathrm{Li}$ ) -rich cathode materials for battery development and significantly improved their performance, interfacial stability, and charge rates.

Current research and development efforts in Li-ion batteries seek to increase energy density, reduce costs, and improve cyclelife and safety performance. High-energydensity Li-ion cathodes are a high research priority, and the development of highvoltage manganese-nickel spinel cathodes $\mathrm{LiMn}_{1.5} \mathrm{Ni}_{0.5} \mathrm{O}_{4}$ and of Li-rich composite nickel-manganese-cobalt (NMC) cathodes is an important step.

However, significant technical challenges still must be addressed at the materials and electrode levels, including structural and phase stability under continuous highvoltage cycling; manganese dissolution that leads to capacity fade; electronic and ionic transport limitations essential to the electrode material; and higher first-cycle irreversible capacity loss due to interfacial issues and passive film formation.

ORNL researchers conducted systematic studies of Li-rich NMC composite cathodes with the nominal composition $\mathrm{Li}_{1.2} \mathrm{Mn}_{0.525} \mathrm{Ni}_{0.175} \mathrm{Co}_{0.1} \mathrm{O}_{2}$ and addressed technical barriers to their use. High-voltage Li-rich NMC cathode materials were fabricated into electrodes using a slurry coating method. The electrodes were assembled into half cells or full cells using modified graphite and then were studied, modified, and tested extensively.

Researchers performed life cycle studies in multiple formats to examine capacity fade at different temperatures, cycling cells between 4.9 and $2.5 \mathrm{~V}$ using $\mathrm{LiPF}_{6}$ salt in an ethylene carbonate:dimethyl carbonate mixture. 
The team used electrochemical impedance spectroscopy, cyclic voltammetry, and various structural and surface spectroscopy techniques to characterize the electrodes to correlate between materials degradation and observed electrochemical performance. Materials modifications such as nanoscale surface coating and electronic filler additives were also tested for possible improvement in the electrochemical performance.

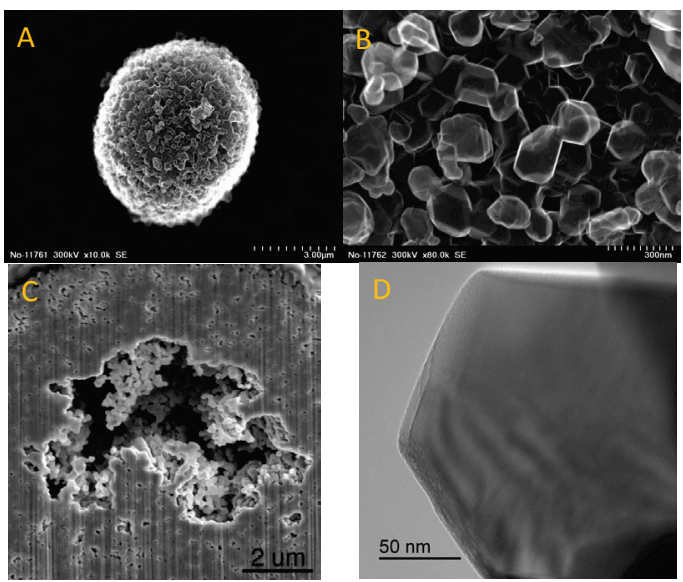

A spherical secondary Li-rich NMC composite cathode particle (A), faceted structures of primary Li-rich 80-100 nm NMC particles (B), focused ion beam section of a secondary particle showing hollow interior core (C), and a single Li-rich high voltage NMC primary particle with a faceted surface (D).

Significant improvements were achieved in the rate performance and interfacial stability of high-voltage Li-rich composite cathodes. The research showed that a coating of a solid electrolyte layer of $\mathrm{Li}$ phosphorus oxynitride (LiPON) can notably improve the charge transfer at the interface. Improved interfacial stability leads to better capacity retention at higher C-rates (battery charge rates).

The next phase of the effort will involve stabilization of the Li-rich NMC phase against structural transitions to suppress the voltage fade phenomenon. Efforts will be directed toward isovalent cation doping strategies to stabilize the structure and/or prevent transition metal dissolution.

\section{Publications and Presentations}

[1] S. K. Martha et al., "Electrochemical and interfacial studies of high-voltage lithium-rich composition:

$\mathrm{Li}_{1.2} \mathrm{Mn}_{0.525} \mathrm{Ni}_{0.175} \mathrm{Co}_{0.102}$," J. Power Sources 199, 220 (2012).

[2] S. K. Martha et al., "Surface studies on high voltage lithium-rich composition: $\mathrm{Li}_{1.2} \mathrm{Mn}_{0.525} \mathrm{Ni}_{0.175} \mathrm{Co}_{0.1 \mathrm{O} 2}$," J. Power Sources 216, 179 (2012).

[3] G. Veith et al., "Influence of lithium salts on the discharge chemistry of Li-air cells," J. Phys. Chem. Lett. 3(10), 1242 (2012).

\section{In Situ Electron Microscopy of Energy Storage Materials}

Accelerating the development of materials for electrical energy storage systems is critically dependent upon an understanding of how interfaces control electrochemical processes during charge and discharge cycles. Insight into dynamically evolving electrochemical reaction mechanisms and kinetics remains limited by the present lack of in situ highresolution characterization methods.
Electrochemical fluid cell microscopy is an emerging method that allows for the direct, real-time imaging of electrochemical processes within a fluid environment. This technique uses microelectromechanical systems-based (MEMS-based) biasing microchip platforms that seal highly volatile electrolytes between electron-transparent $\mathrm{SiN}_{\mathrm{x}}$ membranes; these membranes also serve to interface electrodes to an external 
potentiostat for electrochemistry experiments.

ORNL researchers working at the Shared Research Equipment User Facility developed an electrochemical liquid cell for in situ transmission electron microscopy (TEM) studies of electrochemical reactions in electrical energy storage material systems. In these studies, MEMS-based silicon microchip devices, each containing a central thin $\mathrm{SiN}_{x}$ viewing membrane, are stacked upon one another and placed within a TEM holder. Liquid electrolyte is delivered through the TEM holder via a microfluidic delivery system to wet the space between the membranes. Biasing contacts on the lower cell chip serve as a platform for attaching battery electrodes.

To demonstrate both structural and chemical changes during in situ electrochemical experiments, researchers must improve upon the spatial resolution by using energy-filtered TEM to minimize chromatic aberration, and then determine the chemical changes via electron energy loss spectroscopy (EELS). This presents a formidable challenge because the overall thicknesses through which electrons are scattered in the multiple layers of the cell may be from hundreds of nanometers to microns. Also, scattering degrades image resolution and decreases the signal-tonoise ratio for spectroscopy.

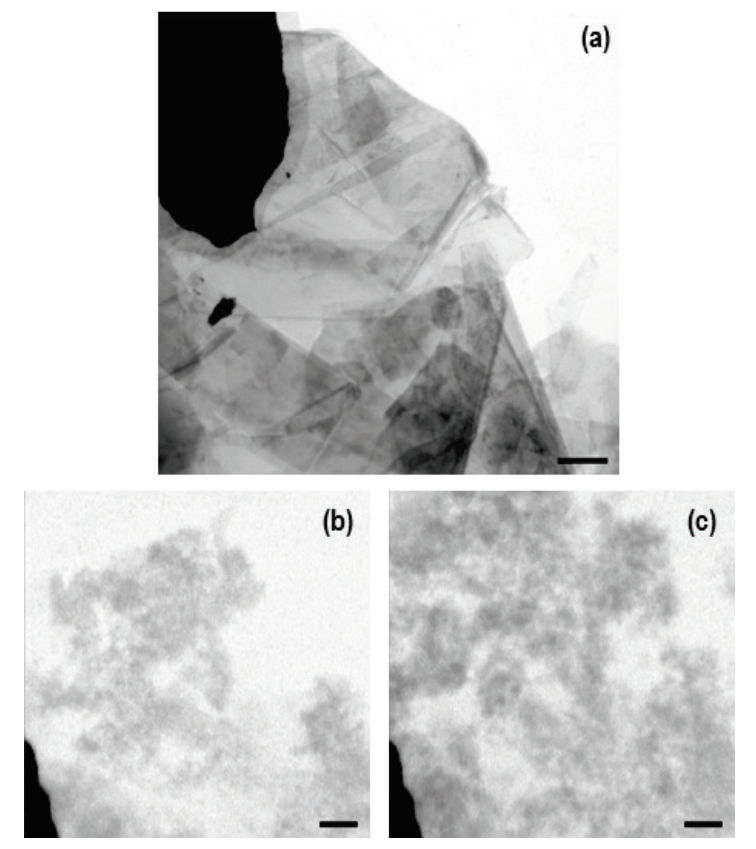

Bright-field TEM image (a) of the natural graphite anode materials within the electrontransparent membrane region of the electrochemical cell (imaged without liquid electrolyte). Time-lapse images ( $b$ and $c$ ) extracted from in situ TEM video showing solid electrolyte interphase growth dynamics. Scale bar in the bottom right corner represents 1 micron.

In situ electrochemical liquid cell microscopy is useful for characterizing dynamically evolving electrochemical processes in a liquid environment. When the technique is coupled with methods such as EELS, researchers may be able to characterize chemical changes during battery cycling. In future work, more emphasis will be placed on characterizing the role of additives and electrolyte solvent in the formation of the solid electrolyte interphase, degradation mechanisms in electrode materials during 
charge-discharge cycling, and correlation of microstructural and microchemical changes with battery performance, lifetime, and capacity.

\section{Publications and Presentations}

[1] R. R. Unocic et al., "Coupling EELS/EFTEM imaging with environmental fluid cell microscopy," Microsc. Microanal. 18, Suppl 2, 11041105 (2012).
[2] R. R. Unocic et al., “Development of in situ electrochemical fluid cells for electrical energy storage Research," Batteries Gordon Conference, Ventura, Calif., March 2012.

[3] R. R. Unocic et al., "The versatility of in situ environmental fluid cells for materials science research," MS\&T 2011, Columbus, OH, October 2011.

\section{Nondestructive Evaluation to Cut Waste in Lithium Battery Production}

ORNL is working to improve the economics of lithium secondary battery cell production by researching nondestructive evaluation techniques to reduce manufacturing waste.

Quality control methods currently used in manufacturing lithium cells are inadequate to reduce the loss of material as scrap, which drives production costs to unacceptable levels. Flaws in electrodes are often not detected until the manufacturing process is completed. If defects could be spotted on the line near the processing steps that generate them, processing equipment could be adjusted to eliminate the problems quickly and the flawed components removed from the line. ORNL is examining the usefulness of methods of detecting flaws earlier in the production process by inspecting electrodes for uniformity, flaws, blisters, and the wet thickness of the electrode.

Infrared (IR) thermography has been used to check the homogeneity of electrodes as they are being manufactured. Visual inspection of a coating made on ORNL's tape caster revealed little about the coating quality. IR flashing, however, revealed thin spots and thin lines across the electrode surface, indicating defects; and the temperature profile of the electrode showed coating thickness variations across it. The experiment verified the effectiveness of IR thermography for quality control. Subsequently, IR images were taken of a dried electrode exiting the heating zone of a coater to check the homogeneity and quality of the coating. The IR temperature profile correlated with flaws on the coated electrode, which were not revealed by optical imaging.

In addition, the project team is collaborating with Argonne National Laboratory to address issues with new high-capacity, highvoltage cathode materials that promise to vastly increase the energy density of lithium ion batteries. Lithium-rich high-voltage cathodes have promising discharge capacities, but they are hindered by voltage fade, low efficiency in the first cycle, and a rise in impedance during high-voltage use. ORNL is using its diagnostic resources to establish the microstructural features of cathode materials that contribute to the degradation of electrochemical properties, and to propose ways to prevent the degradation mechanisms.

Neutron diffraction and magnetization studies are ORNL's pillars in this study, revealing details of lithium site occupancy, atomic defects, and detailed oxidation states of the involved transition metals. 

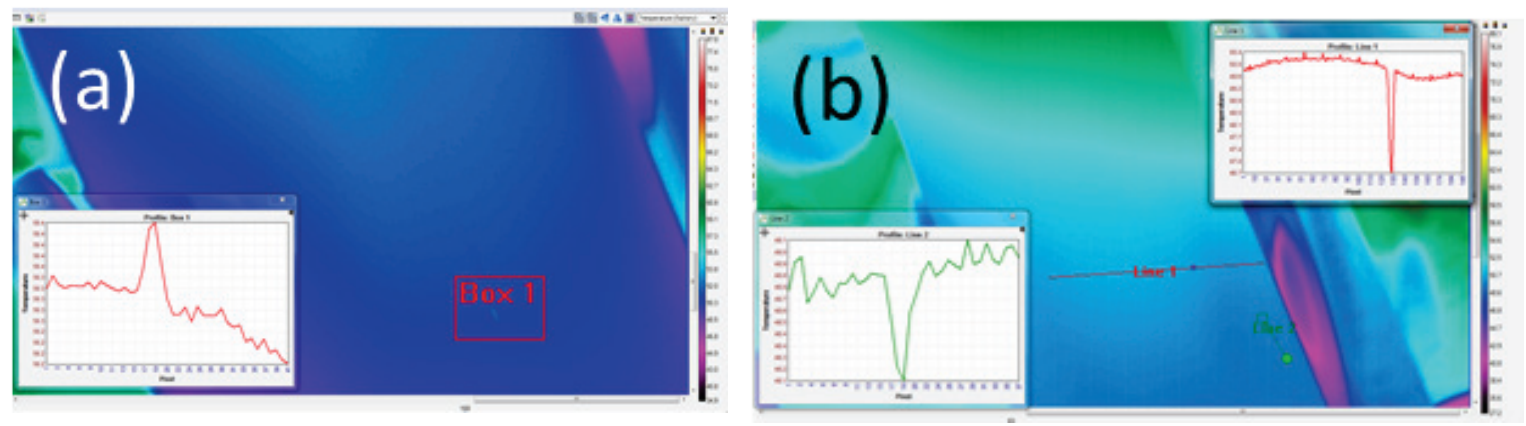

Processed in-line infrared imaging data at different regions of a cathode coating produced on the ORNL coating line.

\section{Publications}

[1] D. Mohanty, S. Kalnaus, R. A. Meisner, A. S. Safat, J. L. Li, E. A. Payzant, K. Rhodes, D. L. Wood, and C. Daniel, "Structural transformation in a $\mathrm{Li}_{1.2} \mathrm{Co}_{0.1} \mathrm{Mn}_{0.55} \mathrm{Ni}_{0.15} \mathrm{O}_{2}$ lithiumion battery cathode during highvoltage hold," R. Soc. Chem. Adv. 3(20), 7479-7485 (2013).

[2] D. Mohanty, A. S. Sefat, S. Kalnaus, J. Li, R. A. Meisner, E. A. Payzant, D. P. Abraham, D. L. Wood, and C Daniel, "Investigating phase transformation in the $\mathrm{Li1}{ }_{2} \mathrm{Co}_{0.1} \mathrm{Mn} 0 .{ }_{55} \mathrm{Ni}_{0.15} \mathrm{O}_{2}$ lithium-ion

battery cathode during high-voltage hold $(4.5 \mathrm{~V})$ via magnetic, $\mathrm{x}$-ray diffraction and electron microscopy studies, J. Mater. Chem. A 1, 6249-6261 (2013).

[3] D. Mohanty, S. Kalnaus, R. A. Meisner, K. J. Rhodes, J. L. Li, E. A. Payzant, D. L. Wood, and C. Daniel, "Structural transformation of a lithium-rich $\mathrm{Li}_{1.2} \mathrm{Co}_{0.1} \mathrm{Mn}_{0.55} \mathrm{Ni}_{0.15} \mathrm{O}_{2}$ cathode during high voltage cycling resolved by in situ X-ray diffraction," J. Power Sources 229, 239-248 (2012). 


\section{Fuel and Lubricant Technologies}

\section{Ionic Liquids Score Breakthrough in Engine Lubrication}

ORNL researchers, working with General Motors (GM) to develop a new automotive engine oil with lubrication-enhancing additives, reached a breakthrough in reducing friction and wear on internal combustion engines. Lubricant advances allowing the use of low-viscosity engine oils are the most cost-effective way to improve engine fuel efficiency. Approximately 10$15 \%$ of the energy generated in automobile engines is lost to parasitic friction, accounting for the consumption of $\sim 500$ million barrels of oil annually. This consumption level has significant impacts on the US economy and national security.

In a project sponsored by DOE's Vehicle Technologies Office (VTO), ORNL has been working with GM since 2009 to develop a new class of engine lubricants using ionic liquids (ILs). The recent team breakthrough involved a unique group of
ILs that exhibit a combination of oil miscibility, noncorrosivity, high thermal stability, excellent metal wettability, and superior friction and wear reduction. Test results suggest a small amount (1-3\%) of ILs added to hydrocarbon oils significantly reduces friction and wear. The antiscuffing, anti-wear functionality is believed to be due to the formation of a protective tribo-film on the contact area as a result of tribochemical reactions between the IL and the metallic surface.

This breakthrough in developing oilsoluble, noncorrosive, anti-wear ILs has attracted significant interest from the lubricant and automotive industries. GM recently signed an agreement with a leading formulator to produce the firstever full engine oil formulation using the IL additives ORNL has developed. GM will conduct high-temperature, high-load
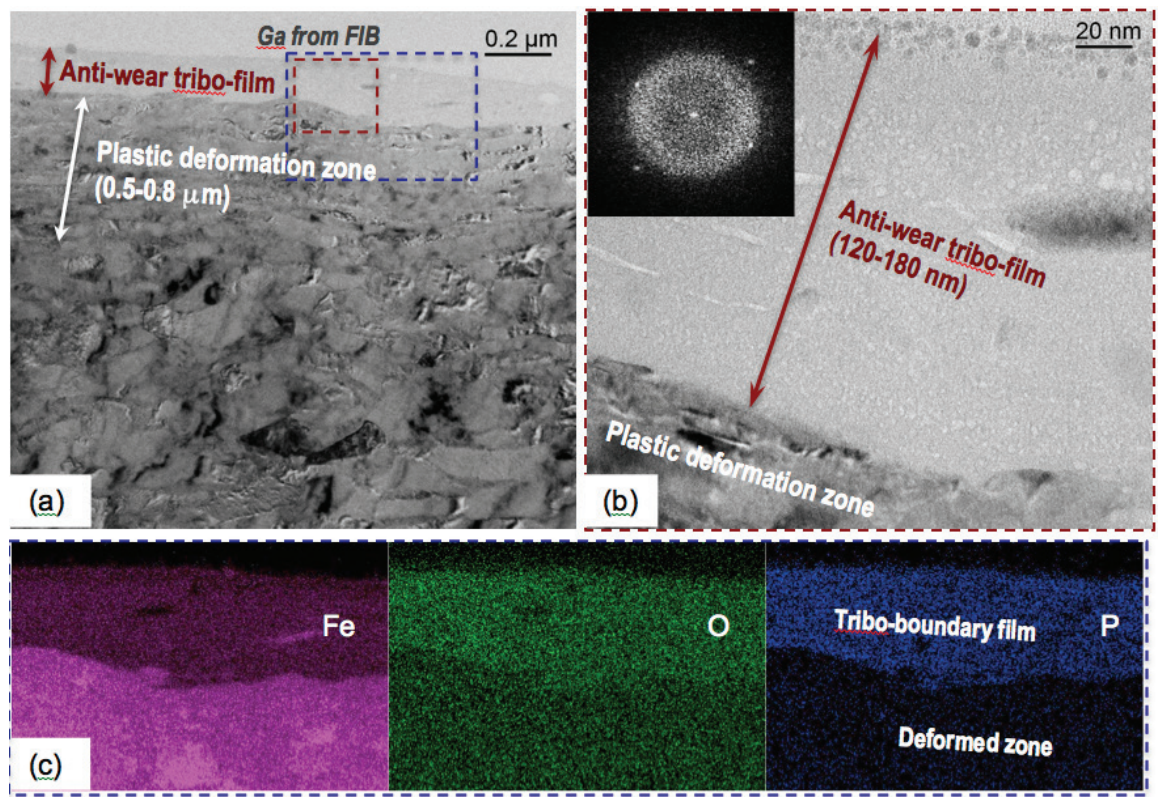

Cross sectional transmission electron microscopy $(a, b)$ and energy-dispersive x-ray spectroscopy element mapping (c) revealed a protective tribo-film on a cast iron surface lubricated by an oil with IL additive. Images in (b) and (c) correspond, respectively, to the red and blue boxes in (a). 
full-size engine dynamometer tests for the IL-additized engine oil, the first such tests for ILs. In a separate effort, Shell Global Solutions, the leading global lubricant manufacturer, recently teamed up with ORNL to win a 3 year DOE VTO award and signed a new CRADA to jointly further develop these engine oils.

Wear reduction with ORNL IL as anti-wear oil additive

\begin{tabular}{|c|c|c|c|c|}
\hline Lubricant & $\begin{array}{c}\text { Friction } \\
\text { coefficient }\end{array}$ & $\begin{array}{c}\text { Friction } \\
\text { reduction }\end{array}$ & $\begin{array}{c}\text { Wear rate } \\
\left(\times 10^{-7} \mathbf{m m}^{3} / \mathbf{N}-\mathbf{m}\right)\end{array}$ & $\begin{array}{c}\text { Wear } \\
\text { reduction }\end{array}$ \\
\hline \hline PAO 4 CSt base oil & 0.21 & - & 1850 & - \\
\hline PAO+IL18 (1-3 wt.\%) & 0.10 & $>52 \%$ & $3.2-3.8$ & $>99.8 \%$ \\
\hline
\end{tabular}

\section{Publications}

[1] J. Qu, D. G. Bansal, B. Yu, J. Howe, H. Luo, S. Dai, H. Li, P. J. Blau, B. G. Bunting, G. Mordukhovich, and D. J. Smolenski, "Anti-wear performance and mechanism of an oil-miscible ionic liquid as a lubricant additive," ACS Appl. Mater. Interfaces 4(2), 9971002 (2012).
[2] B. Yu, D. G. Bansal, J. Qu, X. Sun, H. Luo, S. Dai, P. J. Blau, B. G. Bunting, G. Mordukhovich, and D. J.

Smolenski, "Oil-miscible and noncorrosive phosphonium-based ionic liquids as candidate lubricant additives," Wear 289, 58-64 (2012). 


\section{High Temperature Materials Laboratory}

\section{Determining Residual Stresses in Deep-Roll-Peened Titanium}

ORNL's High Temperature Materials Laboratory (HTML) is supporting efforts at United Technologies Research Center (UTRC) to improve the durability of materials for turbomachinery and power generation.

Mike Humbert of UTRC and Tom Watkins of ORNL used x-ray diffraction (XRD) to measure the residual stress profile due to deep roll peening on specific alloys. Deep roll peening is used to introduce compressive residual stresses at the surfaces of materials down to depths of 1.0 $\mathrm{mm}$. Because compressive stress enhances a material's resistance to cracking, deep roll peening during manufacturing offers the possibility of extending component life by orders of magnitude and decreasing future maintenance costs.

The researchers followed a design-ofexperiments approach to understand the effects of different process parameters of the deep-peening process, including depth of penetration, roller diameter, number of passes, initial surface roughness, spindle speed, and feed rate. Eight sets of deeppeening conditions were selected, and 48 samples were prepared (at 8 conditions) with 6 replicate samples. Within a set, each sample was electropolished to a different depth, ranging from 0 to $1 \mathrm{~mm}$, to determine the residual stress distribution through the thickness.

The samples were examined using the new PROTO LXRD system, which can map the residual stresses on the surfaces of small and large components with complex shapes. For a given condition, the residual stress profile was determined by averaging measurements at different locations on each of six samples at each depth. Each unpeened surface had a starting residual stress of $-475 \mathrm{MPa}$. Overall, large compressive residual stresses were found in the near-surface region, and the stresses decayed rapidly as a function of depth. Some conditions resulted in significant residual stresses at a depth of only $0.2 \mathrm{~mm}$, suggesting that increasing the number of passes of the tool has the greatest influence on the magnitude of residual stress.

The measured values will be incorporated into further experimental fatigue testing and modeling work at UTRC. This work is expected to lead to enhanced manufacturing methods that produce more durable components and operating cost savings throughout the life of power generation systems, including turbochargers for internal combustion engines.

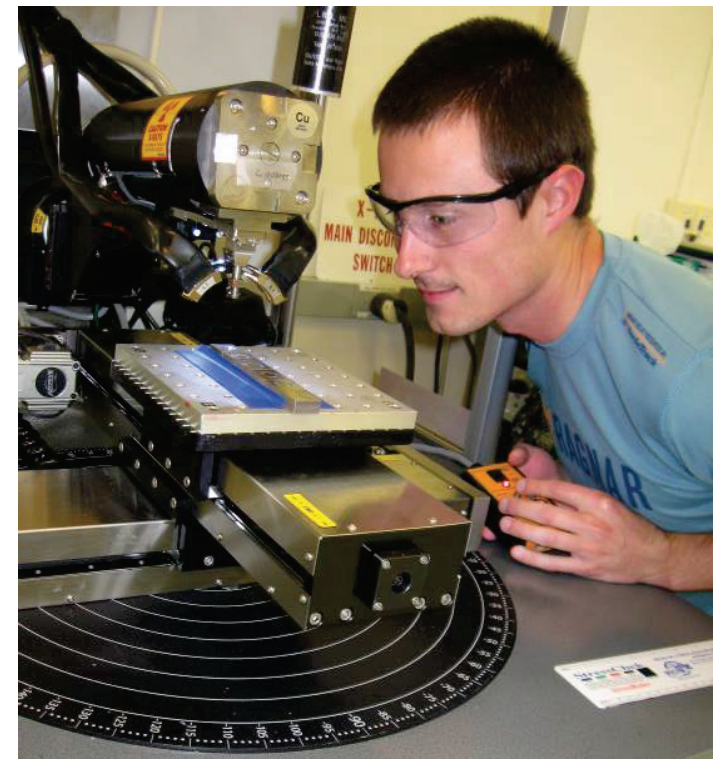

UTRC's Mike Humbert examines the alignment of a series of titanium alloy samples before XRD data collection at ORNL'S HTML. 


\section{Lightweight Materials}

\section{Advanced Oxidation of Carbon Fiber Precursors}

The cost of producing carbon fiber (CF) is the main obstacle to its use in automotive systems. A DOE study shows that $39 \%$ of CF production costs are due to converting the precursor into $\mathrm{CF}$. In this project, ORNL is developing an atmospheric plasma process to rapidly, inexpensively oxidize polyacrylonitrile (PAN) precursor fibers for subsequent conversion to $\mathrm{CF}$.

Conventional oxidation is a slow thermal process that typically consumes more than $80 \%$ of the processing time in a CF conversion line. Rapid oxidation could increase conversion line throughput threefold and appreciably lower fiber cost. Atmospheric plasma oxidation will be integrated with other advanced fiber conversion processes to produce lowercost CF with properties suitable for automotive use.

Conventional oxidative stabilization produces a "core-shell" geometry with a distinct interphase between the slowly growing, fully oxidized shell and the shrinking, stabilized inner core. Plasma processing enhances oxygen diffusion and produces different chemistries in the PAN oxidation process. This accelerates the oxidized layer growth rate and results in more uniform oxidation of the fiber with a much less pronounced interface between the two regions. The new process is called close proximity indirect plasma (CPIE).

Until late 2011, 3000-filament aerospacegrade PAN was primarily used to eliminate uncertainties associated with using a less well-characterized precursor. However, the research has reached a point where less expensive, 26,000 filament textile-grade PAN can be used with CPIE for further cost reductions in overall $\mathrm{CF}$ production. Using textile-grade PAN couples the cost advantages of a lower-cost precursor with higher-rate, lower-cost production. However, it also introduces new challenges; these, along with further refinement of processing parameters for aerospace-grade precursors, were the focus of experimental work in FY 2012.
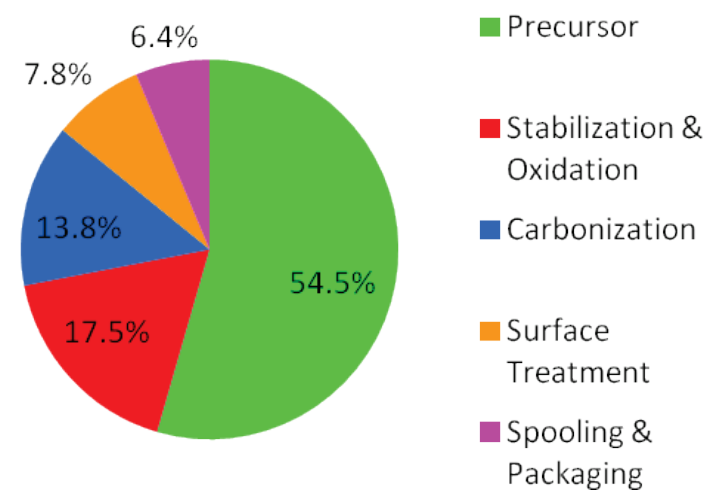

Carbon fiber production costs.

Three significant differences between aerospace-grade and textile-grade PAN presented research challenges:

1. Tow size: Typical aerospace-grade PAN tows used consist of 3,000 filaments, whereas textile PAN tows typically comprise 24,000-26,000 filaments.

2. Chemical purity: Aerospace-grade PAN is typically more than $99 \%$ pure; textilegrade PAN purity is much lower.

3. Physical structure: Textile PAN has a higher percentage of morphological defects.

The ultimate strength of several samples exceeded the program minimum requirement of $250 \mathrm{ksi}$ and the strain at break minimum of $1.0 \%$. The minimum modulus requirement of $25 \mathrm{Msi}$ will be met in early FY 2013. The team continues to focus on optimizing CPIE for PAN fibers. In 


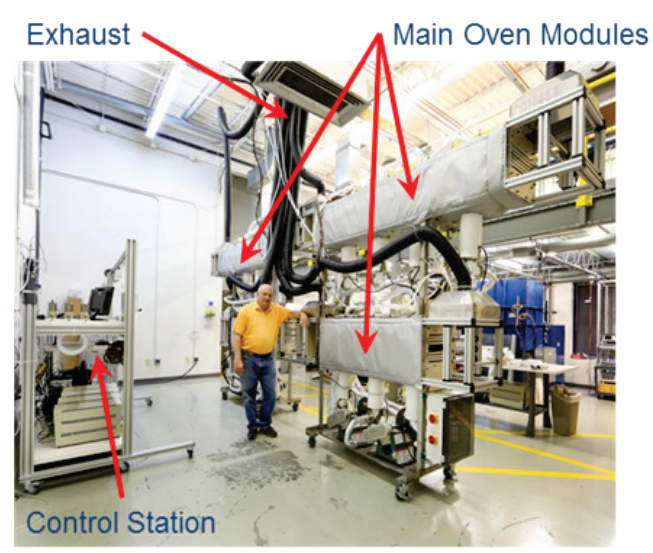

As delivered, core of the new MTR2 CPIE multi-tow processing system.

addition, construction and fabrication continues on the next-generation multiple tow reactor 2 (MTR2) advanced oxidation unit. The MTR2 represents a significant scale-up from the current level of CPIE processing and will involve a minimum capability of processing $4 \times 26,000$ filament tows. Four serial modules will make up MTR2. The fiber stretching system has been designed and procured.

\section{Patents}

[1] Felix Paulauskas and Daniel Sherman, Apparatus and Method for Carbon Fiber Surface Treatment, US Patent 8,227,051 B1, issued July 24, 2012.

[2] Felix Paulauskas, Amit Naskar, and Truman Bonds, Advanced Oxidation Method for Producing High-Density Oxidized Polyacrylonitrile Fibers, US Patent 2012/0322331 A1, filed December 2012.

\section{Equipment Installed and Tested at Carbon Fiber Technology Facility}

Equipment installation was completed and onsite testing of precursor fiber and carbon fiber semi-production equipment began in 2012 at the Carbon Fiber Technology Facility (CFTF) at ORNL. The CFTF is designed to scale up low-cost carbon fiber (CF) technologies and move them into the marketplace. This project supports DOE's agenda to develop technology to advance the use of lightweight materials in highvolume energy applications.

The American Reinvestment and Recovery Act of 2009 funded construction of the $42,000 \mathrm{ft}^{2}, \$ 39$ million facility through the DOE's Vehicle Technologies Office (VTO); operations are co-funded by DOE's VTO and Advanced Manufacturing Office.

ORNL has performed research for many years to demonstrate that, at a laboratory scale, CFs can be produced using alternative precursors such as textile grade polyacrylonitriles, polyolefins, and lignins. ORNL has also researched lower-cost methods for converting precursors into CF. To commercialize this technology, researchers must prove the viability of these processes on a larger scale in collaboration with industry. CFTF offers a flexible, highly instrumented CF line for demonstrating advanced technology scale-up and producing market-development volumes of prototypical CFs. It bridges the gap between laboratory research and commercial-scale deployment of low-cost CF technologies.

When complete, the semi-production-scale facility will be able to produce up to 25 tons of CF a year based on 24,000 filament polyacrylonitrile tows. In addition to a conventional conversion line, CFTF will have a melt-spun precursor fiber production line with a rated capacity of 65 tons per year. The facility has the capacity for expansion, including the addition of an advanced technology conversion line.

A CFTF operations organization was established at ORNL in early 2012, with a 
director and operations manager to plan and organize the ramp-up and readiness preparations. The program has hired 22 staff members through a rigorous recruitment and evaluation program in collaboration with Roane State Community College.

To implement procedures, CFTF management developed a sophisticated system to train new hires and provide a workforce development capability to share with industries that may commercialize

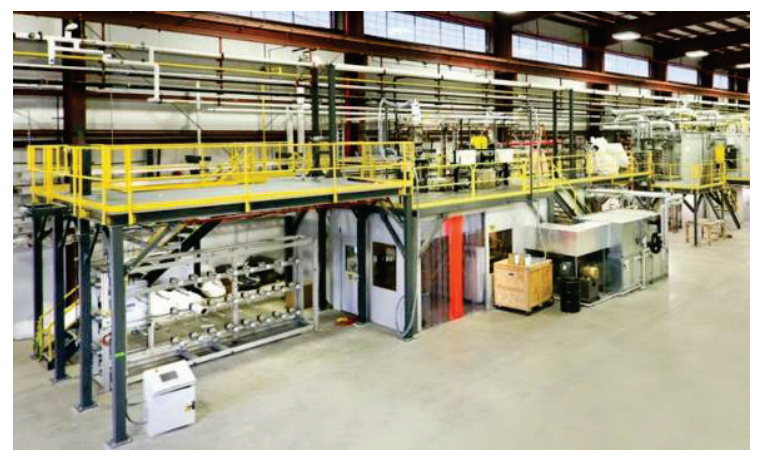

In-line precursor and carbon fiber production equipment. technologies demonstrated at CFTF. The training system features a wireless, tabletbased, real-time system for providing procedures, logging technician observations, and capturing data related to process development.

Technicians will use iPad checklists in the field to guide and record activities while monitoring the $\mathrm{CF}$ line. The checklists will include information such as safety warnings and requirements and will allow technicians to initiate maintenance via touchscreen.

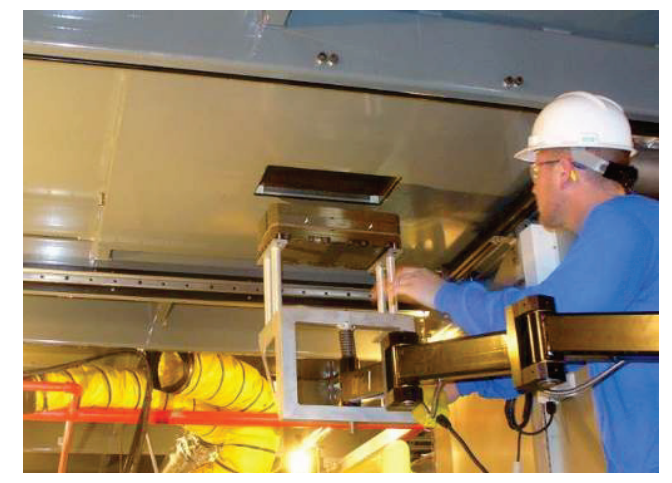

Spin pack installation on the melt spinning semi-production line.

\section{Cost Modeling of Alternative CF Manufacturing Technologies and Materials}

Lighter passenger vehicles require less fuel and are therefore less expensive to operate over the long term, but changing the way vehicles are built using advanced technologies generally increases their price. The goal of this research was to evaluate the cost-effectiveness of materials technologies being considered for trimming vehicle weight.

Carbon fiber (CF) materials are a focus of DOE research because of their high potential for reducing vehicle weight. Improving the market penetration of $\mathrm{CF}$ composites is a multi-dimensional challenge, but the chief hindrance is the cost of the CF. ORNL researchers created a manufacturing cost model to estimate the cost-effectiveness of unconventional manufacturing pathways and materials for automotive-grade 50,000-filament CF tows and to identify cost reduction opportunities.

The model considered a limited, but representative, set of combinations of $\mathrm{CF}$ precursor materials and production processes. Precursors examined included polyacrylonitrile (PAN) in commodity and textile grades, polyolefins, and melt-spun lignin. The advanced processing alternatives under consideration go beyond conventional heating and stretching conversion protocols to embrace close-proximity indirect plasma oxidation, microwave-assisted plasma carbonization, 
and unconventional surface treatment and sizing technologies.

These nontraditional, low-cost pathways were compared with the industry standard solution-spun industrial-grade PAN precursor using conventional thermal conversion. The model design will accommodate future materials and processes as they are developed and matured. By separating the constituent costs of consumable materials, capital equipment investment, energy, labor, and other factors, the model can assess the relative cost-effectiveness of alternatives. Sensitivity analysis based on Monte Carlo computer simulation helped researchers use the model to estimate the probability of achieving specific cost targets in areas in which constituent costs or correlations are uncertain.

The modeling effort revealed significant cost reduction potential for alternative precursors and processes. Even greater cost reduction is feasible using multiple technologies (precursors and advanced conversion processes) in combination. With a broad market goal of generating $\mathrm{CF}$ in the $\$ 5-7 /$ lb range (to effectively compete with conventional steel), the model identifies these needs:

- lower-cost raw materials/precursors

- higher-conversion-yield precursors

- $\quad$ higher line speeds (CF production is a sequential set of processes) and higher mass throughput

- more energy-efficient conversion steps

- post-treatment options that increase resin-to-fiber adhesion, providing better load transfer in the composite and thus reducing the quantity of fiber required in a composite

The model developed is expandable to consider other baseline grades of $\mathrm{CF}$, such as aerospace-grade materials, as well as other production materials or processes. It also may be used to examine the effects of multiple technology combinations.

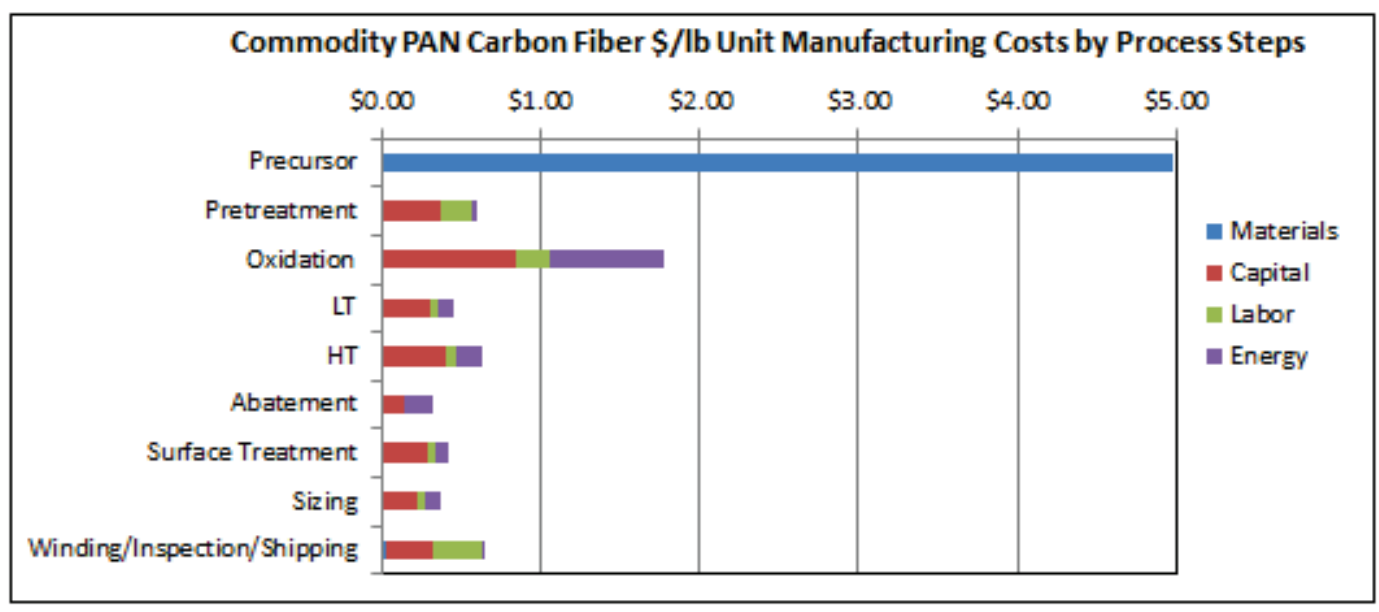

Commodity PAN CF cost distribution by major cost components and process steps for 1,500 ton/year production volume. 
Total manufacturing costs for industrial-grade PAN and alternative CF technologies for low and high production volume

\begin{tabular}{|c|c|c|c|c|c|c|c|}
\hline Technology & $\begin{array}{l}\text { Commercial } \\
\text { PAN }\end{array}$ & $\begin{array}{c}\text { Commercial } \\
\text { PAN } \\
\text { (advanced } \\
\text { post- } \\
\text { treatment) }\end{array}$ & $\begin{array}{c}\text { Commercial } \\
\text { PAN } \\
\text { (microwave- } \\
\text { assisted } \\
\text { processing) }\end{array}$ & $\begin{array}{c}\text { Textile } \\
\text { PAN }\end{array}$ & $\begin{array}{l}\text { Commercial } \\
\text { PAN with } \\
\text { plasma } \\
\text { oxidation }\end{array}$ & Polyolefins & $\begin{array}{c}\text { Lignin } \\
\text { mat }\end{array}$ \\
\hline $\begin{array}{l}\text { Low volume: } \\
\text { One fully } \\
\text { utilized CF } \\
\text { line(i.e., 1500- } \\
6500 \\
\text { tonne/year)a }\end{array}$ & $\$ 10.20 / \mathrm{lb}$ & $\$ 10.13 / \mathrm{lb}$ & $\$ 8.89 / \mathrm{lb}$ & $\$ 7.61 / \mathrm{lb}$ & $\$ 7.51 / \mathrm{lb}$ & $\$ 4.55 / \mathrm{lb}$ & $\$ 4.22 / \mathrm{lb}$ \\
\hline $\begin{array}{l}\text { High volume: } \\
\text { (18,000 } \\
\text { tonne/year) }\end{array}$ & $\$ 9.35 / \mathrm{lb}$ & $\$ 9.28 / \mathrm{lb}$ & $\$ 8.15 / \mathrm{lb}$ & $\$ 7.01 / \mathrm{lb}$ & $\$ 7.06 / \mathrm{lb}$ & $\$ 4.10 / \mathrm{lb}$ & $\$ 4.09 / \mathrm{lb}$ \\
\hline
\end{tabular}

a Annual volume varies with oxidative stabilization times required for some alternate precursors and conversion methods. Reduced time allows greater mass throughput using the same scale of equipment.

\section{Textile-grade PAN Promising Low-cost, High-strength CF Precursor}

The objective of this project is to use lowercost polyacrylonitrile (PAN) material produced in a high-volume textile manufacturing process as a CF precursor, rather than the more expensive specialty material typically used.

The previously developed fiber has strengths slightly below 500,000 pounds per square inch (KSI). This is far above the strength suitable for automotive structural applications but insufficient for many demanding uses with more stringent performance requirements, such as hydrogen storage tanks. To preserve the cost advantages of using a high-volume PAN fiber while still meeting the needs of higher-performance applications, researchers are developing the capability to use methyl-acrylate based, textile-grade PAN as a CF precursor manufactured on a textile line. A textile line that formerly made knitting yarn has been retrofitted to commercialize the fiber.

The purpose of this project is to take one precursor technology - textile-based PAN- using a higher-performance formulation, from the technical feasibility stage and scaleup to technology demonstration. This process will determine the best polymer formulation and conversion protocol (timetemperature-tension profiles) to produce a CF precursor that also can be manufactured readily and inexpensively in existing textile PAN plants.
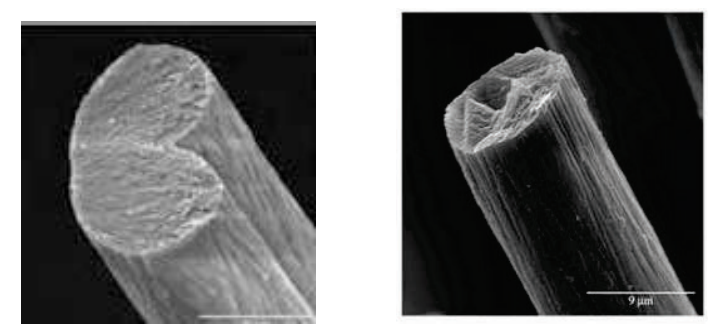

Typical textile-produced PAN fibers (left). Carbon fiber-grade PAN fibers (right).

ORNL evaluated 11 polymer formulations and selected 3 to be spun into precursor fiber for attempted conversion into CF. Portuguese acrylic-fiber manufacturer FISIPE, which works with ORNL to develop PAN precursors, determined how to spin each of the formulations into precursor fiber 
tows and sent them to ORNL for conversion trials. The best precursor formulation was then selected from the three candidate formulations and process condition optimization begun. A key portion of FISIPE's effort was to determine how to spin round fibers using textile equipment.

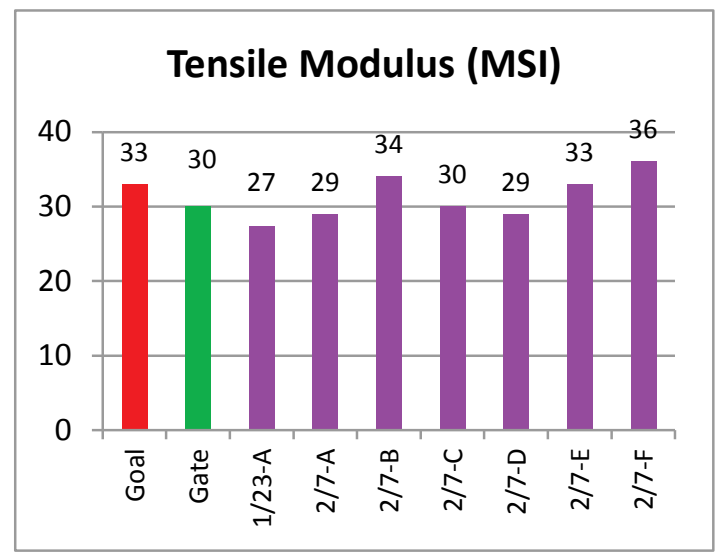

ORNL has determined the conversion temperatures during each step of the conversion and is optimizing the residence time and amount of fiber stretch necessary to obtain optimum properties. In the early stages of development, the team has already produced fibers with breaking strength in excess of $400 \mathrm{KSI}$ and modulus of $35 \mathrm{MSI}$.

Tensile modulus (left) and tensile strength (right) as a function of time for the precursor.

\section{Understanding Element Diffusion in Magnesium Alloys}

The use of magnesium (Mg) alloys, which have a high strength-to-weight ratio, will enable the production of lighter vehicles with higher fuel economy. Researchers with the Mg Integrated Computational Materials project are creating an integrated suite of validated materials and modeling tools for developing $\mathrm{Mg}$ alloys that are suitable for use in vehicles.

This international effort is studying the diffusion of elements in $\mathrm{Mg}$ alloys that are potential replacements for steel or aluminum in automotive components.

Typical Mg alloys require higher processing temperatures than other metals and exhibit brittle failure during vehicle crashes. More ductile Mg alloys processed at lower temperatures can overcome these shortcomings. Understanding the diffusion of various elements in $\mathrm{Mg}$ alloys will aid in developing alloys with improved formability and ductility, because the diffusivities of the alloy components control precipitation and dissolution of Mg-phases during heat treatment of supervacuum die cast $\mathrm{Mg}$ alloys.

The team's approach involves obtaining $\mathrm{Mg}$ tracer diffusion data using secondary ion mass spectrometry (SIMS) for diffusion depth profile measurements of stable isotopes in Mg-rich alloys. This approach is based on the thin film method using stable isotopes rather than radioactive isotopes as tracers. The use of stable isotopes reduces the costs associated with handling and processing radioisotopes and makes it possible to extend measurements to lower temperatures. In 2012, the team accomplished the following: 
- $\quad$ Obtained Mg tracer diffusivities in polycrystalline $\mathrm{Mg}-\mathrm{Al}-\mathrm{Zn}$ alloy samples over a broad temperature range to extend previous $\mathrm{Mg}$ selfdiffusion measurements to $\mathrm{Mg}$ tracer diffusion measurements in alloys.

- $\quad$ Established a technique for zinc tracer diffusion studies in Mg alloys and verified zinc impurity diffusion in pure $\mathrm{Mg}$ using SIMS.

- Modeled effective diffusion in polycrystalline $\mathrm{Mg}$ to include orientation-dependent volume and grain boundary diffusivities.
- Developed a new theoretical approach for isotopic interdiffusion analysis involving diffusion couples with endmembers having varying isotopic abundances.

- Modeled grain boundary diffusion analytically and designed experiments using SIMS with small-grained Mg thin films.

- Established websites for interaction and data sharing/analysis among collaborators and for the general public (www.ornl.gov/sci/diffusion).

- Obtained interdiffusion coefficients using incremental diffusion couples in the Mg-Al-Zn system.

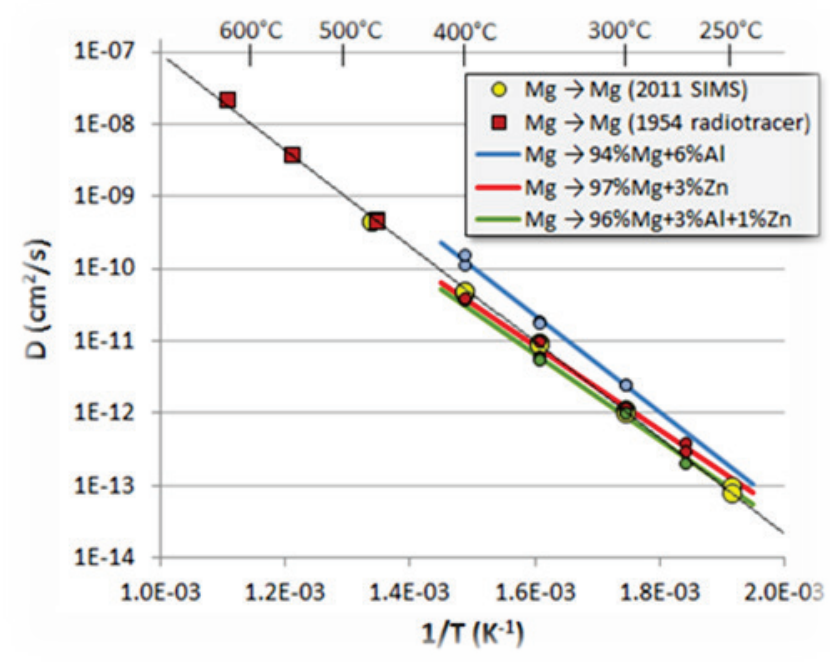

Arrhenius plot for the Mg tracer diffusivities in Mg alloys.

\section{Publications}

[1] I. V. Belova et al. "The Harrison diffusion kinetics regimes in solute grain boundary diffusion," Philos. Mag. 92, 1748-1763 (2012).

[2] S. Brennan et al. "Interdiffusion in the $\mathrm{Mg}-\mathrm{Al}$ system and intrinsic diffusion

in $\beta-\mathrm{Mg}_{2} \mathrm{Al}_{3}$," Metall. Mater. Trans. A 43A, 4043-4052 (2012).

[3] S. Brennan et al. "Aluminum impurity diffusion in magnesium," JPED 33, 121-125 (2012). 

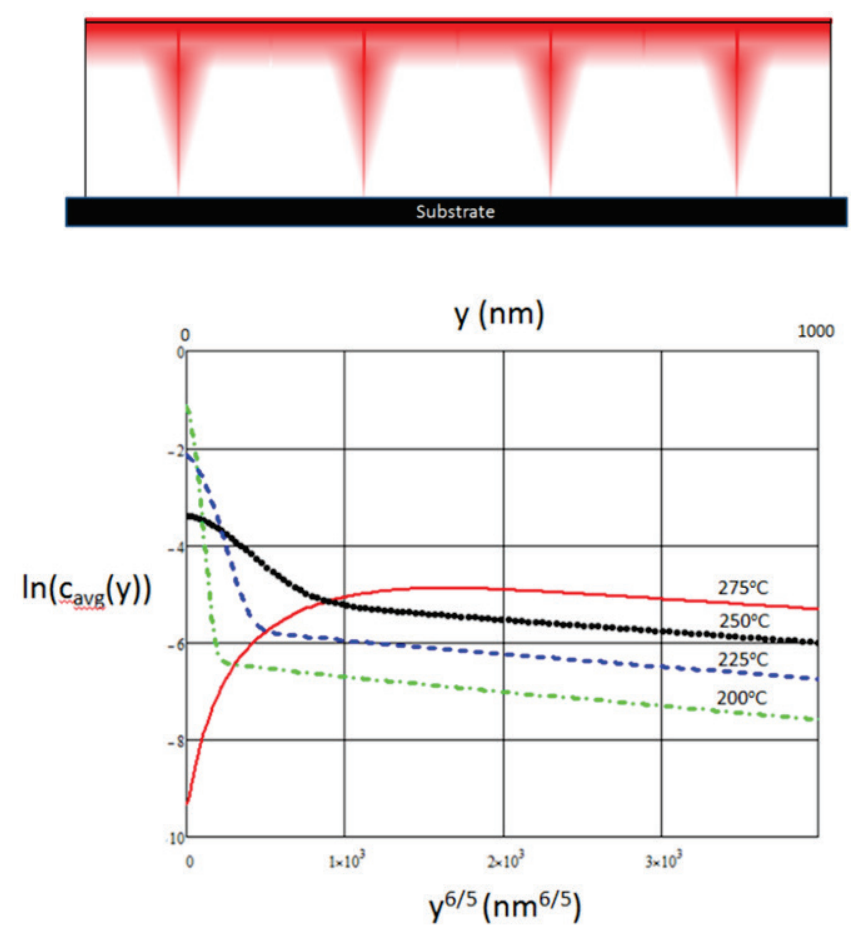

(Top) Schematic representation of tracer diffusion (in red) through multiple parallel grain boundaries in a thin film. (Bottom) Model for the variation of averaged tracer concentration as a function of penetration distance $\mathrm{y}^{6 / 5}$ applied to the case of $\mathrm{Mg}$ grain boundary self-diffusion.

\section{Enabling Technologies for Multiple Lightweight Materials}

Reducing vehicle weight requires the use of a variety of materials, including light metals. Critical technologies are needed to enable the cost-effective performance necessary for these materials, including multi-material joining, corrosion prevention, and nondestructive evaluation (NDE).

This project consists of seven tasks critical to implementing lightweight metal structures: dynamic characterization of spot welds in advanced high-strength steels (AHSSs); friction stir spot welding (FSSW) of AHSS; improving fatigue performance of AHSS welds; online weld quality monitoring with infrared (IR) thermography; IR heat treatment of cast bimetallic joints and residual stress characterization; understanding how magnesium alloys form protective films; and developing high-strength, lightweight engines for heavy-duty diesel trucks. The tasks are aimed at developing computational tools, process methods, and inspection methods for joining lightweighting metals; developing higherstrength materials to improve engine efficiency; and understanding corrosion mechanisms for magnesium alloys.

In FY 2012, a failure model was developed to catch deformation and failure behavior for spot welds of AHSSs and was validated against test coupons using multiple materials and test geometries. Based on the results of the model, development of a spot weld element model began. 
FSSW tools made of six different materials were evaluated. FSSW methods for joining AHSSs were developed with quasi-static strengths exceeding the minimum values required for resistance spot welds using the same materials.

A CRADA was initiated with ArcellorMittal to develop the technical basis and demonstrate the viability of innovative technologies to improve the weld fatigue strength and durability of automotive body structures. Weld production equipment, experimental analysis equipment, and weld fatigue models were put in place for this research.

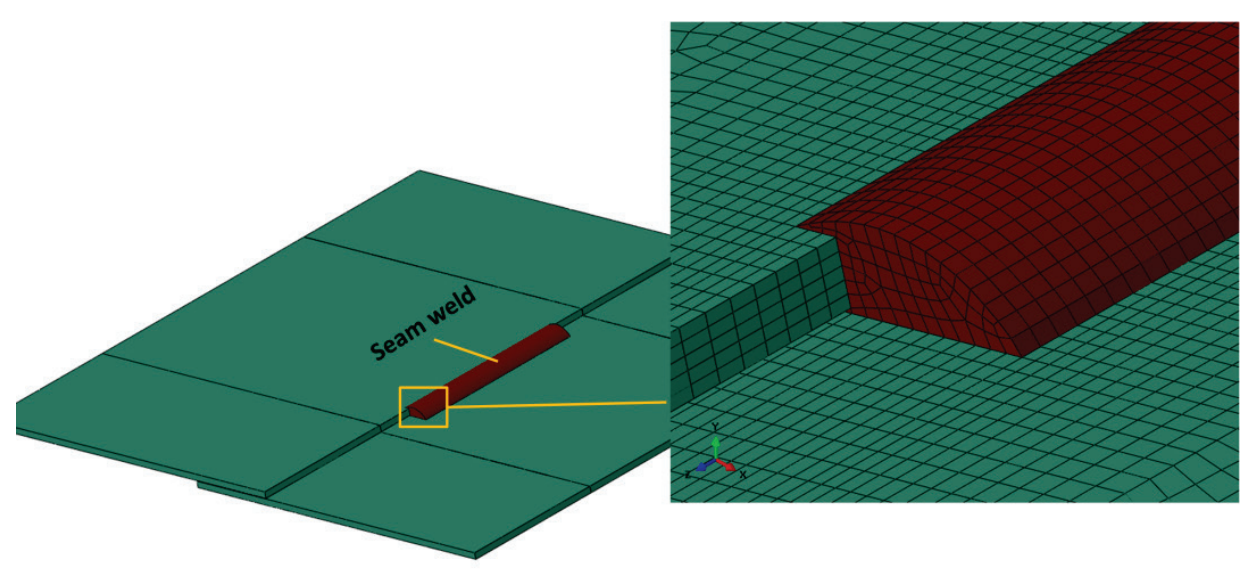

Finite element geometry and mesh of the seam weld of a lap joint.

Significant progress was made toward developing cost-effective, robust, accurate IR thermography inspection of spot weld quality. Inspection time was reduced to 3 seconds, and reliable detection of stuck welds was demonstrated (see "Infrared thermography enables nondestructive online weld inspection" in this section).

Work continued on a CRADA with Cosma to develop an IR heat treatment to increase yield strength and elongation of the cast aluminum portion of an aluminum-steel bimetallic joint to achieve a superior joint. Residual stress and torsion strength characterization began. Thermal modeling is almost complete, and stress modeling has begun.
An effort was initiated to understand the corrosion response of magnesium alloys by complete characterization of the micro/nanoscale location of key alloying elements and impurities in the surface film and near-surface alloy regions. The capability to cross-sectionally image thick and thin film formation was demonstrated.

Materials were selected for study in support of the SuperTruck program goal to improve engine efficiency by increasing the high-temperature capabilities of exhaust manifolds and pistons. Constrained thermal fatigue of several materials at one temperature cycling condition was completed, and oxidation tests on alternate exhaust materials identified new alloys that perform better than materials currently used. 


\section{Publications and Presentations}

[1] J. Chen, et al., "Automated spot weld inspection using infrared thermography, in Trends in Welding Research 2012: Proceedings of the 9th International Conference (ASM International), 148-151, eds. S. Babu, et al., February 2013.

[2] S. H. Hong, et al., "Failure modes of friction stir spot welds in lap-shear specimens of dissimilar advanced high strength steels under quasi-static and cyclic loading conditions," SAE Technical Paper 2012-01-0479, 2012 SAE Congress, Detroit, April 16, 2012, SAE International: Warrendale, PA.
[3] D. Qiao, et al. "The effect of martensitic phase transformation on weld residual stress distribution in steel sheet lap joint - A computational study, in Trends in Welding Research 2012: Proceedings of the 9th International Conference (ASM International), eds. S. Babu, et al., February 2013.

[4] M. Santella, Y. Hovanski, and T. Y. Pan, "Friction stir spot welding (FSSW) of advanced high strength steel (AHSS)," SAE Technical Paper 2012-01-0480, 2012 SAE Congress, Detroit, April 16, 2012, SAE International: Warrendale, PA.

\section{Infrared Thermography Enables Nondestructive Online Weld Inspection}

ORNL researchers have developed a prototype automated online, real-time infrared inspection system for spot welds that meets the demands of a mass production environment and can be readily integrated into existing automotive production lines. The technology will help automakers integrate advanced highstrength steel (AHSS) and other lightweight metals into their products.

Resistance spot welding is the most common technology for assembling auto bodies. During the complex, high-speed assembly process, variations in welding conditions and part fit cause out-oftolerance joints that can impact vehicle quality and performance. As more AHSSs and lightweight metals are used, higher weld quality will be even more necessary. Nondestructive weld inspection is critical for the industry, and inspection techniques must be fast, unintrusive, and inexpensive and have a low false rejection rate.
The project goal is to develop an online weld quality monitoring method based on infrared (IR) thermography, a nondestructive evaluation tool that is nonintrusive and noncontact in nature.

Researchers made significant progress in three major areas:

1. New weld-quality IR thermal signatures and associated data analysis algorithms that improve the sensitivity and accuracy of weld quality determination

2. A system for automated IR image acquisition, hardware control, system triggering, and synchronization

3. A fully automated prototype inspection system

A prototype hardware system was integrated with prototype expert software for IR image acquisition and data analysis. The hardware mainly consists of (1) a 
computer with specially designed software, (2) a low-cost IR camera, (3) a heating device for postmortem inspection, and (4) auxiliary $\mathrm{I} / \mathrm{O}$ interface instruments for signal communication among the computer and other devices. The system is synchronized with the spot welding machine for real-time monitoring; for postmortem inspection, it can be triggered by an external signal to meet synchronization requirements for online automated inspection.

Extensive testing and development of both real-time and postmortem approaches were conducted on AHSSs of different grades, thicknesses, coatings, and stackup configurations.

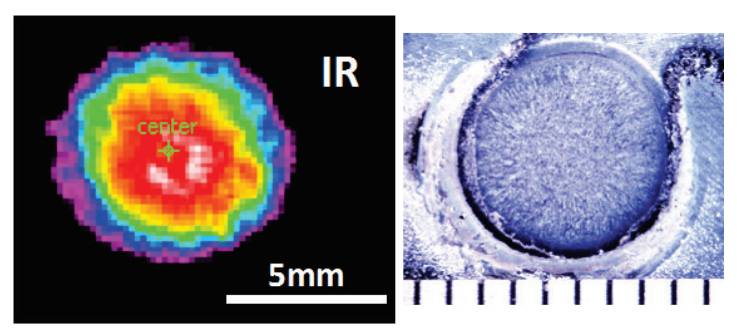

DP590 1.2-1.2mm \#170

(a)

IR image analysis algorithms also were improved. For postmortem inspection, image collection and data analysis can now be completed in 3 seconds; the weld shape can be examined; and weld shape, nugget size, and indentation depth can be quantified accurately.

In addition, a number of welds were examined destructively to obtain data for a weld quality database that includes nugget size, weld thickness (indentation depth), weld shape, and stuck welds and porosity for a wide range of steels, coatings, thicknesses, and stackup configurations.

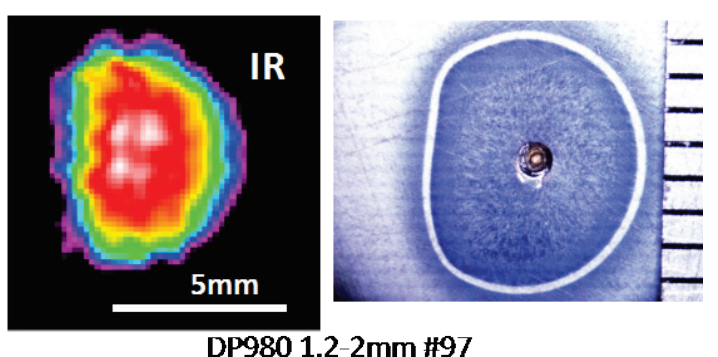

(b)

Comparison of the processed postmortem IR thermal signature: (a) good weld; (b) weld with irregular shape and void defect.

\section{Publications}

[1] J. Chen, et al., “Automated spot weld inspection using infrared thermography, in Trends in Welding Research 2012: Proceedings of the 9th
International Conference (ASM International), 148-151, eds. S. Babu, et al., February 2013.

\section{Manufacturing and Processing of AHSS and Magnesium Alloys}

Advanced high-strength steels (AHSSs) and magnesium $(\mathrm{Mg})$ alloys have the potential to replace conventional steels in vehicles to reduce their weight. But research is needed to improve the manufacturability and lower the costs of these lightweight materials.
Thermomechanical processes used in auto manufacturing degrade the mechanical strength of current AHSSs. This research characterizes AHSS microstructures to aid in developing new AHSSs that retain the strength of the current metals but are easier to form and less expensive to 
produce. $\mathrm{Mg}$ alloys are more complex in their behavior and less ductile than more commonly used metals. This project is examining ways of controlling the microstructural texture of $\mathrm{Mg}$ alloys to make them easier to work with.

Researchers used neutron scattering at ORNL's Spallation Neutron Source and $x$-ray diffraction at the Advanced Photon Source at Argonne National Laboratory to characterize the behavior of AHSSs as they transition from the austenite to the ferrite phase during rapid heating and cooling, and to examine deformation and failure processes. Neutron diffraction successfully quantified the phase transformation behavior and the role of alloying elements during the annealing of the AHSS DP980. X-ray microdiffraction determined two predominant phases responsible for the excellent properties of DP980 and identified microscopic strain distribution within individual grains of the metal as the root cause of deformation phenomena during phase transitions.

This fundamental knowledge provides the scientific underpinning to support the ongoing development of new AHSSs by steelmakers and automakers.

$\mathrm{Mg}$ alloys could be more widely used in automotive applications if they were easier to form and cheaper to produce. Research has shown that a technique called shear rolling can modify the texture of cast $\mathrm{Mg}$ alloy sheet, making it more formable and less expensive to produce. This project seeks to identify the effect of shear rolling on the texture and formability of cast $\mathrm{Mg}$ sheet and develop a simulation tool to predict the microstructure and texture during shear rolling.

Experimental work in 2012 demonstrated that shear rolling combined with annealing can improve the texture of the $\mathrm{Mg}$ alloy AZ31B. A model that predicts the evolution of the microstructure and texture of the alloy AZ31was developed by coupling a CP (crystal plasticity) model of microstructural deformation with a Monte Carlo-based annealing model.

Future work will focus on evaluating and improving the formability of the $\mathrm{Mg}$ alloy sheets with modified texture.

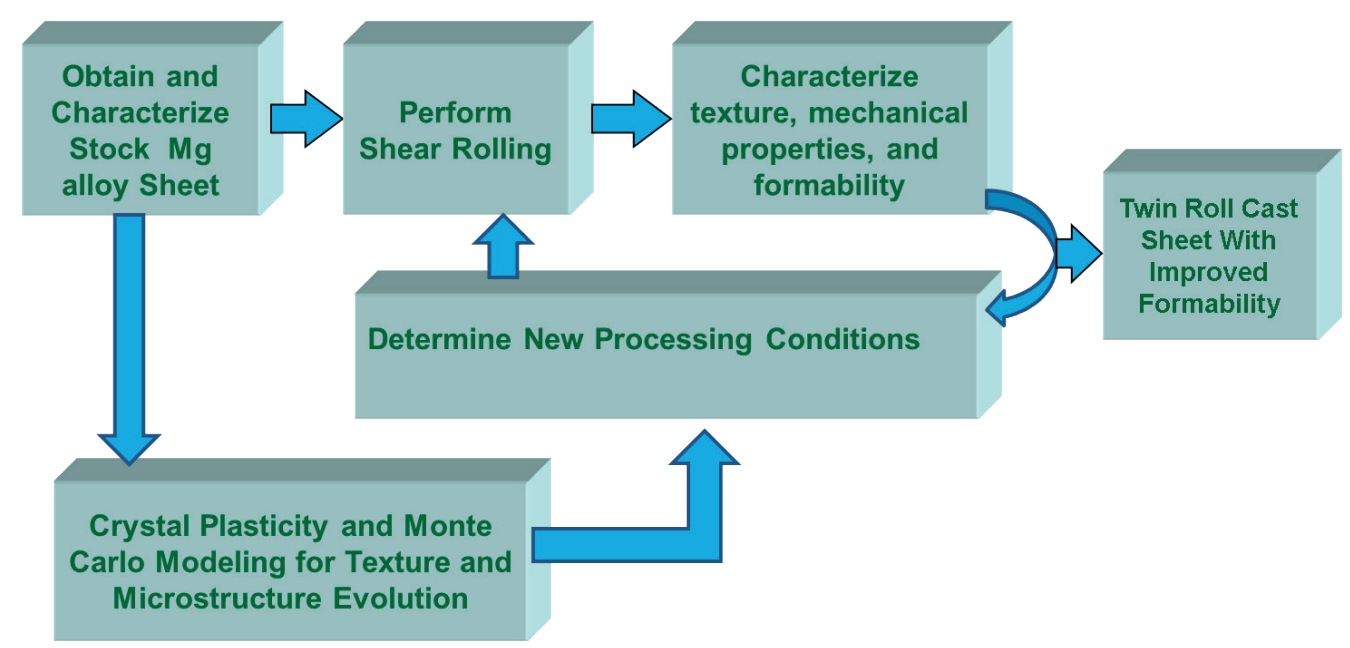

Schematic of the overall process used for $\mathrm{Mg}$ research in this project. 


\section{Policy Analysis}

\section{Managing the Transition to Alternative Vehicles and Fuels}

Moving to sustainable transportation implies a transition from petroleum-based, internal combustion engines to zeroemission electric drive vehicles. ORNL researchers are developing models and analysis tools that help to understand how the transition might be accomplished and the role of public policy in managing it efficiently and effectively.

The tools developed were used in a US National Research Council study of the transition to alternative vehicles and fuels.

ORNL has developed the Light-duty Alternative Vehicle Energy Transitions (LAVE-Trans) model for studying the transition to sustainable energy systems. ${ }^{1}$ According to LAVE-Trans results, assuming technological success, the present value of the total private and social benefits of a transition to electric drive vehicles appears to exceed the excess costs by approximately an order of magnitude. ("Excess costs" are those over and above what producers and consumers are willing to pay voluntarily. These are the explicit and implicit subsidies required to overcome the barriers to transition.)

Accomplishing major energy transitions for the public good poses new and different challenges and calls for a new paradigm. This effort proposes that the new economic paradigm for efficient energy transitions be built on the concepts of net social value, network external benefits, and adaptation to an uncertain future. Net social benefits must

\footnotetext{
1 The model was initially developed by David Greene as a Senior Fellow of the UT Baker Center for the International Council on Clean Transportation and was improved and enhanced by Greene and Changzheng Liu of ORNL for use in the National Research Council study.
}

be the key metric because a broadly based cost/benefit framework is necessary to compare very different future states of the world. Network external benefits are key concepts because the process of breaking down the natural economic barriers to transition requires that innovators and early adopters pay high initial costs that eventually reduce costs and increase the availability of alternative fuels for future consumers. Uncertainty is inescapable because future technologies and markets will undoubtedly surprise us, and even our knowledge of current market behaviors is in many ways inadequate.

The core of LAVE-Trans combines a model of consumer choices among competing automotive technologies, linked to models that age and scrap vehicles and predict their usage. Feedback loops represent network external benefits of scale, learning, infrastructure development, and reduction of the risk aversion of consumers. The model calculates costs and benefits by comparing policy-driven transition scenarios with a base case scenario with identical assumptions about market behavior and technological progress, but without policy interventions. Thus the model can be used to analyze the policies that may be necessary to achieve the transition, potential costs and timing of the transition, and the conditions that could lead to a self-sustaining market.

\section{Publication}

[1] C. Liu and D. L. Greene, “Analyzing the role of subsidies in motor vehicle electrification in the US, in Proceedings of the 26th World Battery, Hybrid and Fuel Cell Electric Vehicle Symposium E Exhibition, Los Angeles, May 2012. 


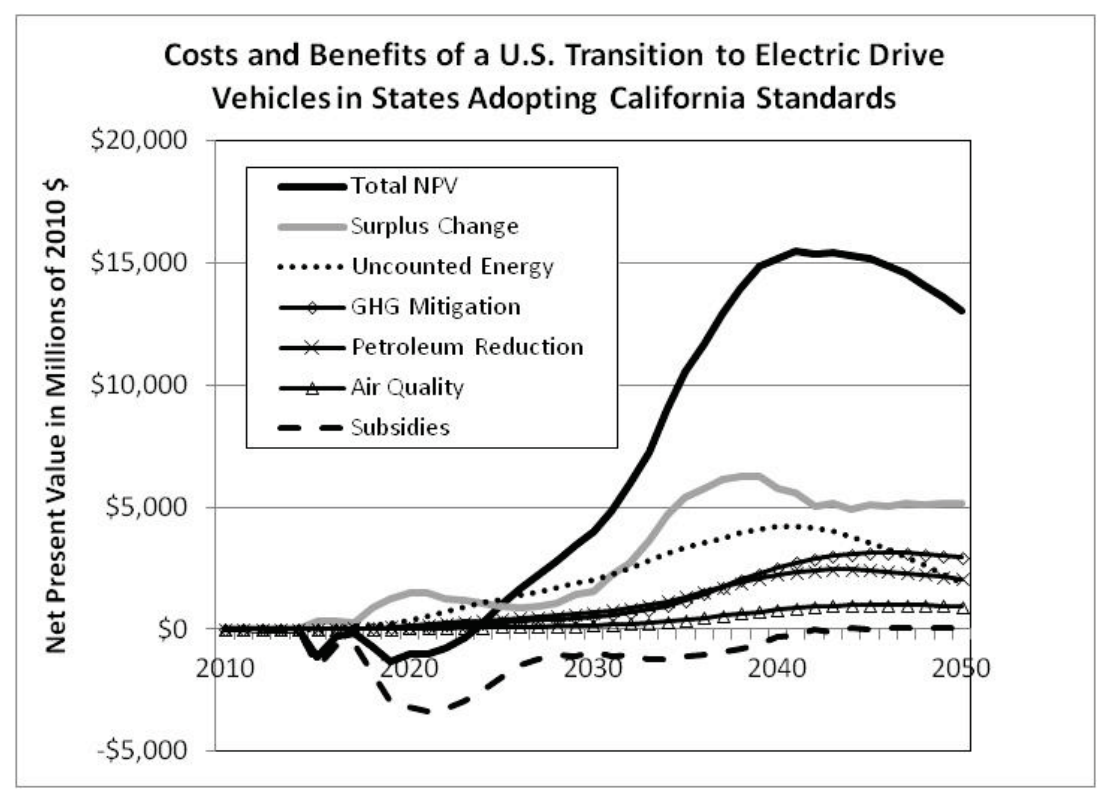

Estimated present value costs and benefits in states adopting California zero energy vehicle mandates. 


\section{Power Electronics and Electric Motors}

\section{Benchmarking Commercial Advances in Electric Vehicle Technologies}

Details of important technological advances in electric traction systems generally are not readily available for new hybrid and electric vehicles emerging in the market. To overcome this limitation and allow open discussion of new developments, ORNL researchers are performing detailed, objective, operational and packaging analysis of advanced automotive technologies.

The ORNL work provides data to support the DOE Vehicle Technologies Office in establishing baseline data and validating models for simulation tasks. Additionally, the information is used to identify technology trends, confirm the validity of US DRIVE (Driving Research and Innovation for Vehicle efficiency and Energy sustainability) programmatic targets, and aid in the planning and guidance of future research efforts.

Extensive work is done at various levels to obtain performance characteristics as well as volume, mass, material, and manufacturing analysis. At the power module level, work has been performed on various state-of-the-art component packaging types to ascertain thermal characteristics, novel innovations, cooling methods, and material improvements to help determine reliability, cost benefits, and technology trends.

At the system level, work is ongoing to benchmark inverters, motors, and chargers. Efficiency maps are generated for the modules via bench and dynamometer testing, and temperature limitations and performance are ascertained. Key materials also are characterized for performance improvements. Tests on capacitors and magnets are done at elevated temperatures to determine their limitations and operational capabilities.

Extensive work was completed recently on benchmarking the 2010 Prius motor to establish a baseline for motor projects. The work focused on obtaining an in-depth understanding of the electromagnetic and mechanical design. Those results were used to validate a model used in multiple projects for simulation tasks. The knowledge from this analysis will be carried forward in future simulation and design efforts, resulting in more efficient electric machine designs.

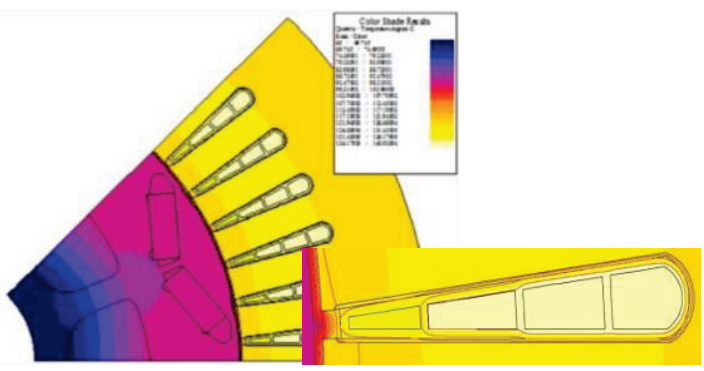

2010 Toyota Prius motor, showing the temperature distribution of the model, later validated through benchmarking work.

In 2012, ORNL performed benchmarking on the Nissan LEAF ${ }^{\circledR}$, the first all-electric vehicle commercially available in the

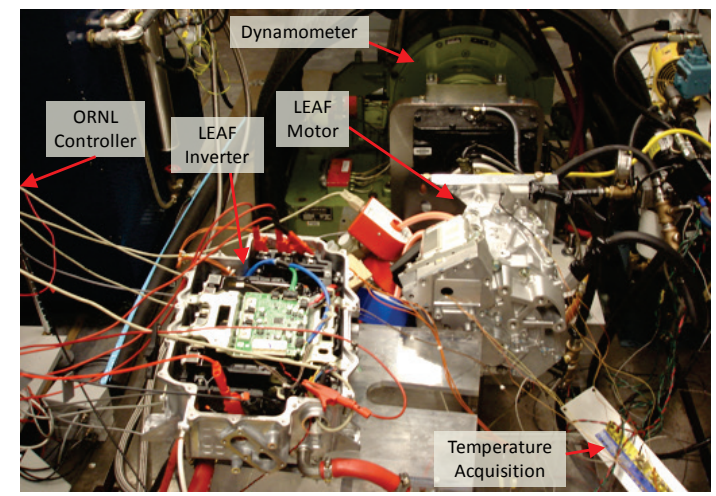

2012 Nissan LEAF® test setup. 
United States. The motor mapping revealed a highly efficient motor. ORNL test results were confirmed when correlated against publicly released efficiency data from Nissan.
Benchmarking activities are peer-reviewed via collaborative presentations to both the Electrical and Electronics Tech Team and Vehicle Systems Analysis Tech Team, and are instrumental in guiding future research activities.

\section{Increasing Electric Vehicle Efficiency by Improving Motor Materials}

Heat generated during operation limits the continuous power ratings of traction drive vehicles and must be successfully managed to avoid premature failures or reduced capacity of the traction drive components. Developing more efficient thermal management designs, heat removal mechanisms, and improved materials will help increase power capability and reduce cooling requirements and system costs.

ORNL researchers conducted studies in 2012 on improving motor materials to develop more efficient electric machines. The work focused on stator potting materials for better heat rejection, as well as magnetic steels to reduce core losses.

A baseline internal permanent magnet machine, the motor used in a 2010 Toyota Prius, was analyzed extensively to quantify its characteristic losses for
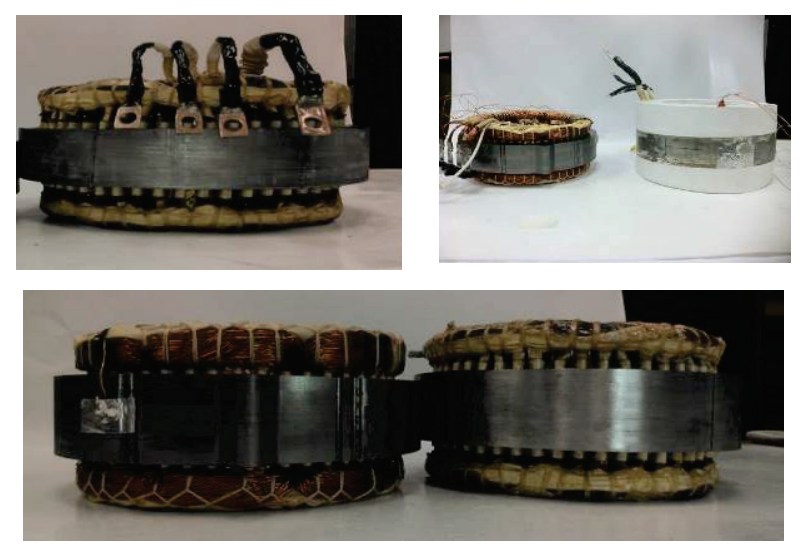

Stators fabricated for thermal and performance comparisons. 
During the study, researchers obtained representative lamination steels and fabricated three experimental stators. Two stators were made using conventional steel lamination material, one of which was potted using an epoxy molding compound. A third stator was fabricated from high-silicon-content steel. Testing confirmed these material changes can result in a $22 \%$ lower peak temperature, more uniform temperatures, and $18 \%$ lower heat rejection to the thermal management system.

\section{Segmented Drive Inverter Can Improve Drive Systems in Electric Vehicles}

An inverter design developed by ORNL has the potential to enable lower-cost, smaller, more reliable traction drive systems for electric, hybrid electric, and plug-in hybrid vehicles. The design offers significant reductions in capacitor requirements and allows power electronics to be integrated with the vehicle motor.

The traction drive systems in electric and hybrid vehicles require the use of dc bus capacitors to maintain stable dc bus voltages and smooth battery currents. These bus capacitors are costly and large, and their performance depends on temperature. Novel approaches are needed to reduce their size and the amount of capacitance required.

Power electronics for traction drive systems are primarily composed of power semiconductor switches, diodes, and dc bus filter capacitors. Their function is to switch the battery dc voltage to produce a set of three-phase ac voltages that regulate the motor current to control motor torque and speed. During the switching process, the power electronics generate large ripple current components (current fluctuations), making it necessary to use problematic dc bus filter capacitors to absorb the ripple currents and suppress voltage transients. If not sufficiently constrained, these currents are detrimental to the battery life and the reliability of the semiconductors.

A segmented drive suitable for integration into a vehicle motor has been developed, fabricated, and tested at ORNL. Compared with a standard voltage source inverter, the prototype has demonstrated

- a $60 \%$ reduction in dc bus capacitance

- a 55-75\% reduction in capacitor ripple current

- a 70-90\% reduction in battery ripple current

- A $60-80 \%$ reduction in motor ripple current

The prototype inverter has been tested with both a permanent magnet and an induction machine. It has been proved to significantly reduce battery losses and improve battery operating conditions as a result of substantially reduced ripple currents.

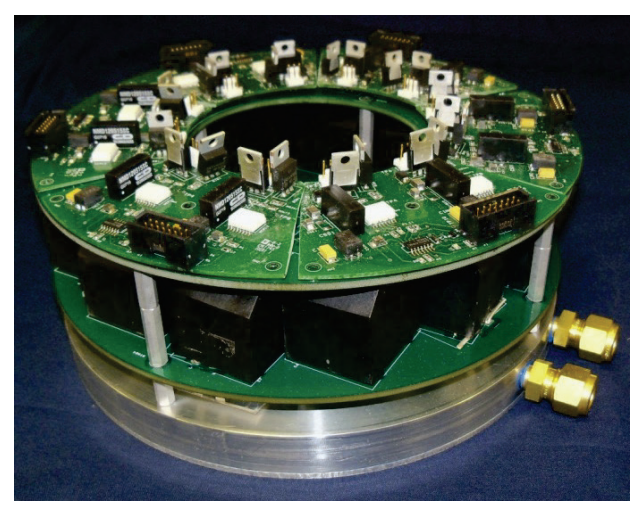

Ring-shaped segmented inverter prototype.

\section{Publication}

[1] G. J. Su, "Electrical motor/generator drive apparatus and method," US Patent 8,373,372, February 2013. 


\section{Propulsion Materials}

\section{Combining Simulation and Experiment to Develop Improved Catalysts}

Researchers at ORNL are combining computational modeling/design and experimentation to develop new catalysts to help the automotive industry meet the dual challenges of higher fuel economy standards and more stringent emissions regulations for light-duty vehicles over the next decade. They scored successes on two fronts in 2012: (1) understanding and improving the durability and stability of supported platinum catalysts and (2) discovering a low-temperature NOx treatment catalyst material based on structural insights gained through first principles theoretical studies.

Higher federal fuel economy standards are spurring work on engine technologies that improve fuel efficiency, including diesel and lean-burn gasoline engines. Emissions from these engines generally contain high concentrations of NOx and little or no carbon. They will operate at lower combustion temperatures, leading to lower-temperature exhaust that requires lower-temperature catalysts. The US DRIVE Advanced Combustion and Emission Control team has identified a need for catalysts that effectively treat engine emissions at $150^{\circ} \mathrm{C}$ to meet targets for 2020 and beyond. Doing so will require new materials or designs, because current NOx treatment systems are effective only at temperatures of $200^{\circ} \mathrm{C}$ and up.

This project is working toward durable emission treatment catalysts such as lean NOx traps, three-way catalysts, oxidation catalysts, and selective catalytic reduction catalysts.

First principles studies and experimental work on platinum/alumina systems led researchers to suggest the best form of alumina for modeling. Results also show that platinum particles of three atoms or more are energetically favored over single atoms and that palladium incorporation leads to nanoparticles with palladium on the shell.

With support from the Propulsion Materials Program, first principles studies of zeolites provided insight into the design of heterobimetallic zeolites that allow effective treatment of NOx at temperatures as low as $150^{\circ} \mathrm{C}$. Researchers synthesized a series of these zeolites by incorporating
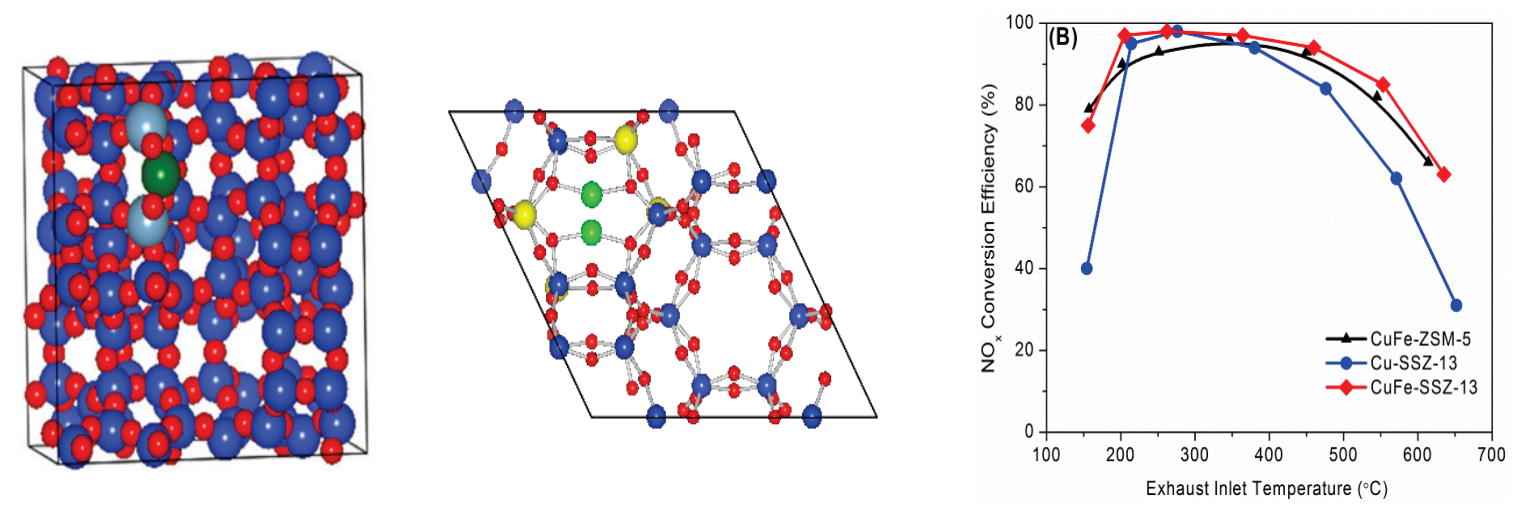

Theoretical models of CU-ZSM-5 (left), CU-SSZ-13 (middle), and experimentally observed NOx reduction under fast selective catalytic reduction conditions by heterobimetallic CUFe-ZSM-5 and CuFe-SSZ-13 (right). 
secondary metal cations under carefully controlled experimental conditions.

Results show the catalyst exhibits high $\mathrm{NOx}$ conversion efficiency at $150^{\circ} \mathrm{C}$ under certain conditions while retaining performance at higher temperatures $\left(250-650^{\circ} \mathrm{C}\right)$. Two patent applications were filed for this process. Test results also show the new catalyst is effective at low $\mathrm{NO}_{2}$ concentrations and performs well as a production catalyst.

The next step is engine testing of the new catalyst. Researchers plan to acquire a full- scale catalyst device to conduct the testing. An effort is also under way to define a catalyst material that can effectively reduce at least $90 \%$ NOx, even under standard selective catalytic reduction conditions.

\section{Publication}

[1] X. Yang et al., "Heterometal incorporation in metal-exchanged zeolites enables low-temperature catalytic activity of NOx reduction," J. Phys. Chem. C, 116 (44), 23322-23331 (2012). doi: 10.1021/jp3056043

\section{Identifying Non-Rare Earth Materials for Permanent Magnets}

Strong permanent magnets (PMs) are critical components of electric vehicle (EV) drive systems. Current PMs contain rare earth elements, for which costs are rising and domestic supplies are limited. Highperformance PMs that do not depend on rare earth elements could lead to less expensive motors for EVs and a more stable supply chain. Since magnets make up about $30 \%$ of the cost of EV motors, the potential benefits of non-rare earth PMs are significant.

The "EV Everywhere" Grand Challenge identifies non-rare earth motor architectures as essential to reducing and stabilizing motor costs and supports basic research in PM materials.

Replacements for commonly used rare earths such as $(\mathrm{Nd}, \mathrm{Dy})_{2}(\mathrm{Fe}, \mathrm{Co})_{14} \mathrm{~B}$ must be capable of high-temperature operation to minimize cooling requirements and retain a competitive magnetic energy density. Researchers are using ORNL's capabilities in computational science and materials synthesis, processing, and characterization to explore rare earth-free candidate PM materials. This effort targets both new materials and understudied compounds from the literature.

Combining light transition metals like iron and cobalt, which tend to be strongly magnetic, with heavy transition metals like hafnium and tungsten, which tend to induce the magnetic anisotropy needed to oppose demagnetization, has been identified as a promising route. These efforts have led to the identification and study of the Hf-Co system and the discovery of promising PM properties in alloys of composition $\mathrm{Hf}_{2} \mathrm{Co}_{11} \mathrm{~B}$.

Hf-Co-B alloys are produced by meltspinning, a common, scalable manufacturing technique. Transmission electron microscopy shows crystallites as small as $5 \mathrm{~nm}$ and as large as $50 \mathrm{~nm}$ in the material; this complex nanostructure, which has not yet been optimized, is thought to be responsible for the alloy's good magnetic performance. A hysteresis loop collected at room temperature shows good "squareness" and a high coercive field ( $\sim 4.5 \mathrm{kOe})$. These properties are required to store a large amount of energy in the material's magnetic field. 
The room-temperature energy product of $\mathrm{Hf}_{2} \mathrm{Co}_{11} \mathrm{~B}$ is competitive with those of other non-rare earth magnetic materials studied for decades, such as AlNiCo. In fact, unoptimized $\mathrm{Hf}_{2} \mathrm{Co}_{11} \mathrm{~B}$ ribbons achieve energy products approaching half that of melt-spun flakes of $\mathrm{Nd}_{2} \mathrm{Fe}_{14} \mathrm{~B}$. $\mathrm{Hf}_{2} \mathrm{Co}_{11} \mathrm{~B}$ has a Curie temperature about $150^{\circ} \mathrm{C}$ higher than $\mathrm{Nd}_{2} \mathrm{Fe}_{14} \mathrm{~B}$, which is critical for
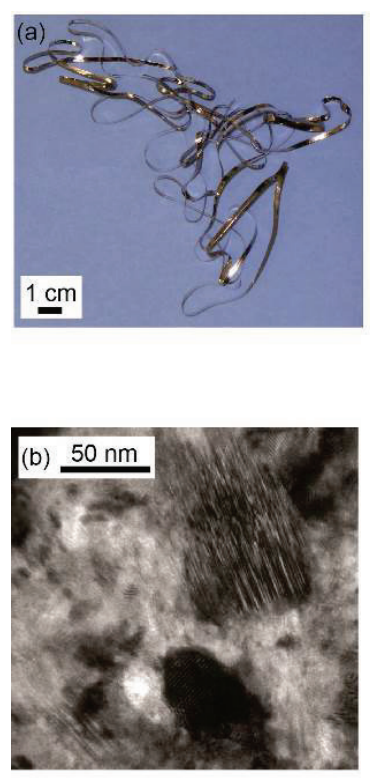

enabling stable use at the high operating temperatures expected in future EV motors. There are also indications that it may be feasible to at least partially replace hafnium with cheaper, more abundant zirconium. Research at ORNL continues to explore the behavior of this material and define routes toward optimizing its PM properties.
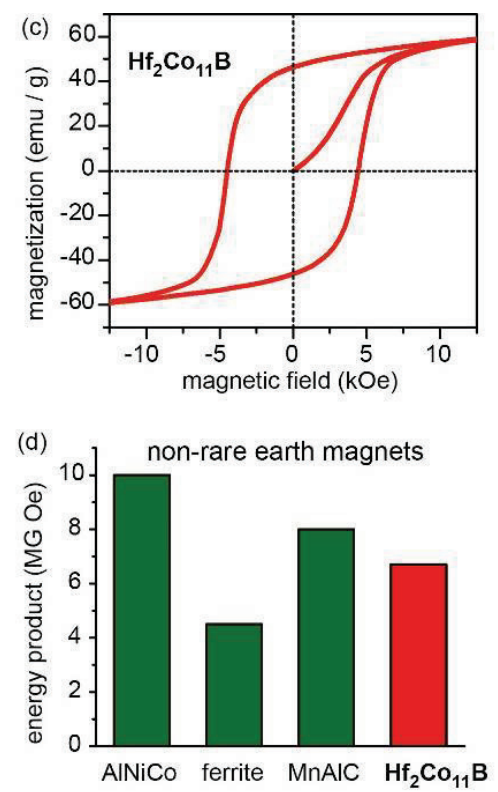

Sample of $\mathrm{Hf}_{2} \mathrm{CO}_{11} \mathrm{~B}$ produced by melt-spinning (a). TEM image of its nanostructure showing a wide range of crystallite sizes, some as small as $5 \mathrm{~nm}$ (b). Magnetic hysteresis loop of meltspun $\mathrm{Hf}_{2} \mathrm{CO}_{11} \mathrm{~B}$ showing high coercivity and good "squareness" (c). Comparison of magnetic energy products for non-rare earth magnets (d).

\section{Thermoelectric Materials: Predicting, Attaining, and Verifying Performance}

Thermoelectric devices convert heat directly into electricity. They could significantly improve fuel economy for electric vehicle (EV) climate control in the DOE “EV Everywhere" Program and recover exhaust heat for electrical power in vehicles with internal combustion engines. A key research challenge is identifying new or improved high-performance thermoelectric materials suitable for these applications.

Propulsion Materials Program researchers at ORNL are using theoretical modeling tools to identify and guide optimization of advanced thermoelectric materials for waste heat recovery, in line with the DOE goal of a $10 \%$ increase in fuel economy from this technology. Their extensive investigation of the electronic structure and thermoelectric capabilities of a candidate material, lead selenide (PbSe), indicated that its thermoelectric performance (figure of merit, or ZT) could be more than twice the values found in previous research; and these predictions of high performance in PbSe have now been experimentally confirmed. 
Several materials were studied for their potential to be incorporated in EV climate control modules to reduce the EV driving range penalty. The material p-type $\mathrm{Bi}_{2} \mathrm{Se}_{3}$ was found to yield thermoelectric performance approaching that of bismuth telluride $\left(\mathrm{Bi}_{2} \mathrm{Te}_{3}\right)$, the material currently used for room-temperature heating and cooling. The discovery demonstrates that materials free of the scarce, expensive element tellurium can deliver comparable performance.

Reliable characterization of the transport properties that make up the ZT is essential for developing and deploying thermoelectric systems. For this reason, researchers at ORNL's High Temperature Materials Laboratory initiated and led, under the auspices of the International Energy Agency, two test program roundrobins between 2009 and 2012. The focus was on bulk bismuth telluride and lab-tolab variability in the transport properties needed to determine the ZT. Detailed analysis was conducted, and test procedures were developed and published in two journal articles. The international collaboration involved 10 laboratories in Canada, China, and Germany.

Study results will help develop and validate high-performance thermoelectric materials for automotive applications. These materials are expected to aid the deployment and consumer acceptance of new generations of vehicles and improve fuel economy in conventional vehicles.

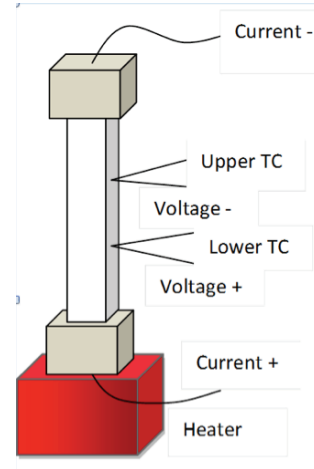

A schematic diagram of the "four point" method used to measure the thermoelectric power of a material.

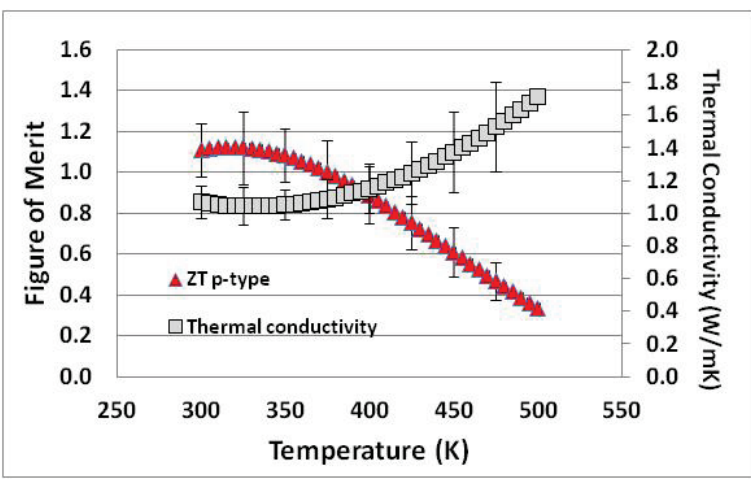

Calculated thermal conductivity and ZT, with associated uncertainties, for p-type $\mathrm{Bi}_{2} \mathrm{Te}_{3}$. 


\section{Vehicle Systems}

\section{Green Racing Showcases Sustainable Vehicle Technologies}

DOE's Green Racing Initiative (GRI) made significant progress in 2012 in showcasing efficient transportation technologies via its partnership with the motor sports industry. All of the full-season Grand Touring class cars racing in the American LeMans Series (ALMS) ran on E85 for the 2013 season. Four hybridized racing vehicles were on the starting grid of the 24 hour Le Mans race in 2012, and the Audi E-Tron diesel/flywheel hybrid took first place overall.

The Nissan DeltaWing, an experimental vehicle built on a lightweight platform and using limited downforce, raced competitively for the first time. The DeltaWing program used the pinnacle event of endurance racing to showcase technologies in an attempt to change the face of motorsports in the future.

Over the 2012 season, taking into the account the total miles raced, the ALMS replaced more than $37 \%$ of the petroleum typically used in its races with renewable fuels and reduced greenhouse emissions by more than $20 \%$. This accomplishment demonstrates that renewable fuels are capable of outstanding performance, reliability, and widespread use in street vehicles.

The automobile Club de l'Ouest announced that in 2013, LeMans Prototype vehicles can expand the size and types of energy recovery and incorporate hybrid technologies. The move toward attention to energy use, as well as speed, represents a substantial change in the perspective of the motor sports community.
GRI takes advantage of the demanding environment and high public profile of auto racing to showcase alternative fuels and vehicle technologies to the public and pave the way for integrating green technologies developed for racing into street vehicles. Manufacturers show they can deliver the types of vehicles consumers want while supporting energy security and sustainable transportation.

To help educate racing fans about green technologies, a mobile Green Racing Simulator developed by Argonne National Laboratory was set up at five Le Mans races and other events in 2012 to disseminate GRI's message that renewable fuels and hybrids can displace a substantial amount of imported petroleum.

The effort is sponsored by DOE in partnership with the Environmental Protection Agency and SAE International. ORNL coordinates GRI activities in the sports car racing arena.

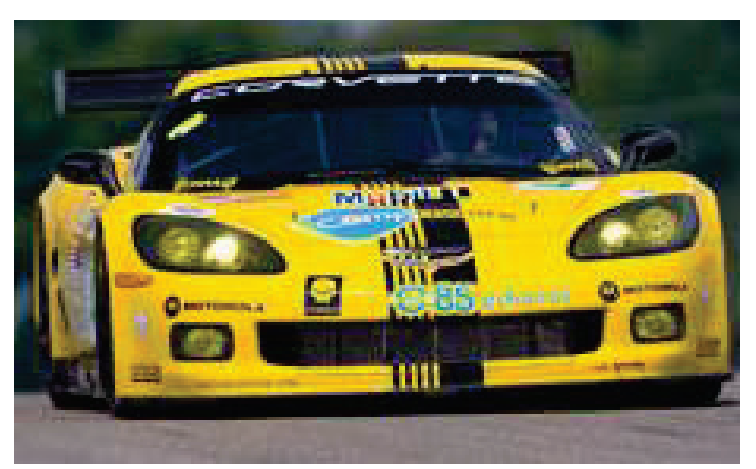

Corvette racing proudly displays its fuel choice on the front bumper. Lessons learned when the racing program was running a gasoline direction injection (GDI) E85 engine went into future GM production GDI vehicles. 
